Energy Systems Strategic Assessment Institute

Economic and Market Challenges Facing the U.S. Nuclear Commercial Fleet

September 2016 


\section{DISCLAIMER}

This information was prepared as an account of work sponsored by an agency of the U.S. Government. Neither the U.S. Government nor any agency thereof, nor any of their employees, makes any warranty, expressed or implied, or assumes any legal liability or responsibility for the accuracy, completeness, or usefulness, of any information, apparatus, product, or process disclosed, or represents that its use would not infringe privately owned rights. References herein to any specific commercial product, process, or service by trade name, trade mark, manufacturer, or otherwise, does not necessarily constitute or imply its endorsement, recommendation, or favoring by the U.S. Government or any agency thereof. The views and opinions of authors expressed herein do not necessarily state or reflect those of the U.S. Government or any agency thereof. 


\title{
Economic and Market Challenges Facing the U.S. Nuclear Commercial Fleet
}

\author{
Idaho National Laboratory \\ Ronaldo Szilard \\ Phil Sharpe \\ Nuclear Economics Consulting Group \\ Edward Kee \\ Edward Davis \\ Grecheck Consulting LLC \\ Eugene Grecheck
}

September 2016

Center for Advanced Energy Studies (CAES)

caesenergy.org

Gateway for Accelerated Innovation in Nuclear (GAIN)

gain.inl.gov

Idaho National Laboratory (INL)

www.inl.gov

Prepared for the

U.S. Department of Energy

Office of Nuclear Energy

Under DOE Idaho Operations Office

Contract DE-AC07-05ID14517 


\section{EXECUTIVE SUMMARY}

This report identifies underlying economic and electricity market factors that have led to early retirements of U.S. operating nuclear power plants, assesses the Gap between operating revenues and operating costs for selected nuclear power plants, and discusses a range of actions that might be taken to stop early retirement of operating nuclear power plants.

The Kewaunee and Vermont Yankee nuclear power plants were retired early for economic and financial reasons. The owners of the Crystal River and San Onofre units chose to retire those units early, rather than invest in needed plant repairs. Early retirement has been announced or proposed for Clinton and Quad Cities in Illinois, FitzPatrick and Ginna in New York, and Fort Calhoun in Nebraska. Other nuclear power plants, including Palisades, Davis-Besse, Prairie Island, and Three Mile Island Unit 1, have been identified as facing financial stress that might lead to early retirement.

The early retirement of operating nuclear power plants will mean the loss of a large amount of zero-emission electricity, inconsistent with the goal of reducing carbon emissions in the electricity sector.

This report provides a high-level view of the major factors driving early retirement:

- The U.S. market and private ownership approach to the electricity sector;

- Low electricity market prices resulting from low natural gas prices, low demand growth, increased penetration of renewable generation, and negative electricity market prices; and

- No compensation to nuclear power plants for public benefits including zero-emission electricity.

The combination of these factors has led to market failure for nuclear power, given the U.S. market approach to electricity combined with sustained low electricity market prices. Continuing financial losses for operating nuclear power plants may increasingly be resolved by early retirement, with this early retirement resulting in the loss of net public benefits.

The Gap between estimated annual operating plant revenues and plant operating costs for a selected set of nuclear power plants was calculated. The analysis of plant revenues included both energy and capacity payments as discussed in detail in the report. The additional revenue generated for the Zero Emissions Credit (ZEC) is also considered in the Gap analysis for operating plants in New York that will receive ZEC payments.

The Gap assessment includes three levels of operating costs: a base level for all units of $\$ 300,000 / \mathrm{MW} /$ year plus a high and low operating cost estimate for each of three nuclear power plant configuration categories (i.e., small single unit, large single unit, and multiple unit site). 
The conclusions and findings based on this study are as follows:

- Our analysis confirms there is an industrywide systemic economic and financial challenge to operating nuclear power plants in deregulated markets;

- Given the confluence of market factors in combination with market structure in deregulated markets, a significant number of operating nuclear plants have negative cash flow positions today;

- Given current trends, these markets factors are unlikely to change significantly over the next 5 years;

- Early retirement of nuclear plants is primarily caused by lower revenue problem rather than higher operating costs, as wholesale electricity prices have precipitously fallen over the last several years;

- Cost cutting measures recently announced by the nuclear industry are timely and will help reduce plant operating cash flow losses, but will not be sufficient to prevent all nuclear plant early retirements;

- The magnitude of the Gap is estimated in the range of $\$ 5$ to $\$ 15$ per MWh. For a 1,000 MW nuclear unit, approximately every $\$ 5$ per MWh of Gap represents about $\$ 40$ million in annual negative cash flow;

- New York has adopted a Clean Energy Standard recognizing the value of zero-carbon nuclear electricity generation, paying selected nuclear plants Zero Emission Credit (ZEC)s with an initial value of $\$ 17.48 / \mathrm{MWh}$;

- Without action to enhance revenue (e.g., New York ZEC payments), more nuclear plants face premature retirements in the future.

This report also provides a discussion of the timing issues related to the retirement and decommissioning of operating nuclear power plants. These timing issues may arise as a result of a nuclear power plant having a capacity obligation in an RTO/ISO market or as a result of NRC requirements and restrictions. A key issue is the degree of flexibility in reversing an announced decision to retire a nuclear plant early.

We also investigate the range of actions that state and federal organizations may take to prevent the early retirement of operating nuclear power plants.

Based on the analysis, it is likely that direct action will be needed to prevent additional early retirements. This could come from additional revenue arrangements (e.g., ZEC payments or bilateral contracts) or from a shift in ownership to a government owner that can take actions based on a broader view of net public benefits provided by nuclear power plants.

In addition, the lack of public and political understanding of the issues involved call for a dedicated effort by the Government to reach out to all segments of society and assist with communicating the vital issues facing our electricity sector. Nuclear generation, both the continuing operation of existing plants, and the addition of new nuclear capacity, is necessary to meet public policy goals. Without prompt action to address market issues, these goals are unlikely to be met. 


\section{CONTENTS}

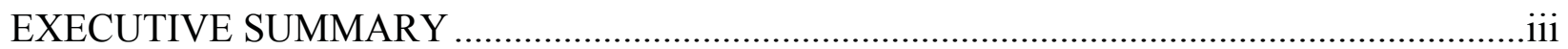

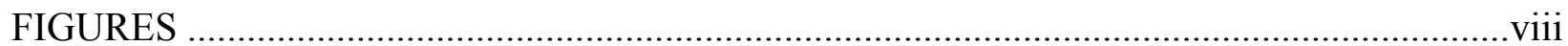

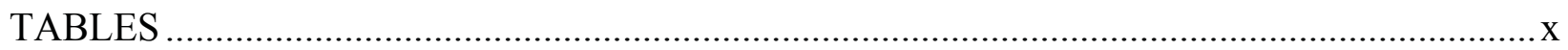

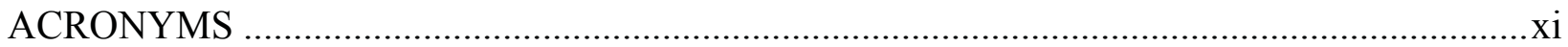

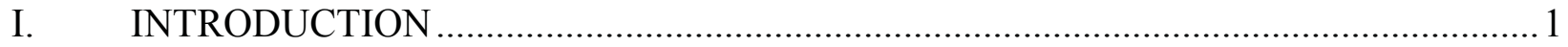

II. BACKGROUND - UNDERSTANDING THE CHALLENGES ...............................2

A. U.S. Electricity Industry Structure ............................................................................ 2

B. Electricity Market Prices - Historically Low .............................................................. 3

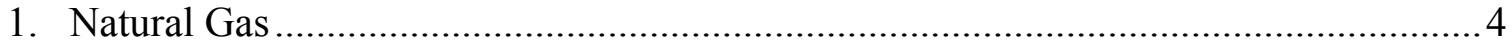

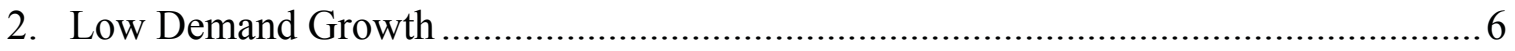

3. Increasing Penetration of Subsidized Renewable Generation ................................. 7

4. Negative Electricity Market Prices .......................................................................... 8

C. No Compensation for Nuclear Power Public Benefits .................................................. 11

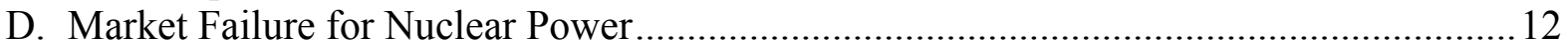

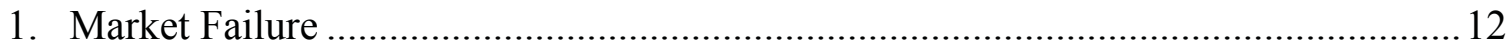

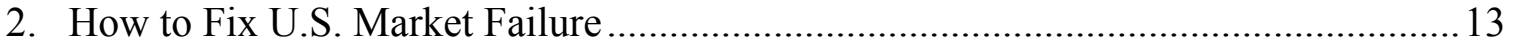

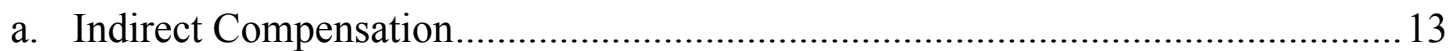

i. Electricity and Capacity Market Improvements........................................ 13

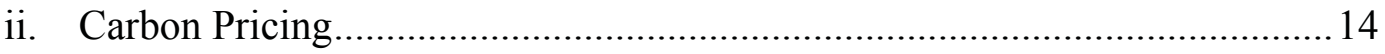

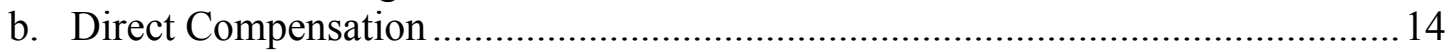

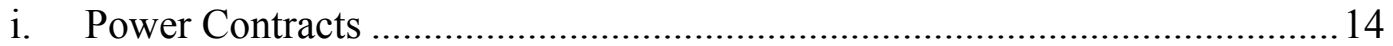

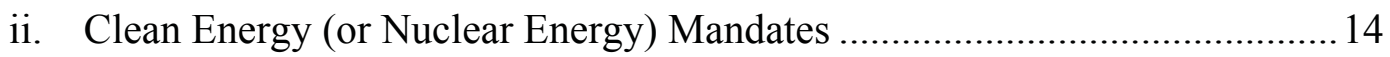

iii. Payment for Clean Energy ...................................................................... 14

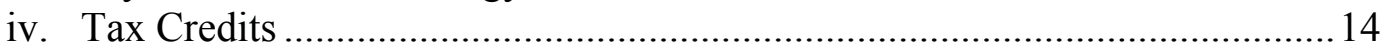

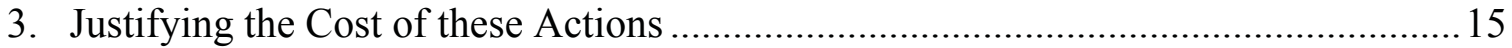

E. New York ZEC Program .................................................................................. 15

III. MAGNITUDE OF NUCLEAR POWER PLANT FINANCIAL PROBLEM.................. 16

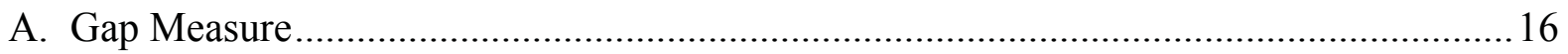

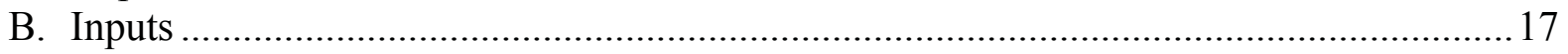

1. Nuclear Power Plant Cash Operating Cost............................................................... 17

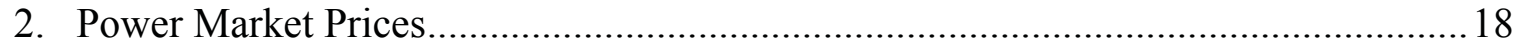

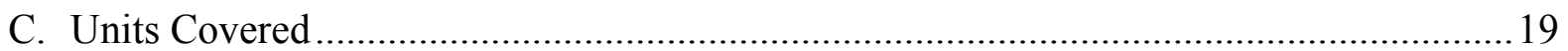

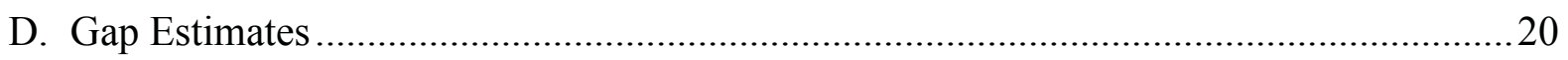

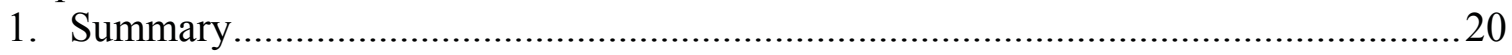

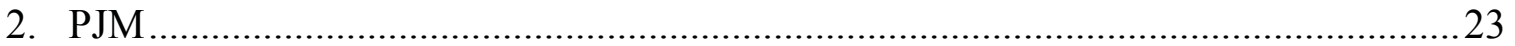

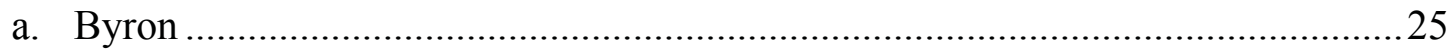

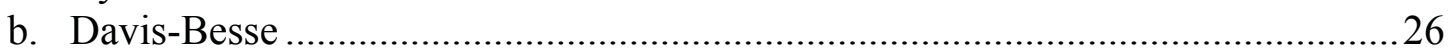

c. Peach Bottom........................................................................................... 28

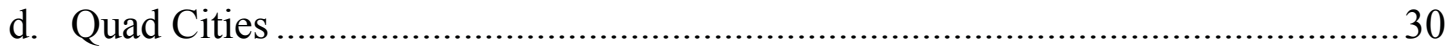




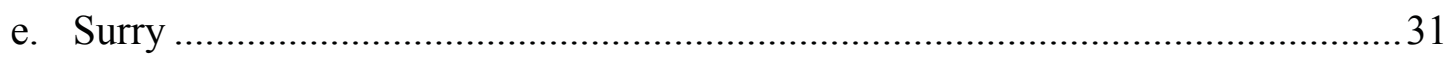

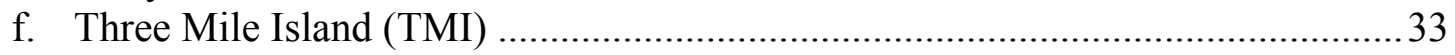

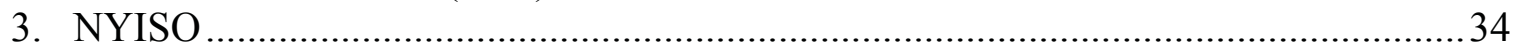

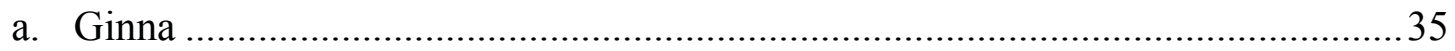

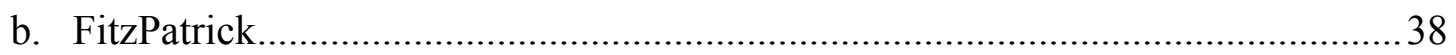

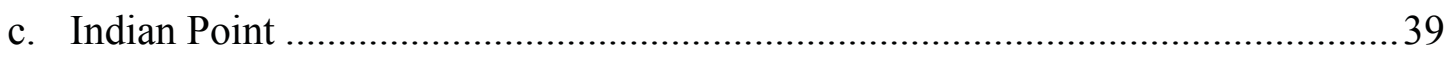

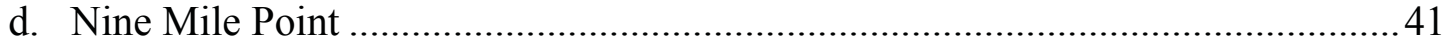

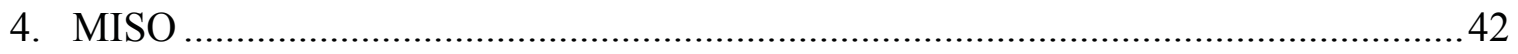

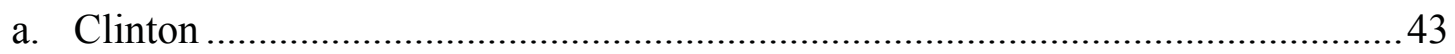

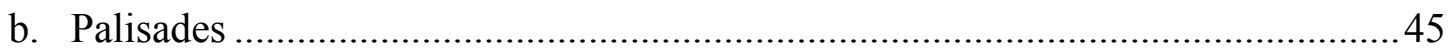

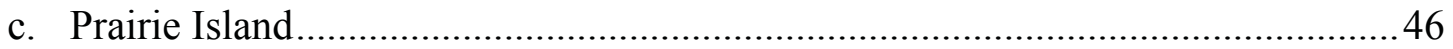

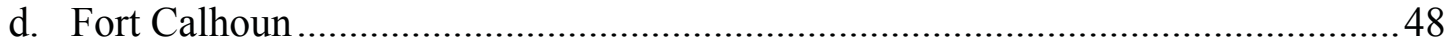

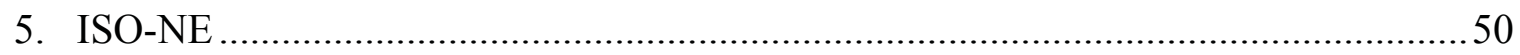

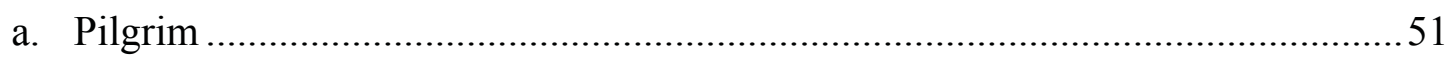

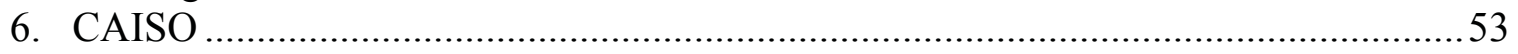

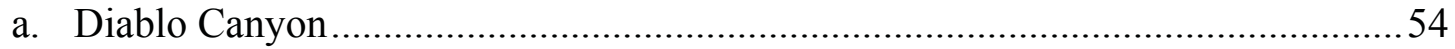

E. Industry Efforts to Reduce Costs (Delivering the Nuclear Promise) …………….............56

IV. TIMING - NUCLEAR PLANT SHUTDOWN DECISION MAKING AND

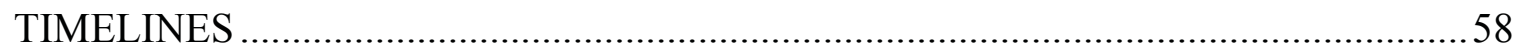

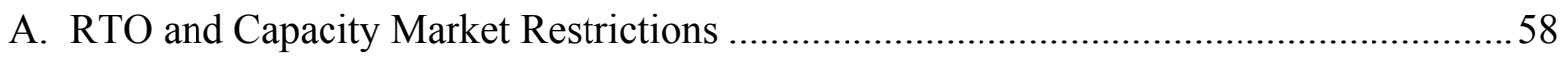

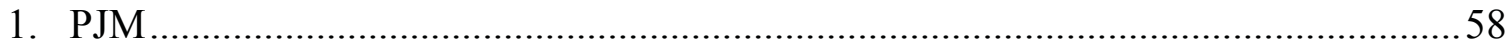

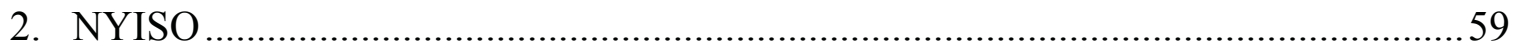

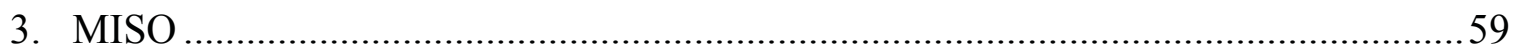

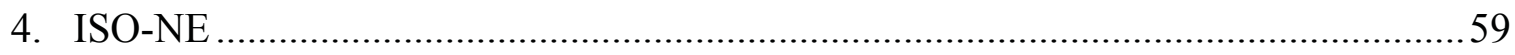

B. Timing and NRC Regulatory Considerations around Decisions to Terminate Nuclear

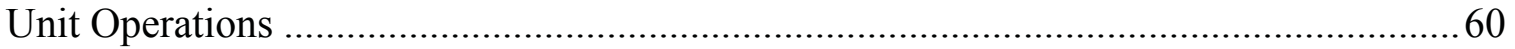

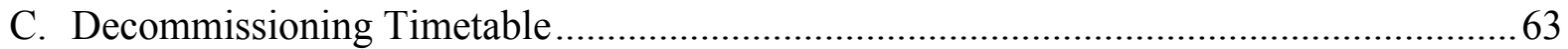

D. Can a Decision to Shut Down Be Reversed? ................................................................64

V. ACTIONS - POTENTIAL ACTIONS TO STOP EARLY RETIREMENTS ..................67

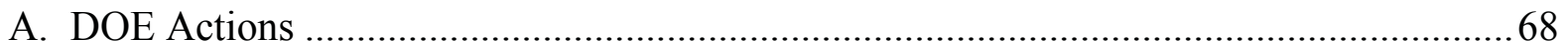

1. Clear Federal Policy Statement that Nuclear Power Is Needed ..................................68

2. Public Information and Awareness ..........................................................................69

3. Facilitate Social Cost of Carbon Approaches.............................................................69

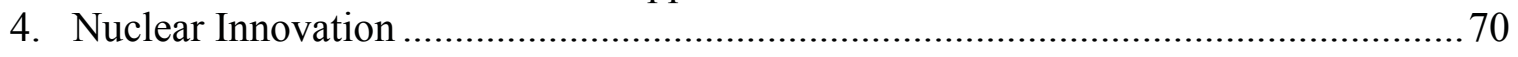

5. Support Nuclear Industry Cost Reduction Efforts....................................................70

6. Study Negative Electricity Market Price Issue .............................................................70

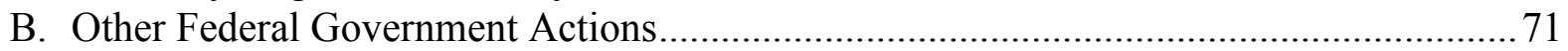

1. Federal Energy Regulatory Commission (FERC) ………………….......................71

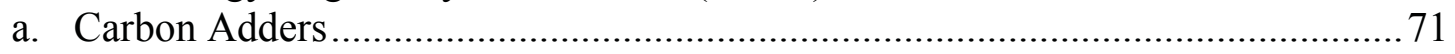

b. RTO/ISO Market Design Changes ......................................................................... 71

2. Other Federal Agencies ………………………............................................ 72

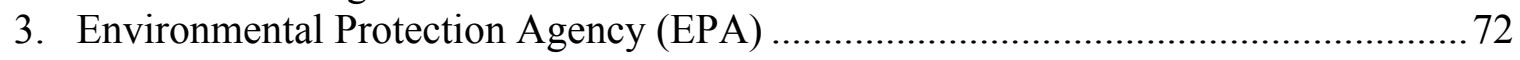

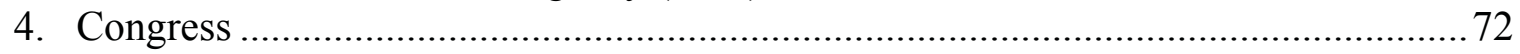

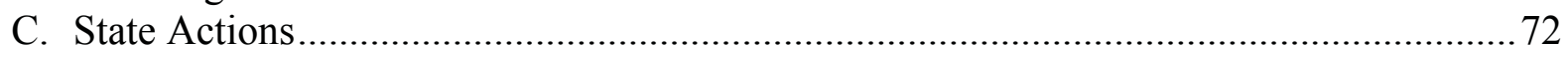

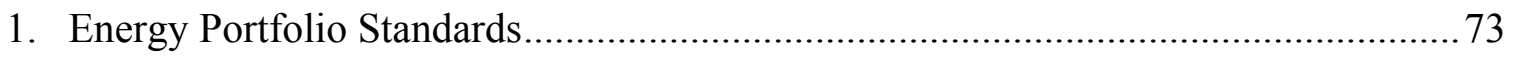




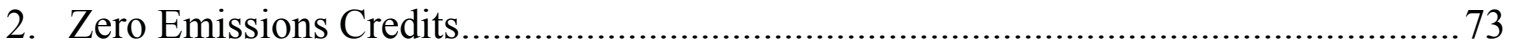

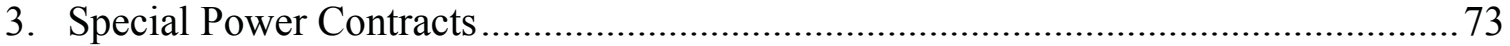

4. Eminent Domain and Public Power Authorities ......................................................... 74

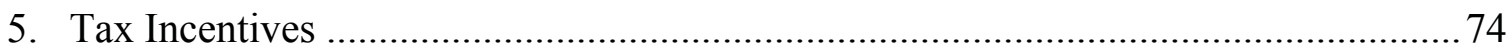

VI. KEY FINDINGS, CONCLUSIONS AND RECOMMENDATIONS ........................... 75

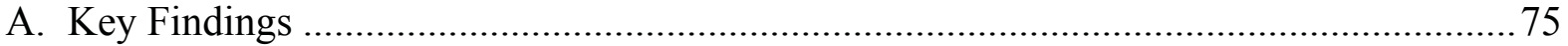

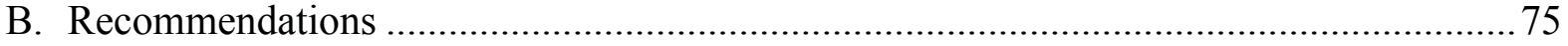

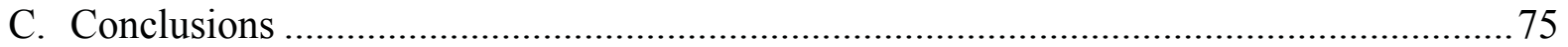

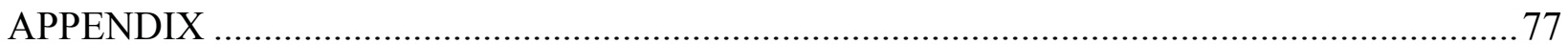




\section{FIGURES}

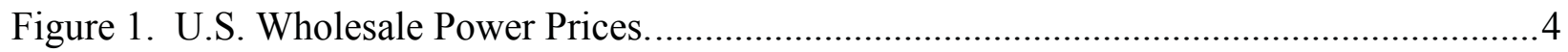

Figure 2. Page 33 from AEO 2016 Rollout Presentation............................................................6

Figure 3. Figure 12 from AEO 2016 Rollout Presentation. …………………………....................

Figure 4. Electricity Bid-Based Supply Curve. .......................................................................

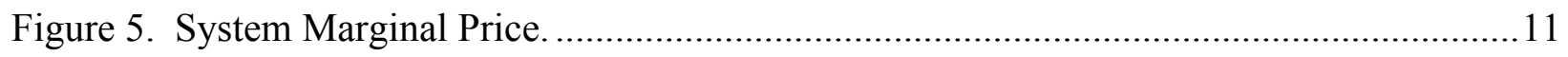

Figure 6. Gap Estimates (\$ Millions/Year) with Components........................................................21

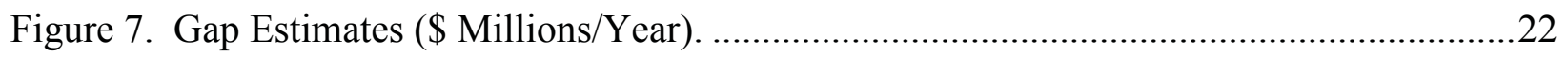

Figure 8. Gap Estimates with Range of Operating Costs..........................................................23

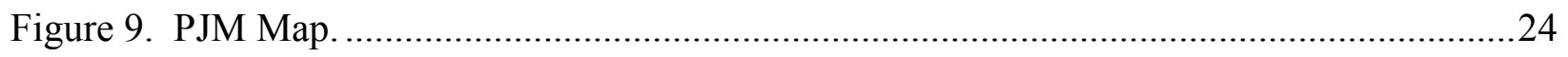

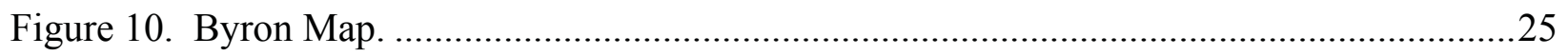

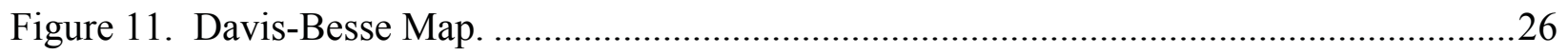

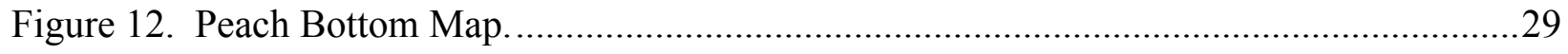

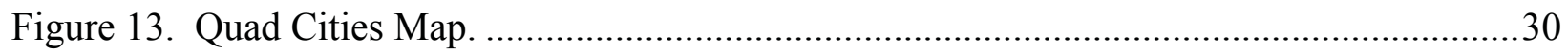

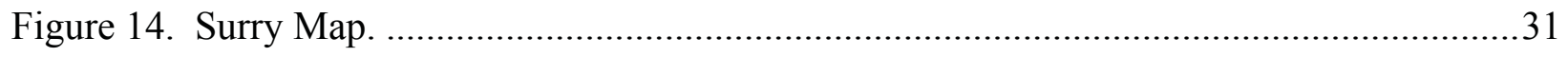

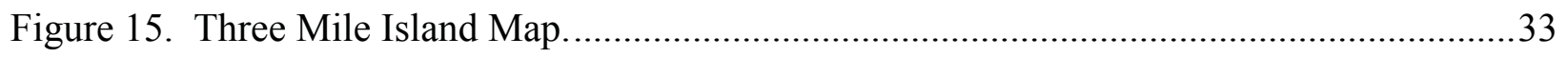

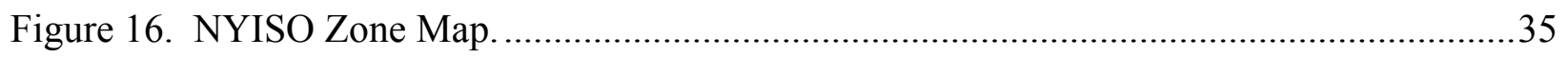

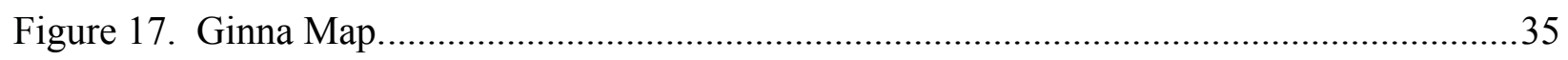

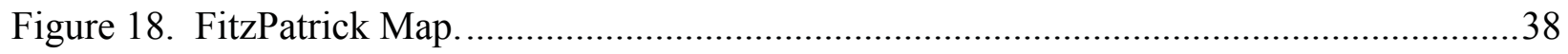

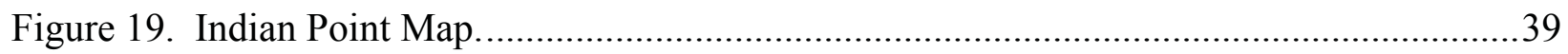

Figure 20. Nine Mile Point Map....................................................................................

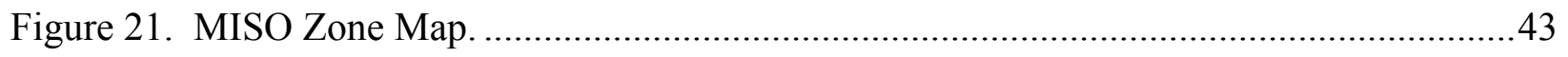

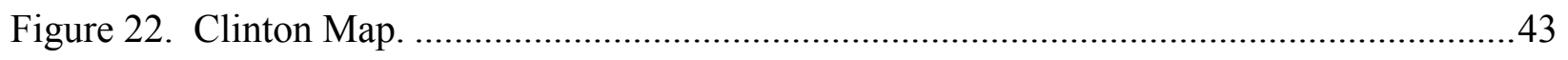

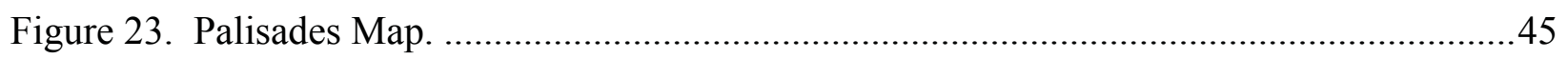

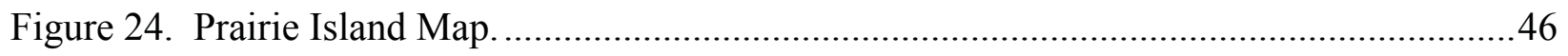




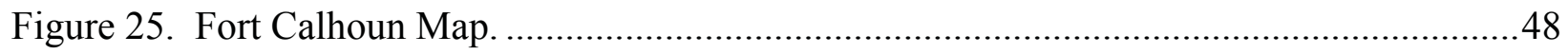

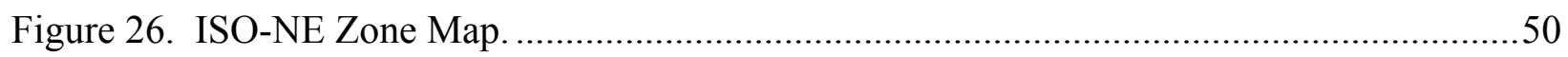

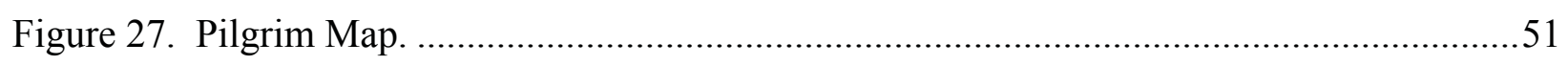

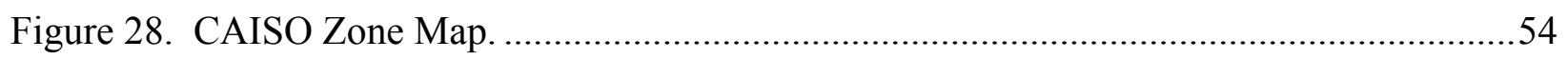

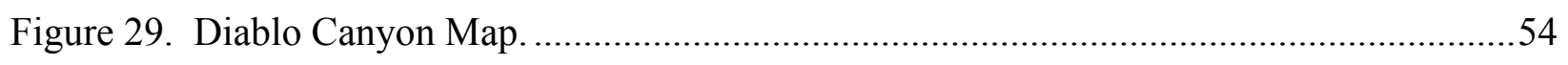

Figure 30. NEI Snapshot of 2015 U.S. Nuclear Power Plant Costs.............................................57

Figure A-1. Gap Estimates (\$/MWh) with Components..........................................................

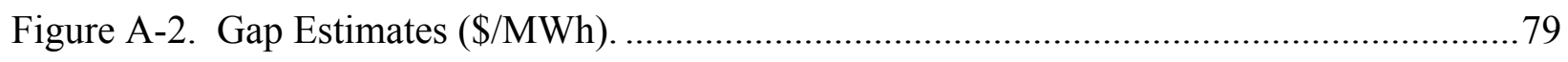

Figure A-3. Gap Estimates (Million \$/Year) for New York Units................................................82

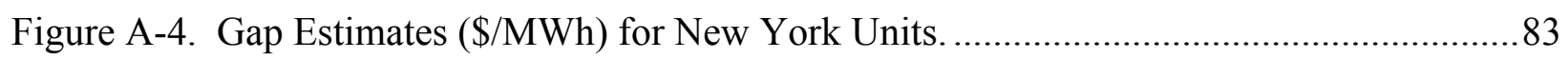

Figure A-5. Gap Estimates (Million \$/Year) for Selected Illinois Units. .......................................84

Figure A-6. Gap Estimates (\$/MWh) for Selected Illinois Units.................................................85 


\section{TABLES}

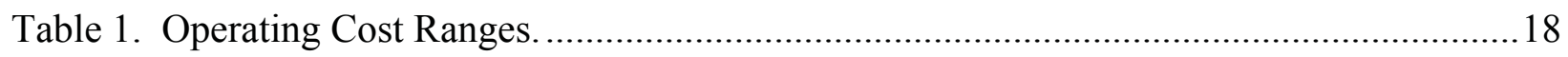

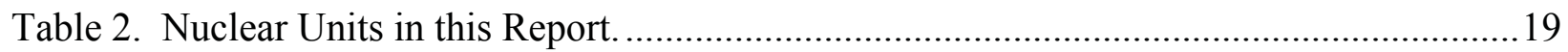

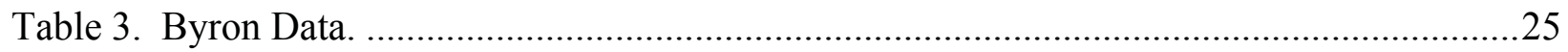

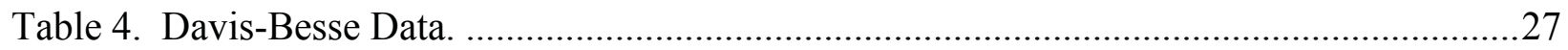

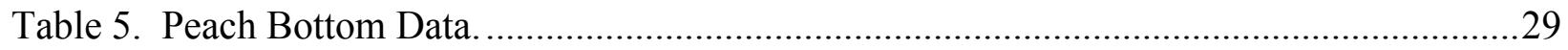

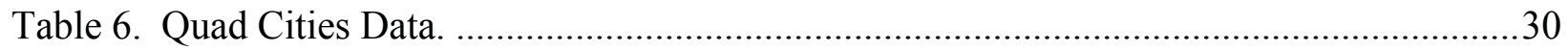

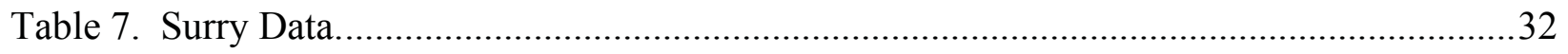

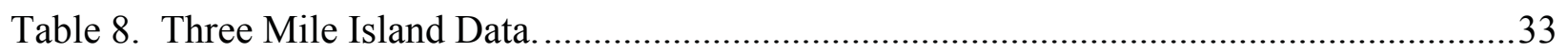

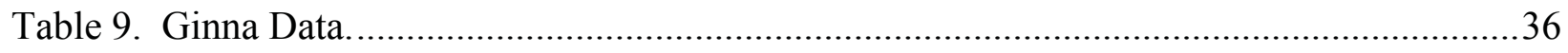

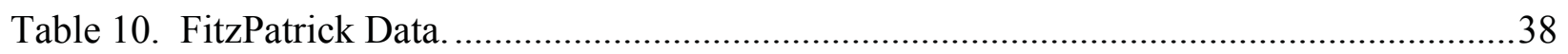

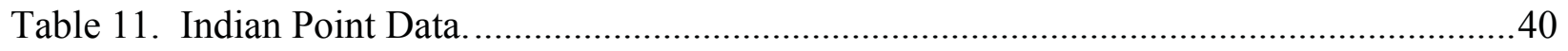

Table 12. Nine Mile Point Data..................................................................................................4

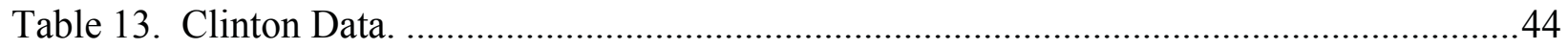

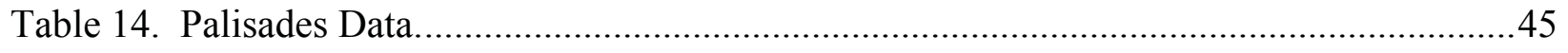

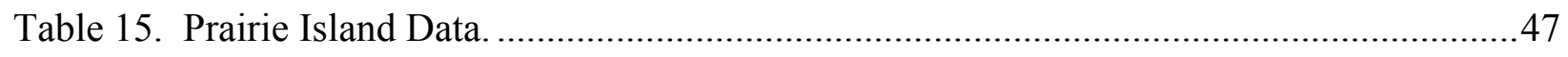

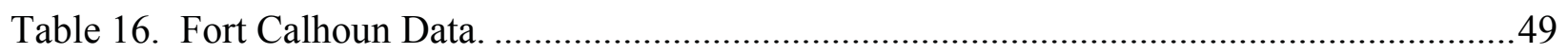

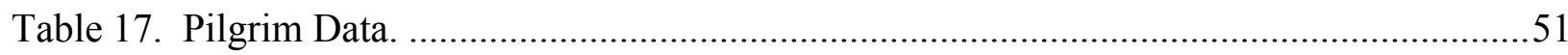

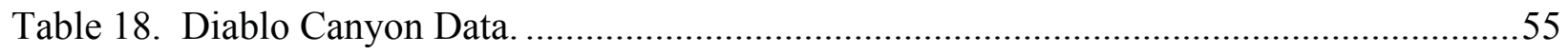

Table 19. NRC Dates for All Units in this Study .................................................................62

Table A-1. Gap Data for Byron, Davis-Besse and Peach Bottom.................................................8

Table A-2. Gap Data for Quad Cities, Surry and Three Mile Island.............................................8

Table A-3. Gap Data for Ginna, FitzPatrick, Indian Point and Nine Mile Point. .........................80

Table A-4. Gap Data for Clinton, Palisades and Prairie Island..................................................... 81

Table A-5. Gap Data for Fort Calhoun, Pilgrim and Diablo Canyon............................................ 81 


\section{ACRONYMS}

10CFR Title 10, Code of Federal Regulations

AEO Annual Energy Outlook

ANS American Nuclear Society

ATSI PJM LMP Zone

BWR Boiling Water Reactor

CAISO California Independent System Operator

CEO Chief Executive Officer

CES Clean Energy Standard

CLECO formerly Central Louisiana Electric Company

CMS Consumers Energy

$\mathrm{CO}_{2} \quad$ Carbon Dioxide

COMED PJM LMP Zone

COP-21 21 $21^{\text {st }}$ Session of the Conference of the Parties

CPP Clean Power Plan

D Dominion

DNP Delivering the Nuclear Promise

DOE U.S. Department of Energy

DOM PJM LMP Zone

EIA U.S. Energy Information Administration

EIM Energy Imbalance Market

EPA U.S. Environmental Protection Agency

EPRI Electric Power Research Institute

ETR Entergy

EU European Union

EXC Exelon Corporation

FCA Forward Capacity Auction

FCM Forward Capacity Market

FE FirstEnergy

FERC Federal Energy Regulatory Commission

GDP Gross Domestic Product 


\begin{tabular}{ll} 
GW & Gigawatt \\
ICAP & Installed Capacity \\
INL & Idaho National Laboratory \\
INPO & Institute of Nuclear Power Operations \\
IRP & Integrated Resource Plan \\
ISO & Independent System Operator \\
ISO-NE & ISO New England \\
LCPS & Low Carbon Portfolio Standard \\
LMP & Locational Marginal Pricing \\
LSE & Load-Serving Entity \\
LWRS & Light Water Reactor Sustainability \\
METED & PJM LMP Zone \\
MISO & Midcontinent Independent System Operator \\
MMBtu & Million British Thermal Units \\
MW & Megawatt \\
MWe & Megawatt electrical \\
MWh & Megawatt-hour \\
NECG & Nuclear Economics Consulting Group \\
NEI & Nuclear Energy Institute \\
NRC & U.S. Nuclear Regulatory Commission \\
NSP & Northern States Power Company \\
NYISO & New York Independent System Operator \\
NYPSC & New York Public Service Commission \\
OPPD & Omaha Public Power District \\
OVEC & Ohio Valley Electric Corporation \\
PG\&E & Pacific Gas \& Electric Company \\
PJM & Pennsylvania-New Jersey-Maryland Interconnection \\
PPA & Power Purchase Agreement \\
PSDAR & Post Shutdown Decommissioning Activities Report \\
PTC & Production Tax Credit \\
PUC & Public Utilities Commission \\
PUCO & Public Utilities Commission of Ohio \\
PWR & Pressurized Water Reactor \\
\hline
\end{tabular}




$\begin{array}{ll}\text { RG\&E } & \text { Rochester Gas \& Electric } \\ \text { Rider RRS } & \text { Retail Rate Stability Rider } \\ \text { RSSA } & \text { Reliability Support Service Agreement } \\ \text { RTO } & \text { Regional Transmission Organization } \\ \text { SAFSTOR } & \text { SAFe STORage (one of three nuclear plant decommissioning strategies) } \\ \text { SEMASS } & \text { SE Massachusetts } \\ \text { SMP } & \text { System Marginal Price } \\ \text { SNL } & \text { SNL Energy } \\ \text { SONGS } & \text { San Onofre Nuclear Generating Station } \\ \text { SPP } & \text { Southwest Power Pool } \\ \text { SRMC } & \text { Short-Run Marginal Cost } \\ \text { TMI } & \text { Three Mile Island } \\ \text { TVA } & \text { Tennessee Valley Authority } \\ \text { UAE } & \text { United Arab Emirates } \\ \text { UK } & \text { United Kingdom } \\ \text { XEL } & \text { Xcel Energy } \\ \text { ZEC } & \text { Zero Emissions Credit }\end{array}$




\section{ECONOMIC AND MARKET CHALLENGES FACING THE U.S. NUCLEAR COMMERCIAL FLEET}

\section{INTRODUCTION}

This report is focused on the financial and economic stresses facing the current U.S. operating nuclear fleet.

The report has several chapters:

- Background;

- Magnitude of the financial problem;

- Timing issues related to potential early retirement;

- Actions that might be taken to prevent more early retirement; and

- Conclusions and recommendations. 


\section{BACKGROUND - UNDERSTANDING THE CHALLENGES}

Some nuclear power plants in the U.S. face financial stress that may lead to early retirement.

The Kewaunee and Vermont Yankee nuclear power plants were retired early for economic and financial reasons. The owners of the Crystal River and San Onofre units chose to retire those units early, rather than invest in necessary plant repairs. Early retirement has been announced for Clinton and Quad Cities in Illinois, FitzPatrick and Ginna in New York, and Fort Calhoun in Nebraska. Other nuclear power plants, including Palisades, Davis-Besse, Prairie Island, and Three Mile Island Unit 1, have been identified as facing financial stress that might lead to early retirement.

The nuclear power plants facing the threat of early retirement are mostly those operating in states with a restructured electricity industry and organized electricity markets, but some nuclear power plants that are regulated and or owned by public power utilities are also at risk.

This situation is the result of a confluence of several factors:

- A long-standing U.S. focus on private ownership of the electricity industry, exacerbated by a relatively recent move to restructure some regions to create merchant nuclear power plants operating in wholesale power markets;

- Very low wholesale electricity market prices, caused by a combination of low natural gas prices, low demand growth, increased penetration of renewables based on tax credits and state mandates, and an increase in negative prices;

- A failure to provide compensation to nuclear power plants for a range of valuable products that they provide, so that the present economics of nuclear power are based only on commodity power sales; and

- A failure of the nuclear power industry to make a convincing argument that market failure is occurring and will continue, if there are not changes, unlike the renewable power industry which receives significant state and federal incentives based on the market failure argument.

This chapter provides a discussion of each of these four factors.

\section{A. U.S. Electricity Industry Structure}

Unlike some countries (e.g., France and China), the U.S. electricity industry is primarily owned by private companies. The portion of the U.S. electricity industry that is government-owned consists mostly of local or regional public power companies that are sensitive to the cost of electricity.

Where the electricity industry is owned and controlled by a national government, this national government can consider the full set of costs and benefits (i.e., both those considered as private 
costs and benefits in the U.S. context and those considered as public costs and benefits) in making investment and other decisions. The U.S. market economy has separated a set of private costs and benefits (e.g., those included in corporate net earnings) from public costs and benefits and usually takes few positions in the market outcomes.

This U.S. approach means that nuclear power is an activity with most costs and benefits assigned to private or public power owners. Thus, nuclear power plant owners typically do not have the perspective that a national owner might have and may decide that a nuclear power plant's private financial outcomes are not sufficient to warrant continued operation, even if early retirement would result in a loss of net public benefits.

Electricity industry restructuring in some regions in the U.S. involved divestment of generation assets that became merchant generators ${ }^{1}$. The merchant nuclear power plants created by this electricity industry restructuring are particularly vulnerable to fluctuations in the price of the electricity and capacity they sell because lower prices can result in some cases in financial losses.

The U.S. electricity industry has a focus on efficient interstate markets as a matter of policy, with an explicit goal of achieving lower market prices. The implicit emphasis on electricity and capacity as short-term commodities in these markets makes it difficult or impossible for any generator participant to have a long-term view of plant value or to focus on externality benefits such as zero carbon emissions that are not reflected in market prices. The focus on efficient electricity markets results in low electricity market prices. These lower electricity market prices directly impact merchant nuclear power plant operating cash flow. These lower prices also depress the price of power purchased by regulated and public power utilities, lowering the relative value of regulated and public power nuclear plants.

Today, about 45 GWs of nuclear capacity (49 plants) operates in deregulated markets and 55 GWs of nuclear capacity (51 plants) operates under rate-based state regulation. Currently, many nuclear power plants operating in deregulated electricity markets face financial stress due to factors identified in the following sections. As the Fort Calhoun early retirement demonstrates, this financial stress may also be seen in regulated and public power nuclear power plants.

\section{B. Electricity Market Prices - Historically Low}

The market-focused approach to the electricity industry in the U.S. means that the economics of nuclear power plants are linked to commodity electricity and capacity prices. When these prices are low, nuclear power plant operating cash flows are low or negative.

\footnotetext{
A merchant generator is one that relies on electricity and capacity markets for revenue, as compared to a regulated generator that has a return set by a state utility regulator or by a public power company.
} 
Average wholesale power prices across the U.S. have dropped by more than half over the past decade

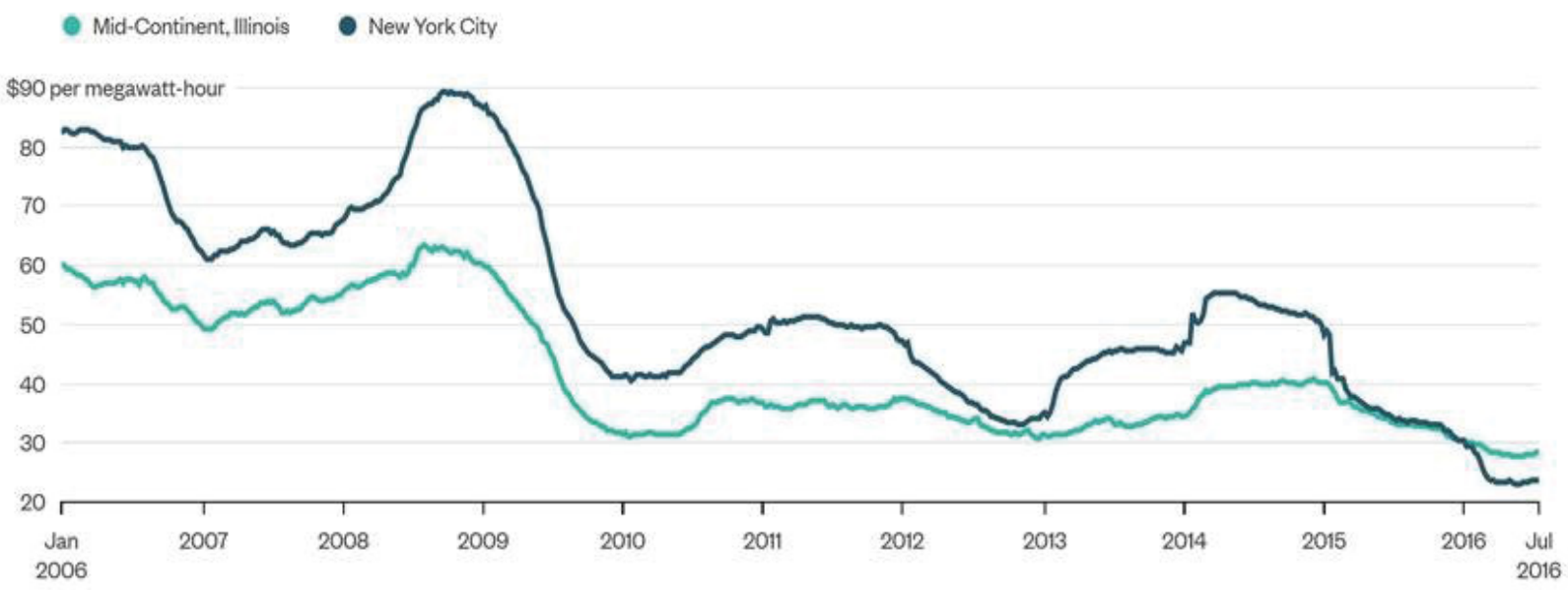

Figure 1. U.S. Wholesale Power Prices. ${ }^{2}$

Wholesale electricity prices in the U.S., both in organized regional transmission organization (RTO) markets and in regions that remain regulated, are very low as a result of several factors, including low natural gas prices, low demand growth, increased penetration of renewable generation, and negative prices.

As an example, the PJM Market Monitor reported that lower demand combined with lower 2016 natural gas prices resulted in PJM load-weighted average real-time locational marginal pricing (LMP) in the first six months of 2016 of $\$ 27.09 / \mathrm{MWh}$. This was 36\% lower than the loadweighted average real-time LMP in the first six months of 2015 which was $\$ 42.30 / \mathrm{MWh}$. A nuclear power plant without any capacity market revenue and with fleet average operating costs of $\$ 35.50 / \mathrm{MWh}$ would experience financial losses at the $\$ 27.09 / \mathrm{MWh}$ electricity market prices seen in the first half of 2016 in PJM.

\section{Natural Gas}

Unlike some countries, the U.S. has an existing and extensive network of natural gas industry infrastructure. This infrastructure includes multiple production basins, multiple intrastate and interstate pipelines, a host of companies that produce, transport, and sell natural gas, and a regulatory structure that facilitates natural gas commerce.

There is relatively easy access to natural gas for electricity generation and a well-established commercial framework related to natural gas procurement and use. Also, natural gas fueled power plants have the capability for flexible operation, low capital cost and short/predictable

2 Source: Bloomberg. 
construction time, making gas-fired generators a preferred option for capacity additions when fuel prices are low.

The move to unconventional natural gas production has resulted in large increases in available natural gas and low natural gas prices that are projected to remain for decades. These current and projected low natural gas prices result in low electricity market prices at peak and mid-peak periods, eroding the revenue for baseload nuclear power plants.

Natural gas prices and their future forward projected price play a crucial role in determining wholesale power prices since the natural gas price is the price maker in the electricity markets and natural gas plants marginal prices in large part determine the market clearing price paid to generators of electricity.

Historically, natural gas prices have proven to be volatile and cyclical and this has led utilities to rely on a diversity of fuels as a hedging strategy against the risk of rising high gas prices due to shortages of supply. In fact, in 1978, Congress passed the Fuel Use Act which prohibited natural gas from being used to generate electricity. Passed in the shadow of a U.S. energy crisis at a time when oil and gas resources were expected to become scarce, this legislation was repealed in 1987. Recent and projected low prices for natural gas has lowered the concern about natural gas price spikes, lowered the expected value of generating fuel diversity and hedging strategies, and led to a significant increase in gas-fired generation.

With the advent of horizontal drilling and hydraulic fracturing, enormous quantities of natural gas have been produced in the U.S. and delivered to market. Natural gas prices peaked in December 2005 at over \$14/MMBtu and then again in July 2008 at over \$13/MMBtu. However, beginning in 2010 natural gas prices declined and have remained below \$5/MMBtu.

More recently (i.e., since 2015), natural gas prices have been below \$3/MMBtu and have been below $\$ 2 /$ MMBtu for 5 out of the last 8 months with prices hitting a 17 -year low in late winter 2015/2016 at below \$1.50/MMBtu.

Natural gas-fired generation is often the marginal unit in electricity markets, so lower natural gas prices result in lower electricity market clearing prices. For regulated utilities, the total cost of electricity from natural gas power plants may be much lower than the total cost of nuclear electricity.

In 2016, natural gas electricity generation is projected by the Energy Information Administration (EIA) to rise to 33 percent of total generation on an annual basis, surpassing coal at 32 percent.

In terms of the long term forecast, the EIA in its Annual Energy Outlook (AEO) 2015 Report in the reference case forecasted natural prices at \$4.88/MMBtu (2013 dollars) in 2020 and \$7.85/MMBtu (2013 dollars) in 2040. However, the EIA in its pre-release AEO 2016 report has lowered this long term forecast:

Natural gas production in the Reference case grows more than 50\% between 2015 and 2040. Annual average natural gas prices rise from their 2015 level, \$2.62/ million British thermal units (MMBtu) at the benchmark Henry Hub, to roughly 
$\$ 5.00 /$ million Btu in the mid-2020s and remain around that level through 2040.

Technology improvements allow natural gas production to rise even as prices

stabilize. Gas prices and production are slightly lower without the Clean Power Plan.

Figure 2 below shows the EIA projections (across multiple scenarios) for U.S. natural gas prices through 2040.

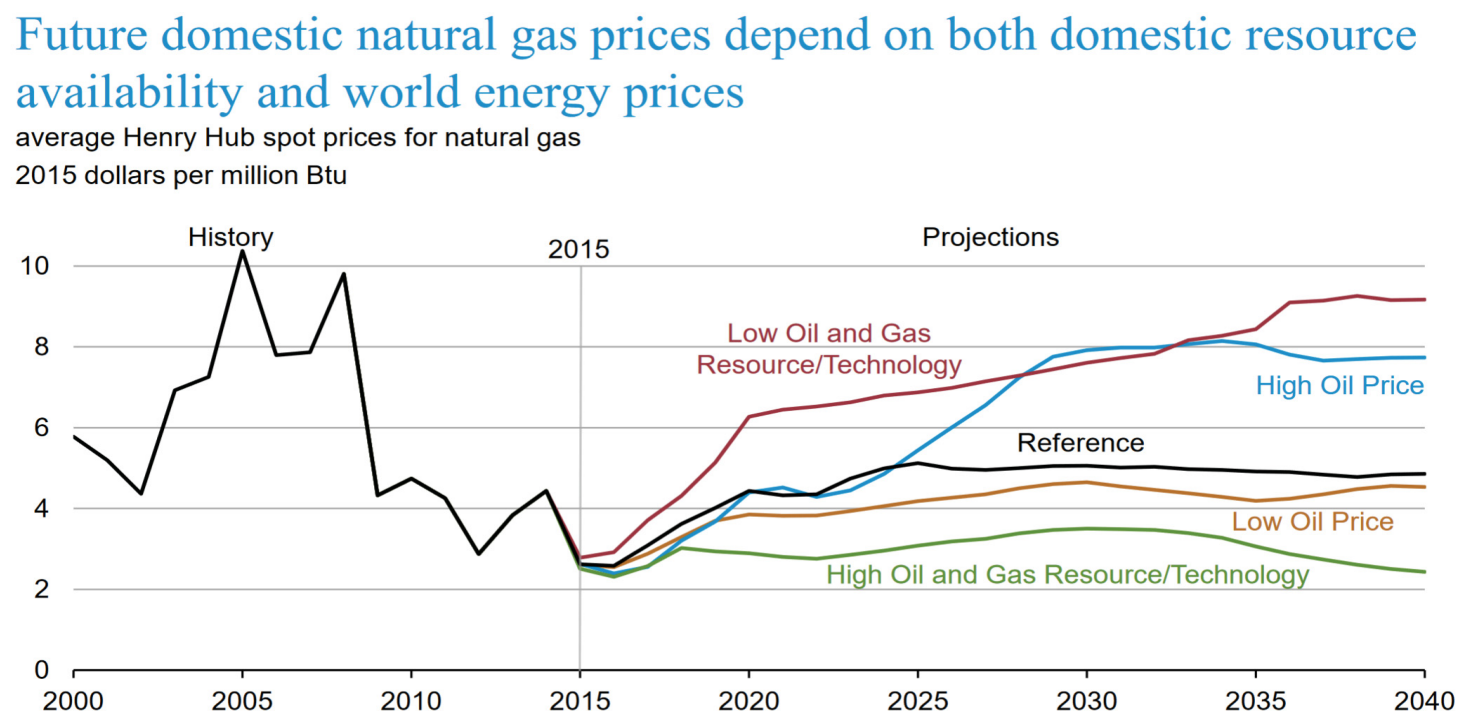

Source: EIA, Annual Energy Outlook 2016

Figure 2. Page 33 from AEO 2016 Rollout Presentation. ${ }^{3}$

More than two-thirds of the electricity generation cost from natural gas is linked solely to the cost of fuel. With both the near -term as well as the long term forecasts for natural gas prices to remain relatively low and stable, more and more utilities are turning to natural gas as the fuel of choice due to its low capital cost and short lead time for siting and construction. For example, in an interview with Columbia Energy Exchange ${ }^{4}$, Christopher Crane, President and CEO of Exelon, stated that he thought natural gas would be in the "\$3-range for a very long time".

\section{Low Demand Growth}

Low (or even negative) growth in demand and consumption is another factor contributing to lower wholesale electricity prices.

Lower electricity demand growth means that the need for both energy (MWh) and capacity (MW at peak) is lower than if load/demand growth were higher. This results in shifting the demand (load) curve towards lower marginal clearing prices and results in lower electricity market clearing prices.

3 John Hopkins School of Advanced International Studies, Adam Sieminski, June 28, 2016.

4 Navigating Shifting Power Markets, August 8, 2016. 
Historically, annual electricity demand grew in lock step with GDP growth, but beginning in the 2000s and continuing today, electricity demand has become uncoupled with GDP growth and is now growing at less than 1 percent per year. The factors causing lower demand growth include slowing population growth and efficiency improvements associated with new appliance standards in the buildings sectors and overall improvement in the efficiency of technologies powered by electricity. As mentioned in Figure 3, there has been a shift toward "less energy intensive industries" resulting from energy intensive industrial activity leaving the U.S. after the economic slowdown starting in 2008.

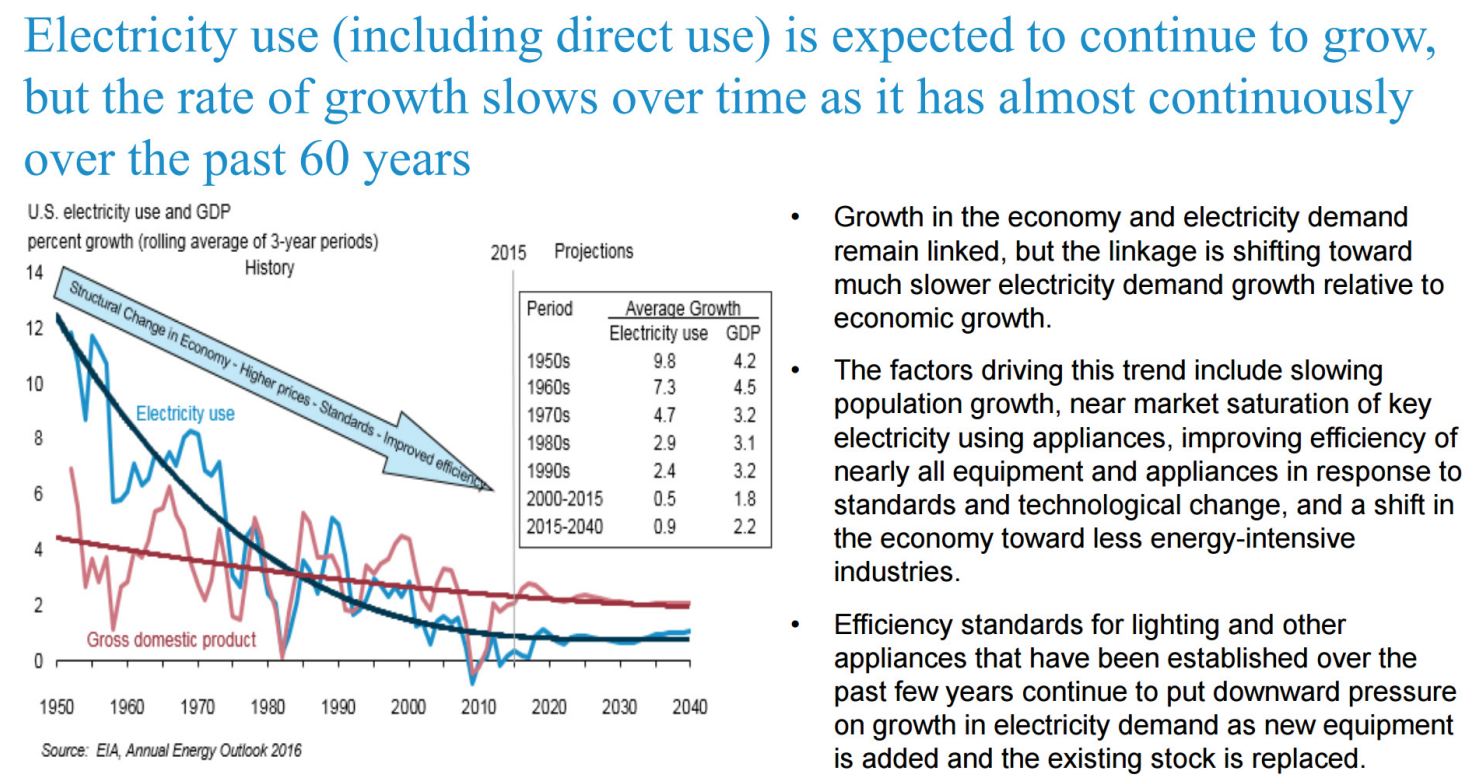

Figure 3. Figure 12 from AEO 2016 Rollout Presentation. ${ }^{5}$

EIA forecasts that annual electricity demand will grow at less than 1 percent through 2040. Significantly, current U.S. annual electricity generation has not fully recovered to the level prior to the recession in 2009.

Moreover, some regions are actually seeing falling demand. For example, PJM average real-time demand in the first six months of 2016 (i.e., 85,800 MW) was 5.3 percent lower than the average real-time demand in the first six months of 2015 (i.e., 90,586 MW).

\section{Increasing Penetration of Subsidized Renewable Generation}

Significant renewable generation capacity has been added, despite low electricity market prices, low natural gas prices and low demand growth.

5 John Hopkins School of Advanced International Studies, Adam Sieminski, June 28, 2016. 
The increase in renewable generation is mostly driven by out-of-electricity-market subsidies that include federal production tax credits, federal investment tax credits, state renewable mandates, and other policies. A combination of intermittent operation and zero or negative bids into electricity markets mean that the increased amount of renewable generation further depresses electricity market prices. These depressed electricity market clearing prices result, in part, from the addition of new renewable resources bidding at zero or negative prices. This pushes out the supply curve, so that the market clears at lower prices in any hour that renewable generation is bidding into the market.

Development of renewables is usually largest in locations with a large amount of wind (e.g., west Texas and the upper mid-west) and sun (e.g., California, Arizona, and Nevada).

In some regions, the potential for large amounts of electricity injected into the market at certain times of the day/year has led to concerns about managing the system.

One example of this is California, where subsidies and policies encourage solar generation that may result in a low need for other generation at times of peak solar output, but require much greater amounts of flexible generation to respond to the changes in net demand as solar output ramps up and down.

Another example of this is West Texas, where significant amounts of wind generation have been installed in a part of the state with little electricity demand. Texas has installed (or is installing) significant new transmission facilities to move this wind energy to the center of the state where large load centers are located. As this power is able to move out of West Texas, local negative pricing events are replaced with lower electricity market prices in other parts of the state.

\section{Negative Electricity Market Prices}

Negative prices are allowed in most of the organized electricity markets. Nuclear power plants are usually operated at maximum output during all hours between refueling outages, so that negative prices in the electricity market means that the owners of nuclear power plants must make payments to the market operator resulting in less net annual operating revenue.

Negative prices happen when there are more inflexible generator offers than demand for electricity in a trading period. When this happens, the market price is lowered until generators withdraw and/or price sensitive users increase demand to match supply and demand. In some instances, the market price can be negative.

A quick discussion of electricity market issues can help explain why prices are sometimes negative.

Market clearing (acceptance of bids needed to meet demand) happens in each trading period. A trading period may be an hour, but most markets are moving to shorter trading intervals (e.g., 5 minutes). 
A typical generator bid will have multiple parts. These parts are typically a base amount (i.e., at the minimum generation level for the unit), then a series of bids up to full capacity with prices that reflect the heat rate at each output level.

A key generator attribute in electricity markets is the generator's short-run marginal cost (SRMC). A quick definition of SRMC is the change in total cost of a generator as a result of a small and temporary change in generator output (e.g., a $10 \mathrm{MW}$ reduction in output for an hour for a 1,000 MW generating unit). SRMC is the fuel cost for a fossil fuel generator. Nuclear, hydro, and renewables have costs that are fixed and have an SRMC of zero, if there are no outof-market revenues.

Some generators, including nuclear power plants, bid as "price takers." A price taker bid ensures that the unit will operate all the time and not be dispatched off by the market operator. A price taker bid does not set the market price and the unit with a price taker bid is paid at the market prices in each trading period.

SRMC can be negative for a number of reasons. Some generating units have limited flexibility and may bid output at minimum generation level at a negative price or as a price taker. For example, a coal-fired power plant may only be able to lower output to the unit's minimum generation level (e.g., $40 \%$ of rated capacity) without shutting down. A shut-down/start-up cycle may take as much as 18 hours. If the coal-fired power plant shuts down for a trading period, it may not be able to return to full power until after peak demand in the next day. The lost revenue and profits can be used to estimate a negative SRMC for the coal plant's output at minimum generation.

Some electricity generators receive payments that are (a) outside the electricity market, but (b) linked to physical output. Such out-of-market payments will result in the generator receiving the payments to have a negative SRMC.

An example is the Production Tax Credit (PTC) for wind generation. The wind generator only gets the financial benefit of the PTC if it generates output that is delivered to the grid. Accordingly, the wind generator's SRMC is shifted to a negative price.

Similar negative SRMC outcomes may result from state renewable mandates (i.e., ZEC value is based on physical output delivered to the grid).

The ZEC program in New York will lower the SRMC of the nuclear units that receive these ZEC payments, replacing the natural economic nuclear power plant SRMC of zero with an artificial SRMC that is equal to the ZEC payment. This is because a nuclear power plant receiving ZEC payments only gets these ZEC payments if there is physical output in the market. Because most (if not all) nuclear power plants bid into the market as price takers (i.e., rather than with a bid of zero), this change may not mean a change in nuclear plant bidding behavior.

Less obvious are electricity market payments for operating reserves, regulatory-must-run contracts, ancillary services agreements, etc. These arrangements may result in the unit receiving these payments bidding as price takers or at negative prices. 
Even less obvious are bilateral power contracts between generators and energy users that may contractually or financially restrict physical output of the generators. These agreements include operation of cogeneration units that provide heat energy in addition to electrical output. Like other out-of-market arrangements, these contracts may result in some generators bidding as price takers or at negative prices.

While details are different, most electricity markets are based on bids received from generators which are used to develop a supply curve (i.e., by ranking the bids from lowest bid to highest bid). The result will look like Figure 4 . The width of the lines is related to the amount of the bid.

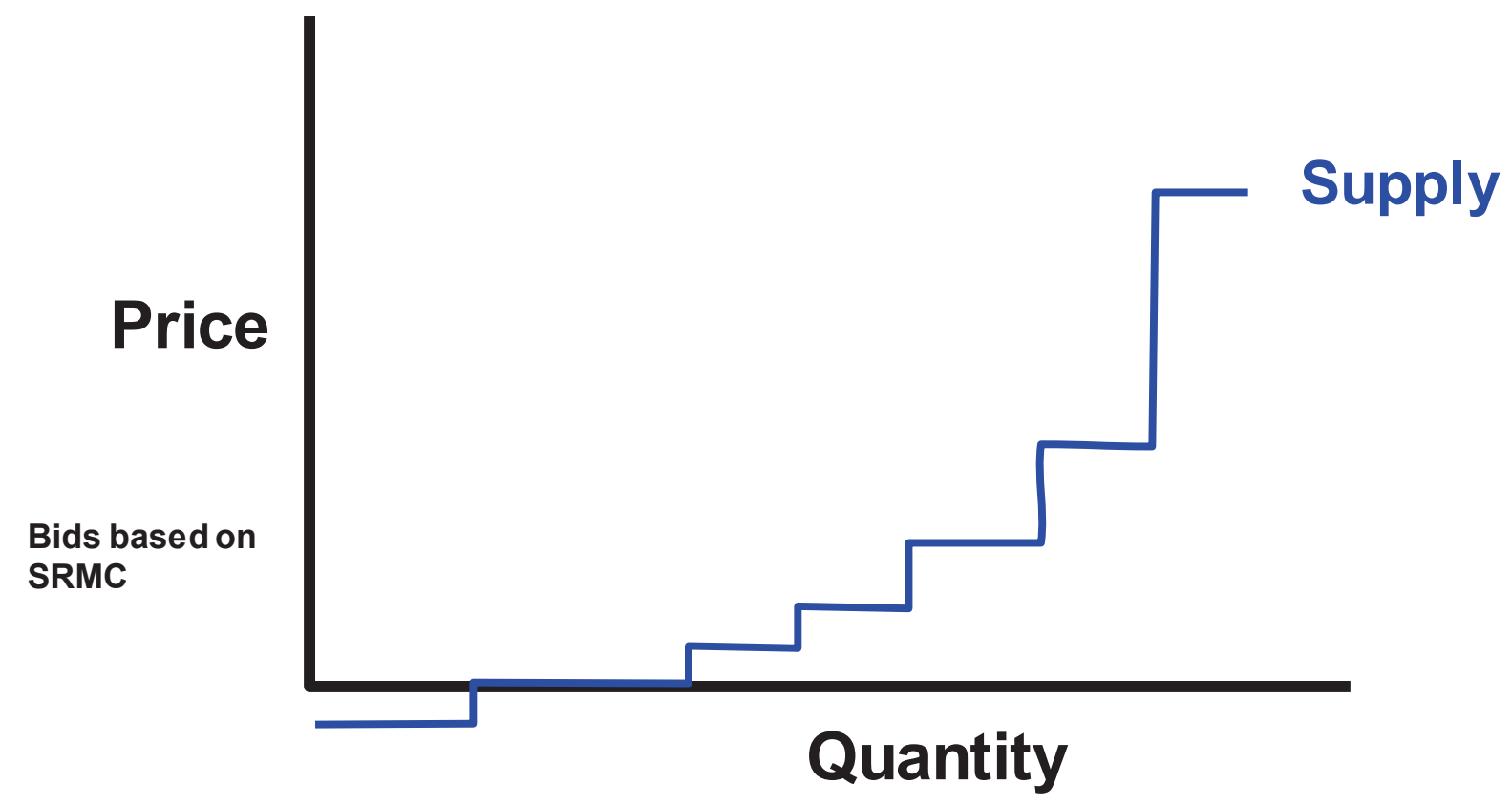

Figure 4. Electricity Bid-Based Supply Curve.

Prior to each trading period, the market operator decides how much electricity will be needed (i.e., based on projected demand in next trading period) and accepts (clears) enough bids to provide that amount of electricity.

In Figure 4, the bids at the bottom left (i.e., at a price of zero) reflect units that bid as price takers or at negative prices.

The bid price of the highest-priced bid selected/cleared (i.e., the marginal bid and marginal unit) in each trading period sets the price for the entire market for that trading period. 


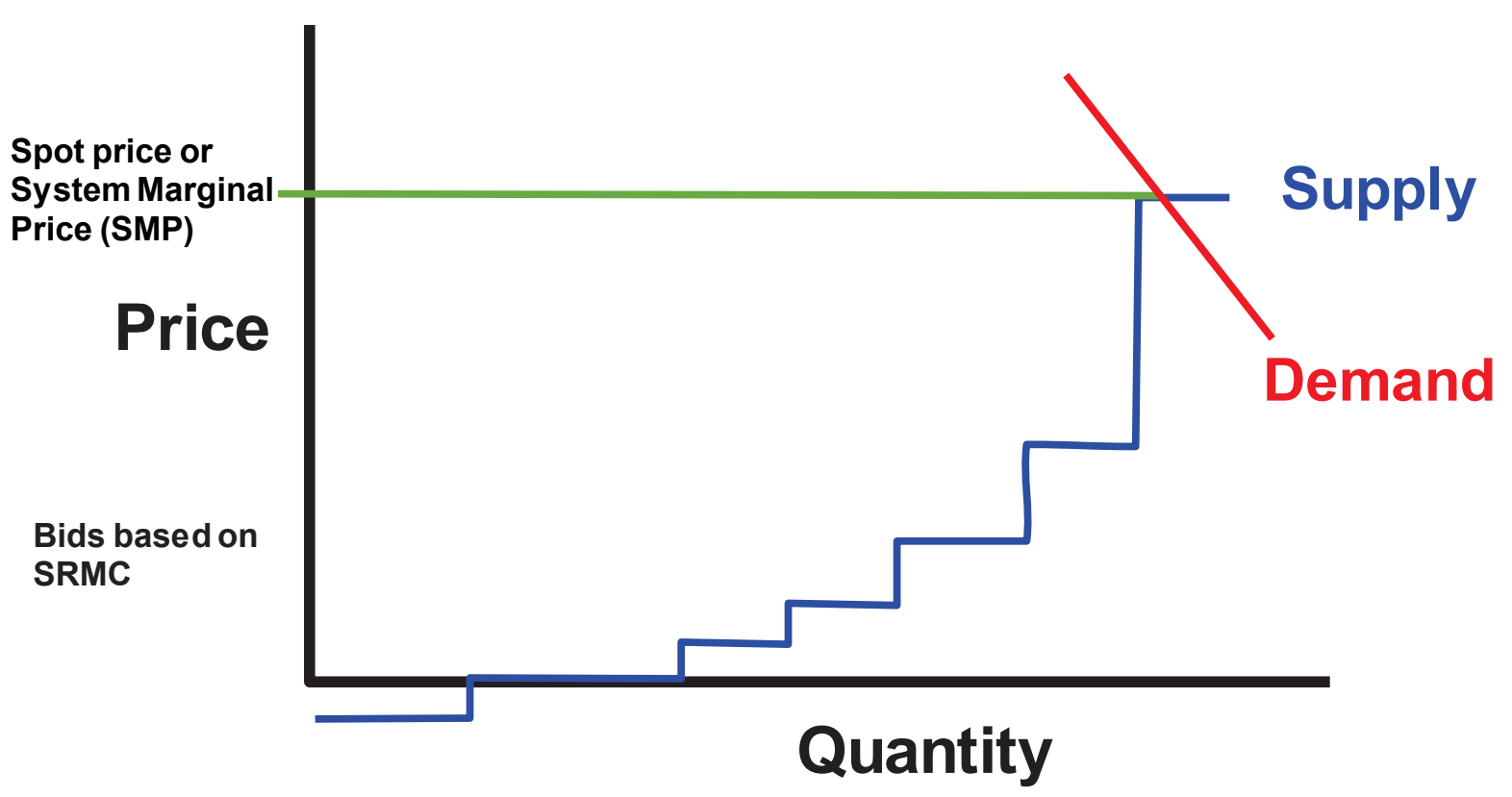

Figure 5. System Marginal Price.

In real electricity markets, demand and generation are not in the same place and electricity must move from generators to load centers. Transmission of power results in losses and may also be restricted by transmission congestion. Losses and congestion are factors that lead to LMPs that may be different at each pricing point in an electricity market.

If there is no congestion in a market, LMPs differ only because of losses. LMP at a load center would be higher than the LMP at a remote generator. A generator close to a load center (e.g., Indian Point is close to the Manhattan load center) would see higher locational prices than a generator in a remote area (e.g., FitzPatrick in northern New York State).

We understand that Exelon has recently developed and implemented a strategy of output reduction for some of its nuclear power plants in Illinois, lowering power at the request of the RTO/ISO during periods of high congestion to reduce the impact of negative electricity market prices. The strategy involves reducing nuclear power plant output in a controlled fashion that does not result in higher operating costs. We understand that this is only a temporary way to mitigate the issue, particularly if additional intermittent renewables are installed and load continues to decline.

\section{No Compensation for Nuclear Power Public Benefits}

Nuclear power plants have been limited to revenue from selling electricity and capacity, until the New York ZEC Order provided additional revenue for the value of the emission-free energy generated by nuclear power plants. 
Early retirement of nuclear power plants has negative impacts on the electricity system, energy security, the environment, and the economy. These negative impacts have not been included in early retirement decisions because there is no compensation to the nuclear power plant for providing electricity system benefits and public benefits.

In other words, the public benefits are generally not "monetized" in a way that can provide a return on the investment of the private owners. The private (or public power) owners therefore take on the investment and market risks, but do not get credit for the public benefits of nuclear power. This is clearly not sustainable.

\section{Market Failure for Nuclear Power}

The wind and solar power industry have successfully argued that the market will fail to build and operate wind and solar power capacity without support from tax credits, mandates, and other support. In economic terms, market failure is when the market will not deliver the type and amount of investments that will maximize public net benefits. The result of decades of renewable industry lobbying has been a wide range of federal tax credits, state mandates and purchase requirements.

This market failure argument can and should be made with respect to nuclear power.

U.S. nuclear power plants provide significant public benefits, but get no compensation for these public benefits. The owners of nuclear power plants make decisions based on the market value of nuclear power plants that sell commodity electricity and capacity.

When electricity and capacity prices are low (as they are today), merchant nuclear power plants lose money, regulated or public power nuclear power plants increase rates for electricity users, and new nuclear power plant projects look unprofitable.

When electricity prices are high, merchant nuclear power plants are profitable, regulated or public power nuclear power plants decrease rates for electricity users, and new nuclear plant projects look more attractive.

Early retirement of existing nuclear power plants and the failure to build new nuclear power plants during this period of low electricity prices results in the loss of substantial electricity system, economic, and environmental public benefits.

This is a failure of the U.S. market approach to nuclear power.

\section{Market Failure}

Market failure, an economic concept, is when the market (defined broadly) does not support activities that provide net public benefits. This can happen when firms decline to undertake activities or investments that result in private losses, even though these activities would provide net public benefits. 
Generic approaches to fix market failure include imposing costs on negative externalities, providing compensation to support positive externalities, and government ownership of sectors likely to experience market failure. Because market failure is about maximizing public good, these approaches usually involve government action.

Carbon pricing is an example of imposing costs on a negative externality.

UK incentives for new nuclear power are an example of providing compensation for positive externalities. Another example is subsidies for renewable generation.

Government ownership of nuclear power, as in France, China, Korea, Russia, the UAE, and other countries, is an example of government ownership to address market failure.

\section{How to Fix U.S. Market Failure}

Ideas to help prevent additional early retirement of U.S. nuclear power plants were discussed at the DOE Summit in May, including reference to the ANS Nuclear Toolkit (see Chapter V, page 68 for additional information on the Toolkit). Actions to resolve nuclear power market failure can be indirect or direct.

\section{a. Indirect Compensation}

Indirect actions may help nuclear power plants, but do not directly address the market failure problem. Two examples of these indirect actions are changes to electricity markets and carbon pricing.

\section{i. Electricity and Capacity Market Improvements}

Electricity (i.e., energy) and capacity markets determine the revenue received for electricity and capacity sales by merchant nuclear power plants. These markets also establish a benchmark valuation for power from nuclear power plants owned by regulated or public power utilities. Electricity and capacity markets are working pretty well to achieve their design objectives (e.g., low system marginal price and reliability). However, these electricity and capacity markets are not designed to maximize public benefits from nuclear power. NECG Commentary \#1 explained why nuclear power and other capital-intensive electricity generation technologies are not a good fit with electricity markets. ${ }^{6}$

If changes to electricity markets were to put a value on electricity system benefits (e.g., reliability, fuel diversity, etc.) from nuclear that are not valued now, this would help, but are likely to be insufficient to address the lack of recognition of broader social and environmental benefits.

6 See http://nuclear-economics.com/nuclear-power-plants/ 


\section{ii. Carbon Pricing}

Carbon pricing is seen by some as a way to save nuclear power. Carbon pricing may help improve nuclear power economics, but may not be certain enough to address the challenges facing nuclear power, as explained in a recent World Nuclear News Viewpoint article. ${ }^{7}$

\section{b. Direct Compensation}

Direct compensation to nuclear power plants for the public benefits they provide (i.e., paying for positive externalities) can be an effective way to fix the market failure problem. Some examples of direct actions are discussed here.

\section{i. Power Contracts}

A power contract between a regulated electric utility and a nuclear power plant can provide stable and sufficient revenue to a nuclear power plant to prevent merchant nuclear early retirement. One example is the 2012 PPA extension for the Duane Arnold merchant nuclear power plant. The Iowa Utilities Board approved this PPA extension based on the added public benefits (e.g., no emissions, jobs, etc.) of nuclear electricity.

\section{ii. Clean Energy (or Nuclear Energy) Mandates}

State clean energy mandates would require regulated retail utilities to acquire a portion of total electricity from clean sources including nuclear. A nuclear energy mandate would recognize that nuclear power provides electricity system and economic public benefits, in addition to environmental public benefits.

\section{iii. Payment for Clean Energy}

The New York Zero Emissions Credit (ZEC) program goes a step further than clean energy mandates. The ZEC program pays nuclear power plants for the zero emission energy these nuclear power plants produce, with the value of this zero-emission energy based on the social cost of carbon emissions that are avoided. This is discussed in more detail below.

\section{iv. Tax Credits}

Federal or state tax credits provide direct revenue to existing nuclear power plants to compensate them for the substantial public benefits provided.

7 See http://www.world-nuclear-news.org/V-Carbon-pricing-not-enough-to-help-nuclear-power-10061601.html 


\section{Justifying the Cost of these Actions}

The cost of resolving market failure related to nuclear power will be seen in higher electricity rates, higher federal expenditures, lower federal tax income, or other ways.

These costs can be justified by the same market failure arguments used to justify U.S. federal tax credits for renewables, state renewable energy mandates, and even EU state aid exemptions for renewables. Because the market fails to invest in renewable generation despite benefits to society (e.g., no carbon emissions), government action is needed to address this market failure.

The cost to keep operating nuclear power plants from retiring early is justified by the substantial public benefits from continued operation.

\section{E. New York ZEC Program}

The New York Public Service Commission (NYPSC) has approved a program to help keep New York's upstate nuclear power plants from retiring early by providing these nuclear power plants with payments to compensate them for the zero-emissions attributes of nuclear power based on the social cost of carbon.

These Zero Emissions Credit (ZEC) payments provide direct compensation to these nuclear power plants. The New York ZEC payments are made over 12 years in a series of 2-year tranches with the initial payment set at $\$ 17.48$ and increasing upward during the subsequent intervals. ${ }^{8}$ As discussed in the following chapter, this ZEC payment, combined with revenues received from energy and capacity payments, will help ensure the nuclear plant cash flow operating margins remain positive throughout the 12-year period and ensure continued operation from a financial perspective.

NYPSC ruled that there is a "public necessity" for ZEC payments to the FitzPatrick, Ginna and Nine Mile Point nuclear power plants located in upstate (or north) New York State. Hence this program is intended to save all upstate nuclear plants from retiring early, not just the most profitable one(s).

The New York ZEC program is a significant shift in policy related to nuclear power plants. The details of the ZEC program appear to be crafted to avoid the legal challenges in other states (e.g., the Ohio arrangement for Davis-Besse and the Hughes v Talen Supreme Court decision).

\footnotetext{
${ }^{8}$ ZECs have an initial price cap of $\$ 17.48$ per MWh (starting April 1, 2017), rising to $\$ 29.15$ per MWh in 2029, when the ZEC provision expires. Source: Statement by Environmental Progress's Cesar Penafiel \& Michael Shellenberger, July 12, 2016. See http://www.environmentalprogress.org/big-news/2016/7/12/new-yorksproposed-clean-energy-standard-a-win-win-for-green-jobs-and-climate
} 


\section{MAGNITUDE OF NUCLEAR POWER PLANT FINANCIAL PROBLEM}

This chapter analyzes and compares nuclear power plant revenue from the sale of electricity and capacity to the value received for this power in the markets (i.e., market prices in the organized electricity markets/regions and wholesale power prices and capacity prices for other regions) to operating costs (i.e., the cost of power delivered to the grid).

\section{A. Gap Measure}

This report includes estimates of nuclear power plant annual cash operating revenue and costs. We measure the "Gap" between cash operating costs and cash operating revenue, when costs are greater than revenue.

Anything that increases revenue or lowers operating cost has the potential to reduce the Gap. If the Gap is zero, the nuclear power plant just breaks even on a cash basis (i.e., cash operating revenue just matches cash operating costs). Reducing the Gap to zero (i.e., a nuclear power plant that just breaks even on a cash basis) may not, however, be enough to convince the owner to continue operation.

A nuclear power plant owner might accept a breakeven financial outcome for a brief period if the situation is expected to improve in the future. Additional net cash flow above the breakeven point will be needed to compensate a nuclear power plant owner for the additional costs imposed by the operational and market risks faced by a nuclear power plant owner as well as for a return on investment.

These risks include:

- The risk that operating costs will be higher than anticipated due, for example, to unanticipated regulatory mandates or unexpected equipment failures;

- The risk that operating costs per megawatt-hour will be higher than anticipated due to a lower-than-expected capacity factor, forcing the owner to recover the same fixed costs over a smaller number of megawatt-hours;

- The risk that nuclear power plant output and capacity factors might be lower than planned (i.e., this would reduce revenue, but not costs);

- The risk that, in the event of an unexpected outage, the nuclear power plant owner will be forced to cover a forward electricity sale obligation (i.e., sales into the day-ahead market) by purchasing electricity on the real-time spot market at a higher price than the buyer has agreed to pay under the forward contract;

- The risk that, in the event of an unexpected outage, the nuclear power plant owner will face financial penalties due to capacity market commitments; 
- The risk that energy and/or capacity market prices and revenue for the nuclear power plant is lower than expected or planned; and

- The risk that the LMP at the nuclear power plant pricing node diverges from overall electricity market prices (i.e., LMP basis risk); this might be due to changes in power flows, transmission constraints, or other factors unrelated to the nuclear power plant.

Depending on the company owning a particular nuclear power plant, a margin of $10 \%{ }^{9}$ or more above breakeven cash flow may be needed to avoid early retirement.

The remaining portion of this report focuses on an assessment of the Gap facing certain nuclear power plants. This Gap does not include an estimate of the margin that might be required by an owner to continue operation of the plant rather than retire it early.

\section{B. Inputs}

The primary determinants of the Gap are the annual cash cost of operation and the cash revenue from sales of electricity, capacity, and other products.

\section{Nuclear Power Plant Cash Operating Cost}

While there is industry-wide average data available on nuclear power plant operating costs, there is little public information on the operating costs of specific U.S. nuclear power plants, and no public information on the operating costs of merchant nuclear plants that make up most of the units covered in this study.

Nuclear power plants included in the rate base of regulated utilities provide information to FERC (i.e., in the Form 1 filed by regulated utilities) on operating costs. The data filed with FERC is processed by EIA, is reported in public documents, and is available from some companies (e.g., SNL).

Nuclear power plants that were divested by regulated utilities and sold to unregulated companies are not required to provide cost information to FERC. Information on operating costs for these unregulated nuclear power plants is considered as commercially confidential because the plants are bidding into competitive power markets.

The base Gap analyses in this report are based on an assumption that cash operating costs will be $\$ 300,000 / \mathrm{MW} /$ year. This is generally consistent with public information (e.g., from NEI) on average operating costs for nuclear power plants. ${ }^{10}$ Using the same cash operating costs focuses attention on differences in revenue, the primary issue threatening nuclear power plants.

A $10 \%$ margin means, in this context, that cash operating revenues are $10 \%$ greater than cash operating costs.

$10 \$ 300,000 / \mathrm{MW} /$ year is $\$ 37.14 / \mathrm{MWh}$ at the 2015 average capacity factor of $92.2 \%$. The average nuclear fleet operating costs of $\$ 35.5 / \mathrm{MWh}$ results in a $\$ 300,000 / \mathrm{MW} /$ year amount if the capacity factor is $96.5 \%$. 
However, all nuclear power plants do not have the same cash operating cost. To reflect these differences in operating cost, we developed a range of operating costs for each unit, based on a review of actual (non-public) and public information on operating costs. The primary factors determining cash operating costs at nuclear power plant are unit size and the number of units on a single site.

A smaller unit will have higher operating costs than a larger unit on a per MW basis, because some of the operating costs for a nuclear power plant (e.g., security, operators, NRC monitoring) are similar for each plant, but a smaller nuclear power plant is able to spread those costs over fewer MW (and fewer MWh).

Dual-unit sites have lower costs than single unit sites, when the units are nearly identical. Security is required for one site with multiple units; operators can be licensed to operate both (or all) units on site; and site management and overhead can be shared.

Accordingly, we have developed operating cost levels that are targeted at each unit in the study, with three sets, small single unit site, large single unit site, and multiple unit sites.

Table 1 shows the range of operating costs, with the equivalent amounts in $\$ / M W h$ (assuming a $90 \%$ capacity factor).

Table 1. Operating Cost Ranges. ${ }^{11}$

\begin{tabular}{|c|c|c|c|}
\hline \$MW/year & $\begin{array}{c}\text { Small Single } \\
\text { Unit site } \\
<900 \mathrm{MW}\end{array}$ & $\begin{array}{c}\text { Large Single } \\
\text { Unit site } \\
=>900 \mathrm{MW}\end{array}$ & $\begin{array}{c}\text { Multiple Unit } \\
\text { site }\end{array}$ \\
\hline 225,000 & & & $\$ 28.54 / \mathrm{MWh}$ \\
\hline 275,000 & & & $\$ 34.88 / \mathrm{MWh}$ \\
\hline 300,000 & & $\$ 38.05 / \mathrm{MWh}$ & \\
\hline 350,000 & $\mathbf{\$ 4 4 . 3 9 / \mathrm { MWh }}$ & $\mathbf{\$ 4 4 . 3 9 / \mathrm { MWh }}$ & \\
\hline 425,000 & $\mathbf{\$ 5 3 . 9 1 / \mathrm { MWh }}$ & & \\
\hline
\end{tabular}

In the discussion of the Gap estimate for each of the units in this study, the base operating cost and the operating cost ranges are presented.

\section{Power Market Prices}

The other factor determining the nuclear power plant annual cash Gap is revenue. The analyses in this report considered and evaluated publicly available data about wholesale electricity market

11 Note that the equivalent operating cost in $\$ / \mathrm{MWh}$ units are the same for all three categories of plants (i.e., if a unit has an annual operating cost of $\$ 300,000 / \mathrm{MW}$, the plant would have an operating cost of $\$ 38.05 / \mathrm{MWh}$ based on a $90 \%$ capacity factor). In other words, the blank cells would have, if completed, the same amounts across the row as the amounts that are displayed. 
prices and capacity market prices to develop an estimate of annual revenue for each nuclear power plant over the period from 1 July 2015 to 30 June 2016.

As a general matter, the hourly Day-Ahead electricity market prices were collected. Day-Ahead market prices are relevant to nuclear power plants, rather than Real-Time market prices.

In addition, capacity market prices in relevant ISO markets, the extent to which nuclear power plants have participated in these capacity markets, and the extent that each nuclear power plant has cleared in a capacity market auction (i.e., has a short-term capacity obligation) were examined to estimate capacity market revenue.

\section{Units Covered}

The nuclear power plants covered in this study and report are shown in Table 2 in alphabetical order, with the state and electricity market for each plant listed.

Table 2. Nuclear Units in this Report.

\begin{tabular}{|l|l|l|}
\hline Unit(s) & State & Electricity market \\
\hline Byron 1 \& 2 & Illinois & PJM (COMED) \\
\hline Clinton & Illinois & MISO (Illinois) \\
\hline Davis-Besse & Ohio & PJM (ATSI) \\
\hline Diablo Canyon 1 \& 2 & California & CAISO (ZP26) \\
\hline FitzPatrick & New York & NYISO (Zone C) \\
\hline Fort Calhoun & Nebraska & SPP/MISO \\
\hline Ginna & New York & NYISO (Zone B) \\
\hline Indian Point 2 \& 3 & New York & NYISO (Zone H) \\
\hline Nine Mile Point 1 \& 2 & New York & NYISO (Zone C) \\
\hline Palisades & Michigan & MISO (Michigan) \\
\hline Peach Bottom 2 \& 3 & Pennsylvania & PJM (PECO) \\
\hline Pilgrim & Massachusetts & ISO-NE (SEMASS) \\
\hline Prairie Island 1 \& 2 & Minnesota & MISO (MN) \\
\hline Quad Cities 1 \& 2 & Illinois & PJM (COMED) \\
\hline Surry 1 \& 2 & Virginia & PJM (DOM) \\
\hline Three Mile Island 1 & Pennsylvania & PJM (METED) \\
\hline
\end{tabular}

Most of the units in this list are either scheduled for early retirement, have been discussed as a candidate for early retirement, or have been identified as economically threatened. Some of the units (e.g., Surry and Peach Bottom) are not currently threatened and are included to illustrate the difference between threatened and non-threatened units. We note that even these non-threatened units may be threatened if electricity market prices are lower and/or if operating costs are higher.

Nuclear utilities usually operate nuclear power plants on a site basis (i.e., rather than at each unit in a multi-unit site) and would likely make decisions on whether to retire a plant early on a site 
basis. However, to illustrate the issues more clearly, this study looks at each unit separately, even if the unit is part of a multi-unit site.

Differences in the financial performance of units at a multi-unit site are typically related to differences in the level of output (i.e., this study uses actual power generation for reach unit) and slight differences in electricity market prices at each unit's pricing node.

As discussed below, one of the nuclear power plants in this study, the Nine Mile Point plant, has units with different size and vintage, so that the two units have different scenarios for operating cost.

\section{Gap Estimates}

The annual operating cash flow Gap was estimated for all units in the study. The primary measure of the Gap is in millions of dollars per year for each unit.

\section{Summary}

Figure 6 shows Gap estimates for the units in the study, with the revenue components (including New York ZEC payments) and operating costs. ${ }^{12}$ This Figure has the same operating cost estimate (i.e., $\$ 300,000 / \mathrm{MW} /$ year) for all units in order to highlight the differences in revenue for the units in different electricity markets and at different locations inside those electricity markets.

\footnotetext{
${ }^{12}$ The costs of generating electricity include operations and maintenance, capital and fuel.
} 


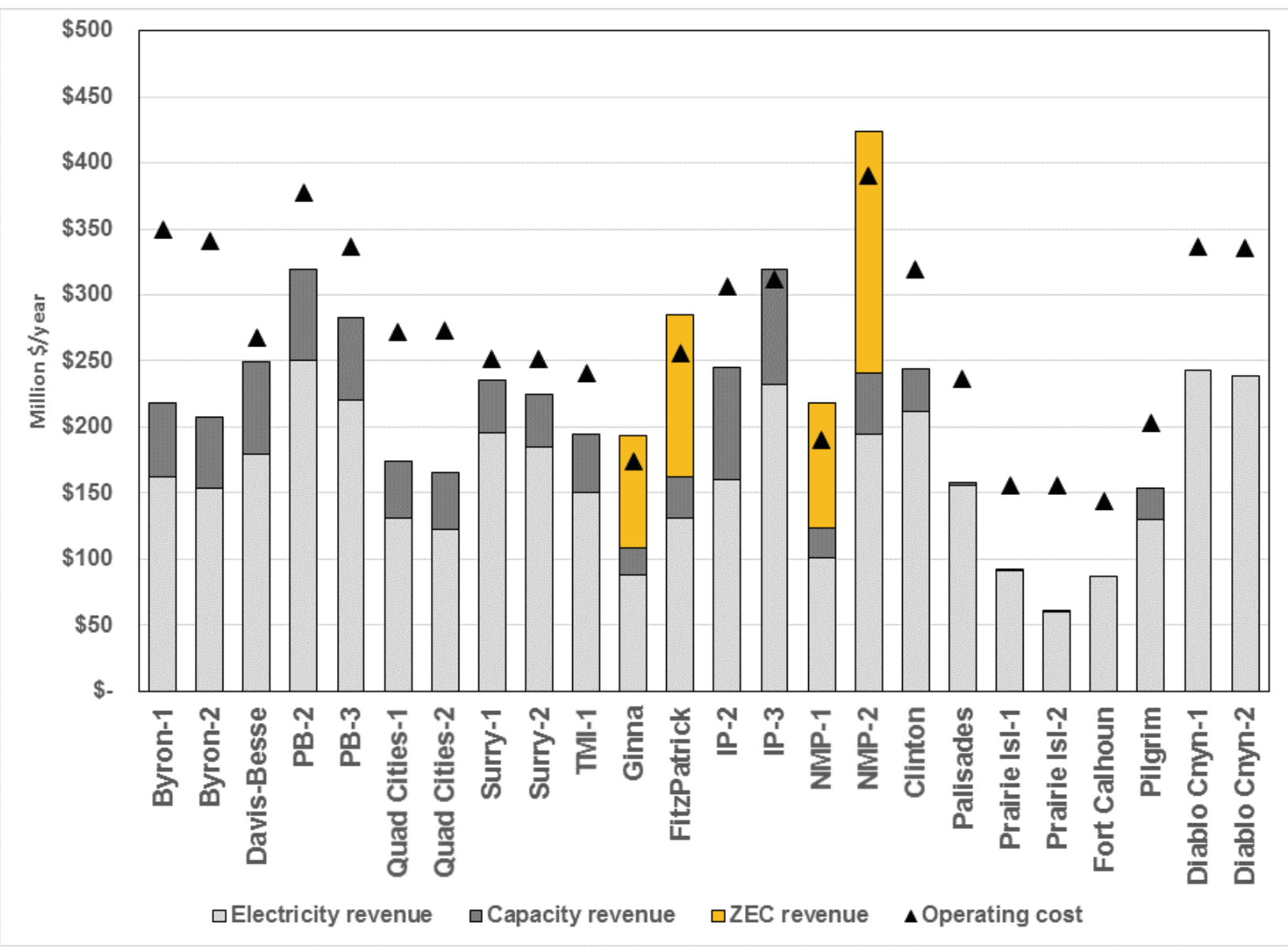

Figure 6. Gap Estimates (\$ Millions/Year) with Components.

Note: The information shown in Figure 6 is also available in units of $\$ / \mathrm{MWh}$ in the Appendix of this report, where a more detailed discussion of plant operating costs is presented.

Figure 7 shows same information as Figure 6, but only shows the Gap (i.e., the difference between the top of the revenue bar and the cost triangle in Figure 7). Positive Gap amounts are an indication that the units are profitable under the assumptions made. 


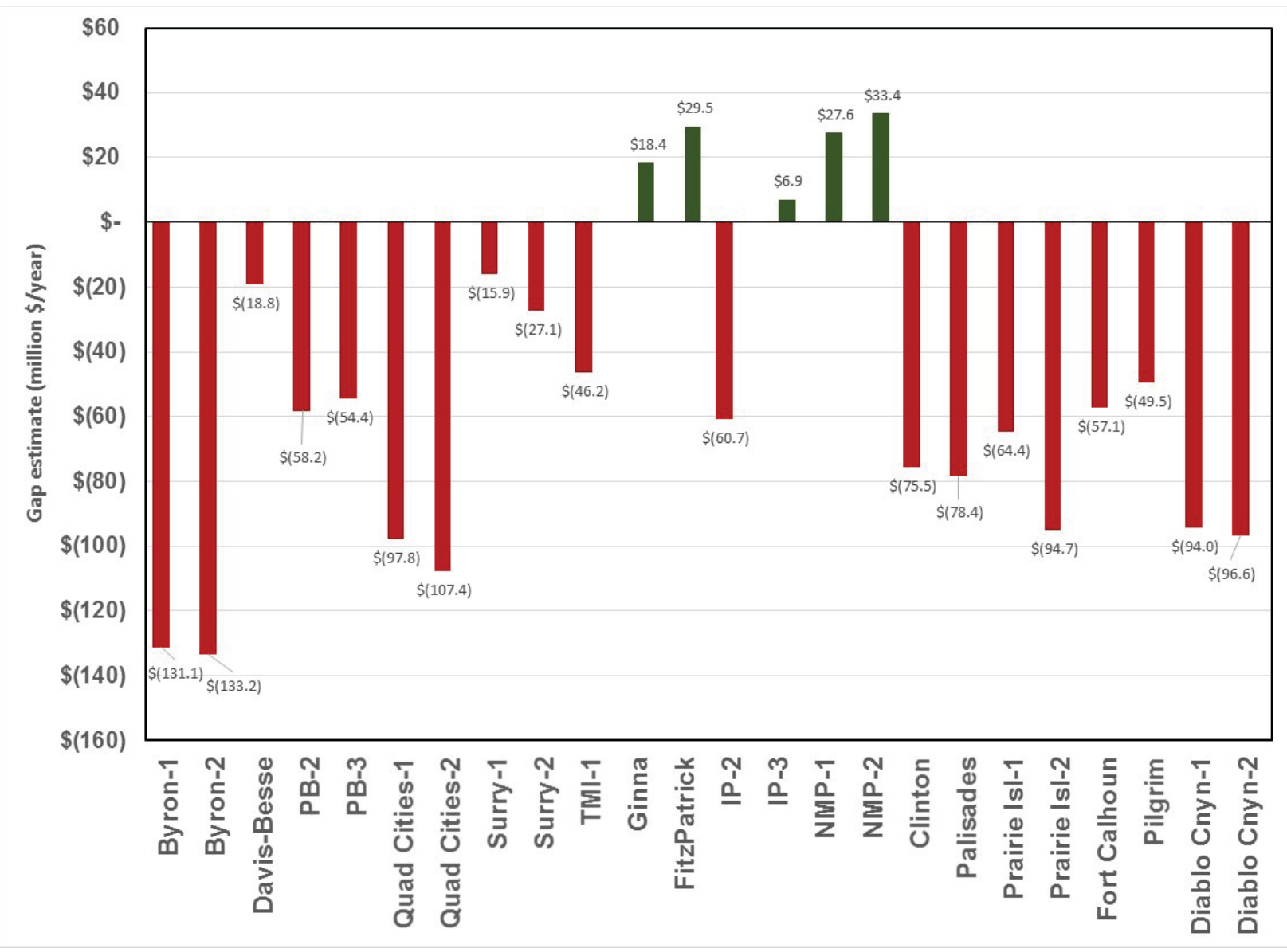

Figure 7. Gap Estimates (\$ Millions/Year). ${ }^{13}$

To reflect the range of operating costs discussed above (i.e., in Table 1), Figure 8 shows Gap estimates using $\$ 300,000 / \mathrm{MW} /$ year for each unit, plus the Gap using the high and low operating cost estimates associated with each unit (i.e., based on whether a unit falls into one of the three categories of small single unit, large single unit, or multiple unit site).

13 Note that this analysis assumes that (a) all units have the same $\$ 300,000 / \mathrm{MW} /$ year operating cost level, and (b) relevant New York units receive ZEC revenue. 


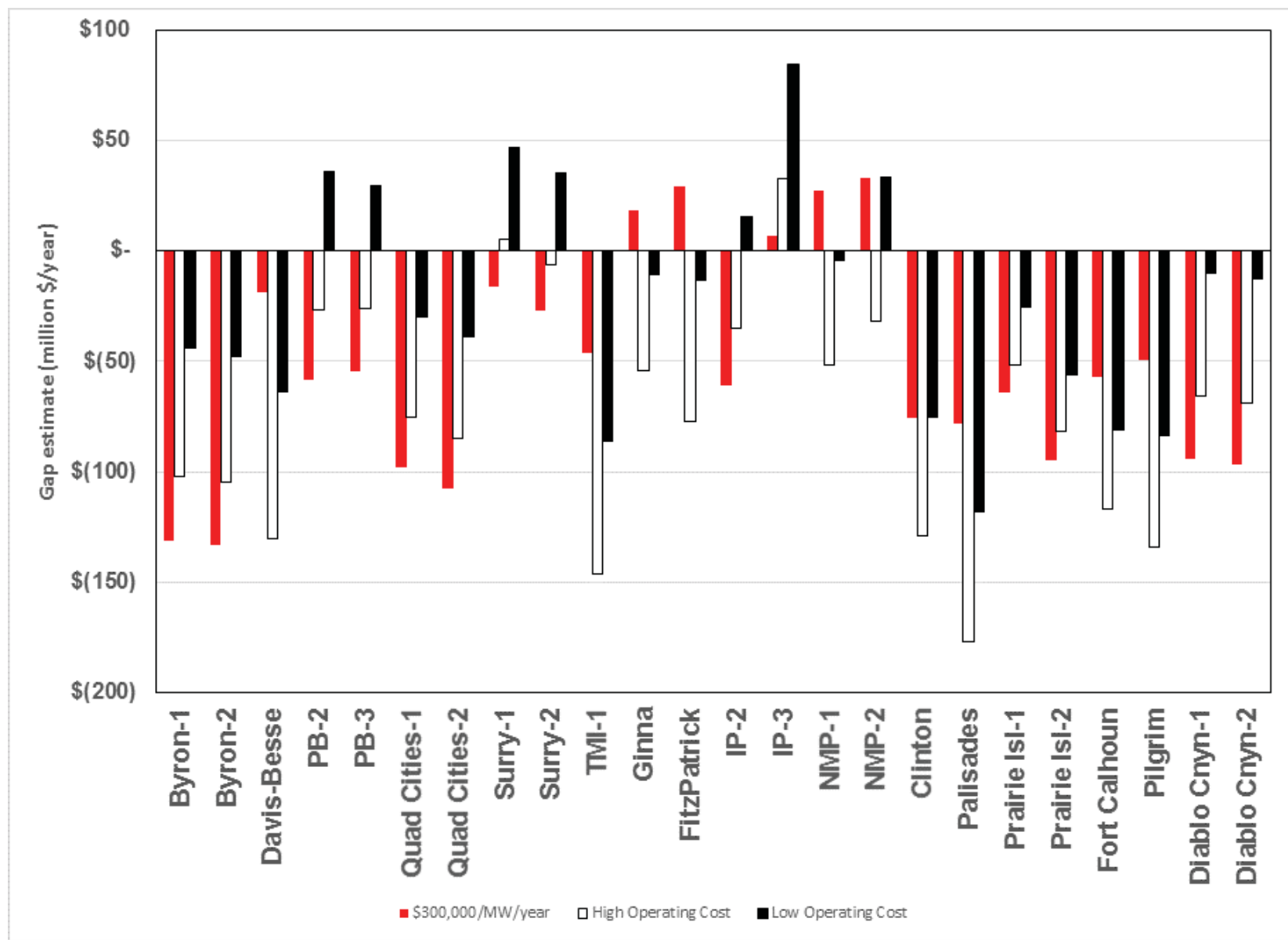

Figure 8. Gap Estimates with Range of Operating Costs. ${ }^{14}$

A more detailed discussion of each unit in the study is provided below. The units are organized by the wholesale electricity market where the unit's power is sold.

\section{PJM}

The PJM Interconnection operates a competitive wholesale electricity market and manages the reliability of its transmission grid. PJM provides open access to the transmission and performs long-term planning. In managing the grid, PJM centrally dispatches generation and coordinates the movement of wholesale electricity in all or part of 13 states (Delaware, Illinois, Indiana, Kentucky, Maryland, Michigan, New Jersey, North Carolina, Ohio, Pennsylvania, Tennessee, Virginia and West Virginia) and the District of Columbia. PJM's markets include energy (dayahead and real-time), capacity and ancillary services.

14 Note that this analysis assumes that relevant New York units receive ZEC revenue. 
PJM was founded in 1927 as a power pool of three utilities serving customers in Pennsylvania and New Jersey. In 1956, with the addition of two Maryland utilities, it became the Pennsylvania-New Jersey-Maryland Interconnection, or PJM. PJM became a fully functioning ISO in 1996 and, in 1997, it introduced markets with bid-based pricing and locational marginal pricing (LMP). PJM was designated an RTO in 2001.

The geographic scope of the PJM market is shown in Figure 9.

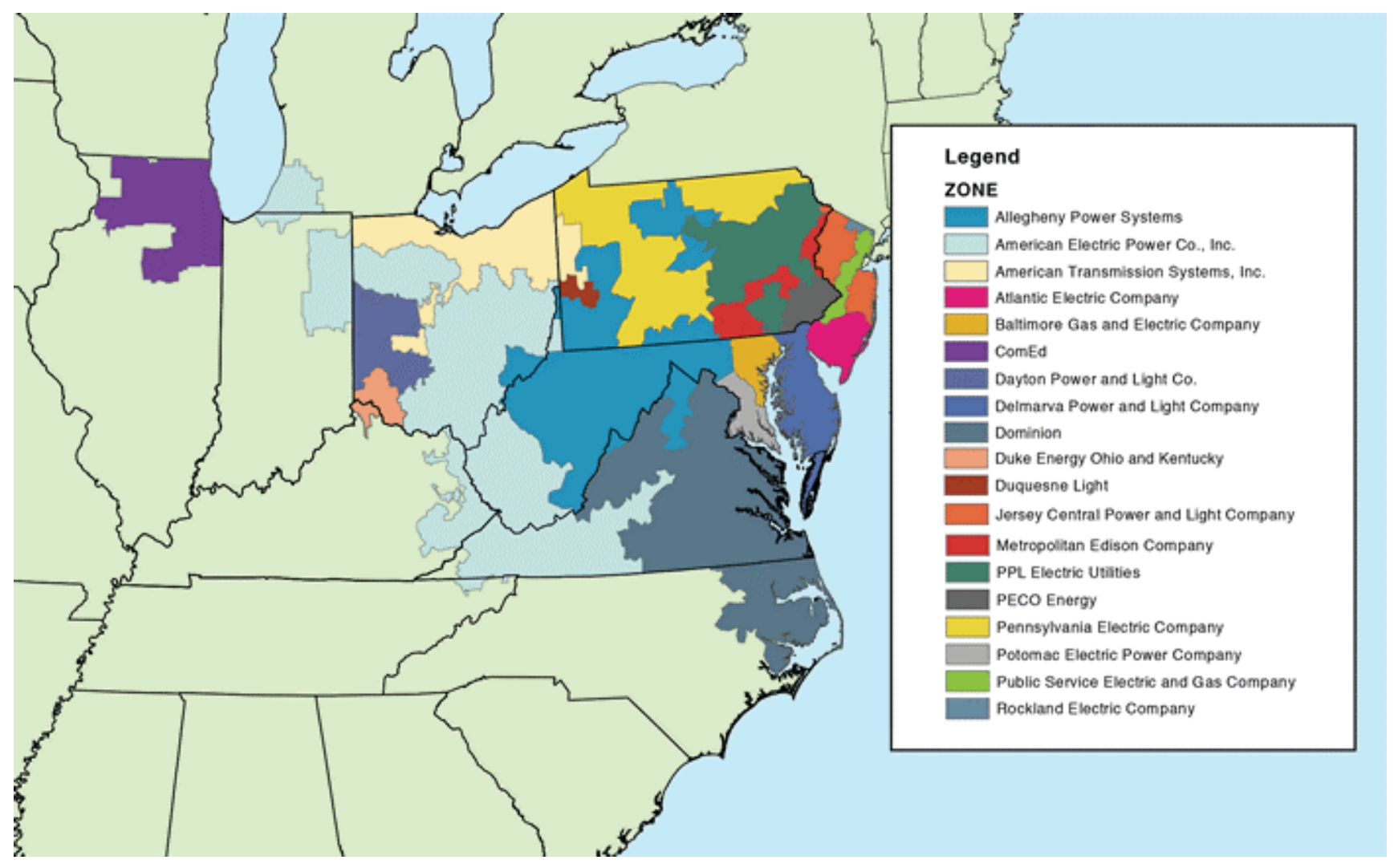

Figure 9. PJM Map. 


\section{a. Byron}

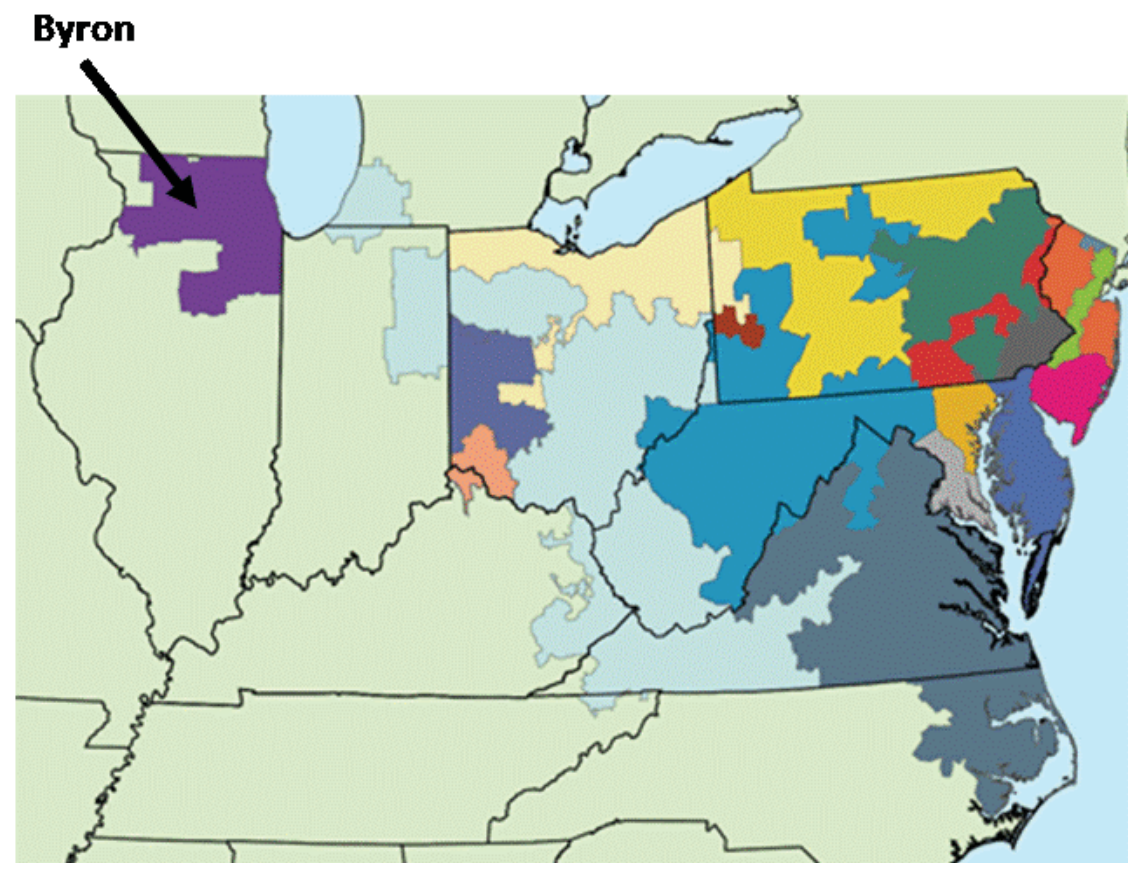

Figure 10. Byron Map.

Table 3. Byron Data.

\begin{tabular}{|l|c|c|}
\hline Unit & Byron-1 & Byron-2 \\
\hline Owner & Exelon & Exelon \\
\hline Summer Capacity (2015) & $1,164 \mathrm{MW}$ & $1,136 \mathrm{MW}$ \\
\hline Location & North Central Illinois & North Central Illinois \\
\hline Market region/zone & COMED & COMED \\
\hline Output (MWh) & $9,697,263$ & $9,164,453$ \\
\hline Electricity revenue (\$ millions) & $\$ 162.8$ & $\$ 153.6$ \\
\hline Capacity revenue (\$ millions) & $\$ 55.3$ & $\$ 54.0$ \\
\hline Operating cost, base (\$ millions) & $\$ 349.2$ & $\$ 340.8$ \\
\hline Gap, base (\$ millions) & $\$(131.1)$ & $\$ 133.2)$ \\
\hline Operating cost, high (\$ millions) & $\$ 320.1$ & $\$ 312.4$ \\
\hline Gap, high (\$ millions) & $\$(102.0)$ & $\$(104.8)$ \\
\hline Operating cost, low (\$ millions) & $\$ 261.9$ & $\$ 255.6$ \\
\hline Gap, low (\$ millions) & $\$(43.8)$ & $\$(48.0)$ \\
\hline
\end{tabular}

The Byron units are in the "multiple unit" category, with a high operating cost of $\$ 275,000 / \mathrm{MW} /$ year and a low operating cost of $\$ 225,000 / \mathrm{MW} /$ year.

Illinois implemented electricity industry restructuring by allowing its utilities to put generating assets into an unregulated subsidiary, rather than requiring that these assets be divested as in 
other states. Byron and other nuclear power plants in Illinois are operating as merchant nuclear units owned by Exelon Generation. The parent company, Exelon, also owns regulated electric utility subsidiaries in Illinois and other states.

The Byron units are located at a point in the grid where significant wind energy is imported into Illinois from Wisconsin. The transmission congestion inside Illinois due to this imported power means that Byron may see low or negative prices when there is a lot of wind generation in the region.

A temporary power reduction approach has lowered the number of hours when there are negative prices (or very low prices) at Byron. This power reduction approach started in mid-2016, so the results are not seen in the 2015/2016 annual data in this study.

Capacity from the Byron units was cleared in the 2016 PJM capacity auction, adding RTO commitments to operate through the 2019/2020 PJM capacity planning/delivery year.

A bill was introduced in 2015 in the Illinois legislature to establish a Low Carbon Portfolio Standard (LCPS). The LCPS would have, if approved and implemented, would have increased revenue to Illinois nuclear power plants. The legislature did not vote on this bill.

In 2016, a similar bill was introduced. As of the date of this report, the Illinois legislature has not voted on the 2016 version of the bill, but the legislature may act on this bill in sessions held just after elections in November and in early December.

\section{b. Davis-Besse}

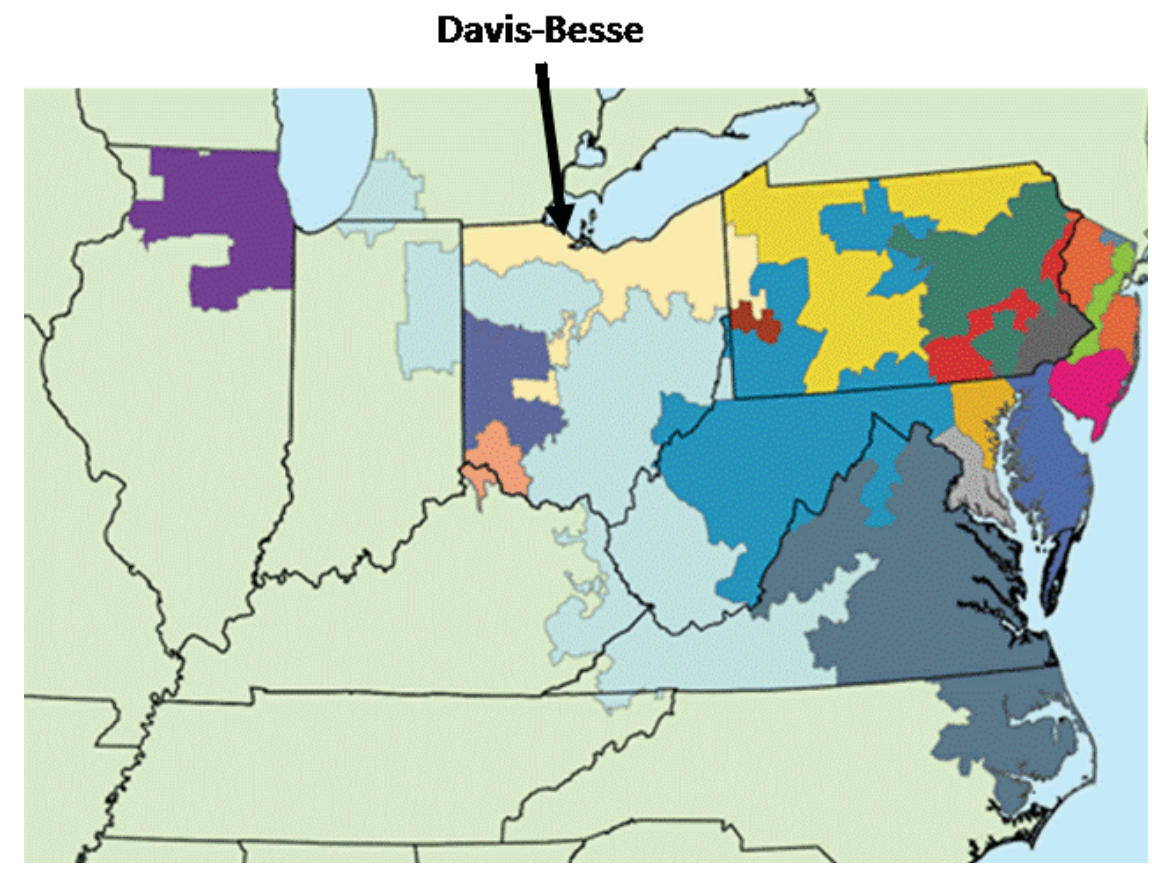

Figure 11. Davis-Besse Map. 
Table 4. Davis-Besse Data.

\begin{tabular}{|l|c|}
\hline Unit & Davis-Besse \\
\hline Owner & FirstEnergy \\
\hline Summer Capacity (2015) & $894 \mathrm{MW}$ \\
\hline Location & North Central Ohio \\
\hline Market region/zone & ATSI \\
\hline Output (MWh) & $6,706,769$ \\
\hline Electricity revenue (\$ millions) & $\$ 179.7$ \\
\hline Capacity revenue (\$ millions) & $\$ 69.6$ \\
\hline Operating cost, base ((\$ millions) & $\$ 268.2$ \\
\hline Gap, base (\$ millions) & $\$(18.8)$ \\
\hline Operating cost, high (\$ millions) & $\$ 380.0$ \\
\hline Gap, high (\$ millions) & $\$(130.6)$ \\
\hline Operating cost, low (\$ millions) & $\$ 312.9$ \\
\hline Gap, low (\$ millions) & $\$(63.5)$ \\
\hline
\end{tabular}

Davis-Besse is in the "small single unit" category, with a high operating cost of $\$ 425,000 / \mathrm{MW} /$ year and a low operating cost of $\$ 350,000 / \mathrm{MW} /$ year.

Davis-Besse is owned by FirstEnergy's unregulated power subsidiary. Ohio implemented electricity industry restructuring by allowing its utilities to put generating assets into an unregulated subsidiary, rather than requiring that these assets be divested as in other states.

Effectively, Davis-Besse is operating as a merchant nuclear unit, even though its parent company also has regulated utility subsidiaries.

On 31 March 2016, the Public Utilities Commission of Ohio (PUCO) approved the FirstEnergy application for a power contract that would prevent the early economic retirement of the DavisBesse nuclear power plant. ${ }^{15}$

The 137-page Opinion and Order reflects a contentious process that took almost two years.

This deal involved an eight-year arrangement with:

- A non-bypassable rider, the Retail Rate Stability Rider (Rider RRS), that will be applied to the rates for all retail customers;

- Power sales under a new power contract between the regulated FirstEnergy companies and FirstEnergy Solutions based on the Davis-Besse Nuclear Power Station, the W. H. Sammis Plant, and the FirstEnergy entitlement to the output of the Ohio Valley Electric Corporation (OVEC);

15 PUCO Docket 14-1297-EL-SSO (http://dis.puc.state.oh.us/TiffToPDf/A1001001A16C31B41521H01842.pdf) 
- Sale of the acquired power by the regulated entity into the PJM electricity markets;

- Comparison of the revenue from sales of power into the PJM wholesale market and the costs of the power contract, with the resulting net cost or credit included in Rider RRS.

If PJM market prices are high, the credit applied to Rider RRS would reduce customer rates. If PJM market prices are low, customer rates will be increased by Rider RRS.

According to the application, this plan will ensure that Davis-Besse continues to operate to provide long-term, reliable base load power. The plan will also reduce retail electricity cost volatility, limit future retail market price increases, enhance system reliability, protect jobs, and promote Ohio economic growth and development.

This PUCO Order is certain to be challenged in court, with the recent U.S. Supreme Court Decision in Hughes v Talen Energy Marketing Decision potentially setting a precedent.

Shortly after the PUCO Order, the U.S Federal Energy Regulatory Commission (FERC) issued an Order rescinding affiliate power contract waivers for FirstEnergy. The FERC Order does not stop the PUCO plan, the resulting power contracts would require FERC review and approval.

In response to the FERC waiver order, FirstEnergy revised its PUCO application to remove the power contract provisions. PUCO has agreed to hearings on the revised FirstEnergy application that are now in progress.

We understand that FirstEnergy and the PUCO has some interest in the features of the New York ZEC program.

\section{c. Peach Bottom}

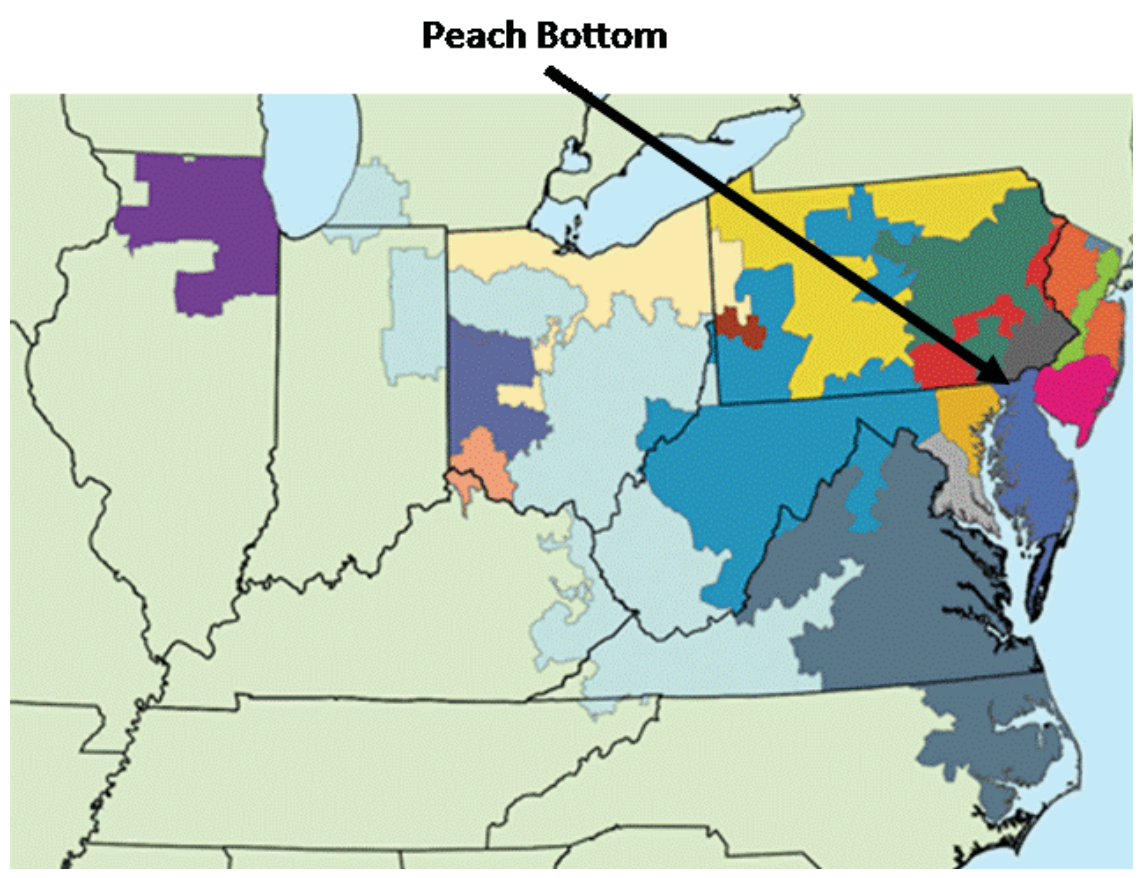


Figure 12. Peach Bottom Map.

Table 5. Peach Bottom Data.

\begin{tabular}{|l|c|c|}
\hline Unit & Peach Bottom-2 & Peach Bottom-3 \\
\hline Owner $^{\mathbf{1 6}}$ & Exelon & Exelon \\
\hline Summer Capacity (2015) & $1,259 \mathrm{MW}$ & $1,123 \mathrm{MW}$ \\
\hline Location & $\begin{array}{c}\text { Southeastern } \\
\text { Pennsylvania }\end{array}$ & $\begin{array}{c}\text { Southeastern } \\
\text { Pennsylvania }\end{array}$ \\
\hline Market region/zone & PECO & PECO \\
\hline Output (MWh) & $11,150,316$ & $9,838,351$ \\
\hline Electricity revenue (\$ millions) & $\$ 250.0$ & $\$ 220.6$ \\
\hline Capacity revenue (\$ millions) & $\$ 69.4$ & $\$ 61.9$ \\
\hline Operating cost, base ((\$ millions) & $\$ 377.7$ & $\$ 336.9$ \\
\hline Gap, base (\$ millions) & $\$(58.2)$ & $\$(54.4)$ \\
\hline Operating cost, high (\$ millions) & $\$ 346.2$ & $\$ 308.8$ \\
\hline Gap, high (\$ millions) & $\$(26.8)$ & $\$(26.3)$ \\
\hline Operating cost, low (\$ millions) & $\$ 283.3$ & $\$ 252.7$ \\
\hline Gap, low (\$ millions) & $\$ 36.2$ & $\$ 29.9$ \\
\hline
\end{tabular}

The Peach Bottom units are in the "multiple unit" category, with a high operating cost of $\$ 275,000 / \mathrm{MW} /$ year and a low operating cost of $\$ 225,000 / \mathrm{MW} /$ year.

The Peach Bottom nuclear power plant is generally considered as having good financial results. In 2016, Exelon announced that it would file an application for a second 20-year license renewal for the Peach Bottom units.

The positive financial situation at Peach Bottom is due to a combination of low operating costs (i.e., as a large dual-unit plant) and its location in a part of PJM with relatively high electricity and capacity prices.

16 Peach Bottom Atomic Power Station is co-owned by Exelon and Public Service Electric and Gas of New Jersey; Exelon is the operator. 


\section{d. Quad Cities}

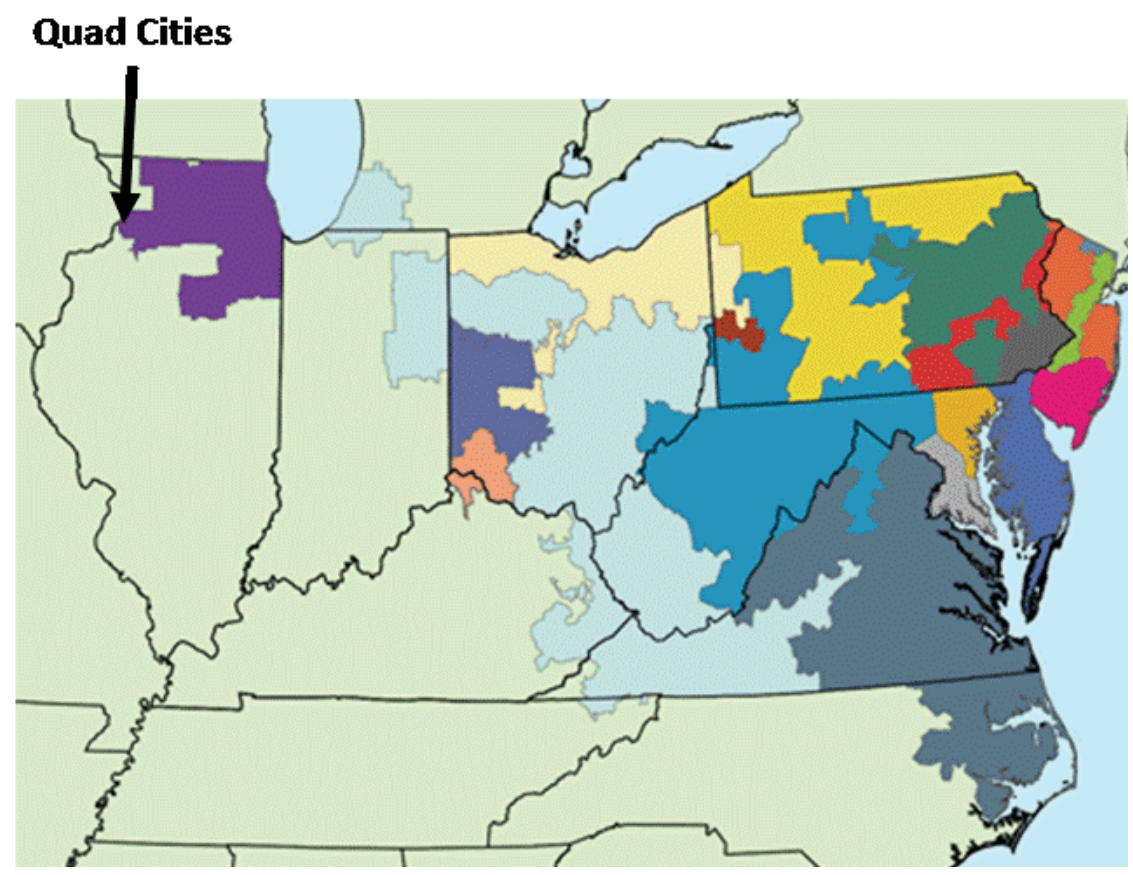

Figure 13. Quad Cities Map.

Table 6. Quad Cities Data.

\begin{tabular}{|l|c|c|}
\hline Unit & Quad Cities-1 & Quad Cities -2 \\
\hline Owner & Exelon & Exelon \\
\hline Summer Capacity (2015) & $908 \mathrm{MW}$ & $911 \mathrm{MW}$ \\
\hline Location & North West Illinois & North West Illinois \\
\hline Market region/zone & COMED & COMED \\
\hline Output (MWh) & $8,105,757$ & $7,515,790$ \\
\hline Electricity revenue (\$ millions) & $\$ 131.5$ & $\$ 122.6$ \\
\hline Capacity revenue (\$ millions) & $\$ 43.2$ & $\$ 43.3$ \\
\hline Operating cost, base (\$ millions) & $\$ 272.4$ & $\$ 273.3$ \\
\hline Gap, base (\$ millions) & $\$(97.8)$ & $\$(107.4)$ \\
\hline Operating cost, high (\$ millions) & $\$ 249.7$ & $\$ 250.5$ \\
\hline Gap, high (\$ millions) & $\$(75.1)$ & $\$(84.6)$ \\
\hline Operating cost, low (\$ millions) & $\$ 204.3$ & $\$ 205.0$ \\
\hline Gap, low (\$ millions) & $\$(29.7)$ & $\$(39.1)$ \\
\hline
\end{tabular}

The Quad Cities units are in the "multiple unit" category, with a high operating cost of $\$ 275,000 / \mathrm{MW} /$ year and a low operating cost of $\$ 225,000 / \mathrm{MW} /$ year. 
The Quad Cities units are located near the border between Illinois and Iowa, which is also the border between the PJM and MISO electricity markets. Significant amounts of wind generation are located in Iowa and other areas to the West of Quad Cities. While there is sufficient transmission capacity to deliver this wind power to the Illinois (and PJM) border, there are constraints in the transmission system inside Illinois/PJM that limit the delivery of this wind energy to the Chicago load center.

These transmission constraints, combined with lower local demand due to the departure of the heavy industry from the Quad Cities area, mean that locational electricity market prices at Quad Cities are low and, at times, negative.

The Quad Cities units did not clear in the 2016 and 2015 PJM capacity auction, but did clear in the 2014 auction so that there are capacity obligations that will constrain the units from retiring early until the end of the 2017/2018 PJM capacity planning/delivery year.

Exelon has announced that the Quad Cities units will be retired early on 1 Jun 2018, if a satisfactory zero emission credit program is not adopted by the Illinois Legislature prior to the end of 2016.

\section{e. Surry}

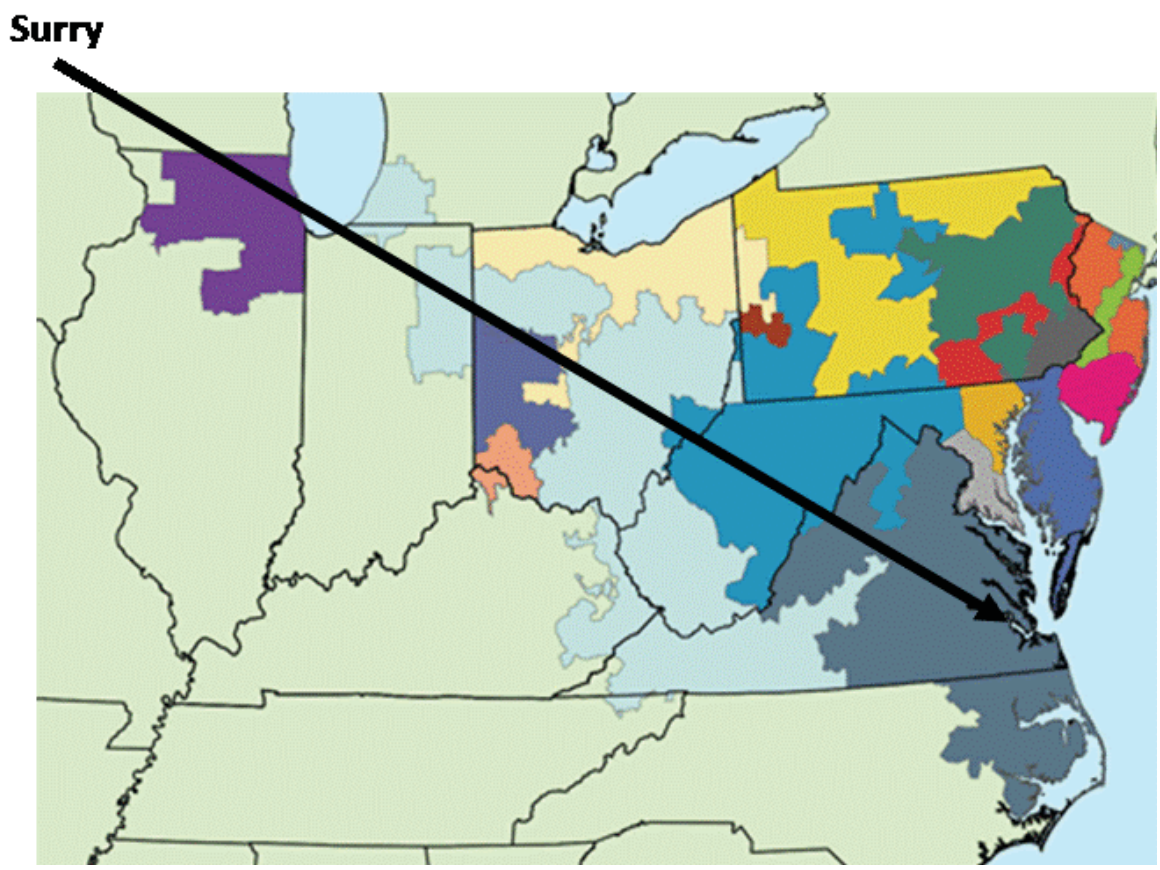

Figure 14. Surry Map. 
Table 7. Surry Data.

\begin{tabular}{|l|c|c|}
\hline Unit & Surry-1 & Surry-2 \\
\hline Owner & Dominion & Dominion \\
\hline Summer Capacity (2015) & $838 \mathrm{MW}$ & $838 \mathrm{MW}$ \\
\hline Location & Southeastern Virginia & Southeastern Virginia \\
\hline Market region/zone & DOM & DOM \\
\hline Output (MWh) & $6,584,138$ & $6,171,063$ \\
\hline Electricity revenue (\$ millions) & $\$ 195.7$ & $\$ 184.4$ \\
\hline Capacity revenue (\$ millions) & $\$ 39.8$ & $\$ 39.8$ \\
\hline Operating cost, base ((\$ millions) & $\$ 251.4$ & $\$ 251.4$ \\
\hline Gap, base (\$ millions) & $\$(15.9)$ & $\$(27.1)$ \\
\hline Operating cost, high (\$ millions) & $\$ 230.5$ & $\$ 230.5$ \\
\hline Gap, high (\$ millions) & $\$ 5.1$ & $\$(6.2)$ \\
\hline Operating cost, low (\$ millions) & $\$ 188.6$ & $\$ 188.6$ \\
\hline Gap, low (\$ millions) & $\$ 47.0$ & $\$ 35.7$ \\
\hline
\end{tabular}

The Surry units are in the "multiple unit" category, with a high operating cost of $\$ 275,000 / \mathrm{MW} /$ year and a low operating cost of $\$ 225,000 / \mathrm{MW} /$ year.

The owner of the Surry units, Dominion, remains a regulated utility and the Surry units are included in Dominion's regulated rate base. These units are regulated and the costs of operating the units is recovered in rates, but Dominion is a part of the PJM wholesale electricity market. For the Gap analyses in this study, the Surry operating cost estimates are compared to the revenue based on PJM wholesale market prices at the Surry nodes.

While this analysis of the Gap shows that Surry would be experiencing negative cash flow under some scenarios, Surry is likely to remain a key part of the Dominion generation portfolio. Surry has notified the NRC that it intends to apply for a subsequent (i.e., second 20 year) license renewal that would allow operation for a total of 80 years. 


\section{f. Three Mile Island (TMI)}

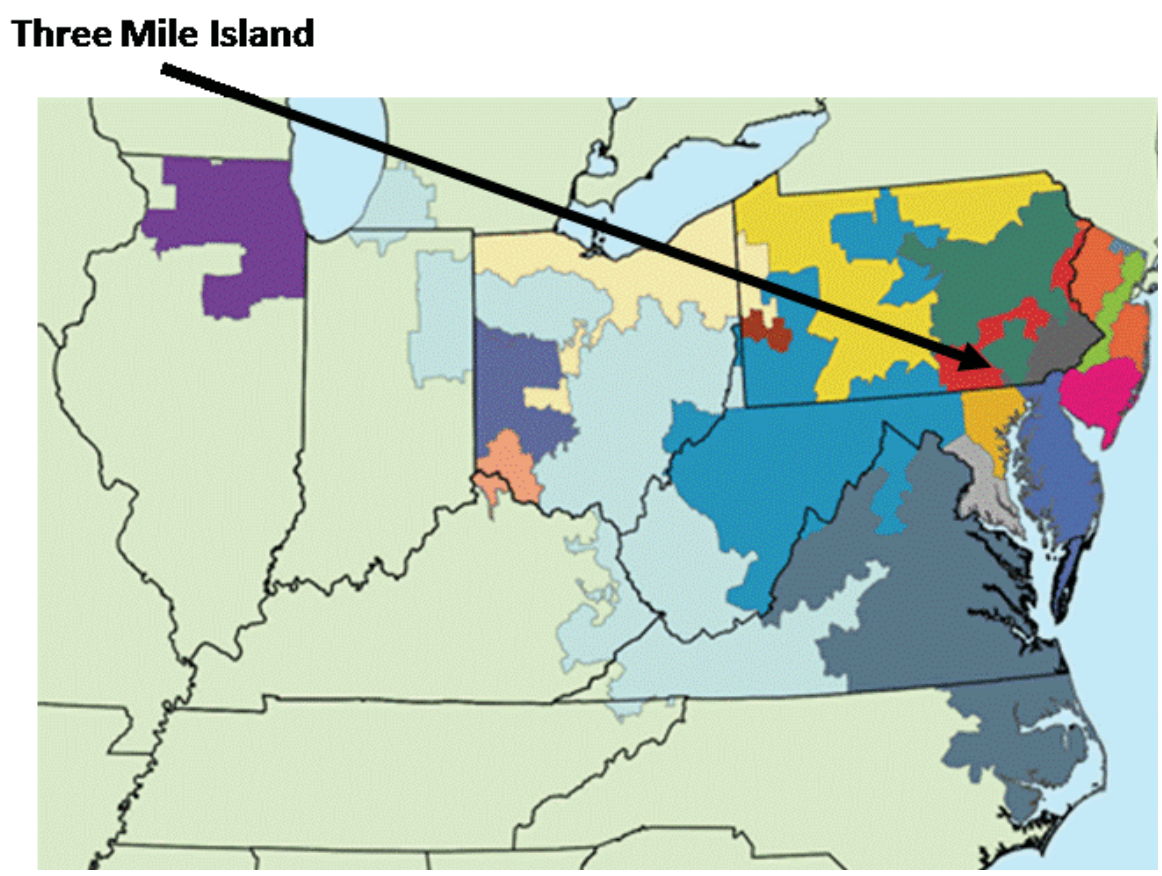

Figure 15. Three Mile Island Map.

Table 8. Three Mile Island Data.

\begin{tabular}{|l|c|}
\hline Unit & Three Mile Island-1 \\
\hline Owner & Exelon \\
\hline Summer Capacity (2015) & $803 \mathrm{MW}$ \\
\hline Location & Central Pennsylvania \\
\hline Market region/zone & METED \\
\hline Output (MWh) & $6,737,422$ \\
\hline Electricity revenue (\$ millions) & $\$ 150.4$ \\
\hline Capacity revenue (\$ millions) & $\$ 44.3$ \\
\hline Operating cost, base ((\$ millions) & $\$ 240.9$ \\
\hline Gap, base (\$ millions) & $\$(46.2)$ \\
\hline Operating cost, high (\$ millions) & $\$ 341.3$ \\
\hline Gap, high (\$ millions) & $\$(146.6)$ \\
\hline Operating cost, low (\$ millions) & $\$ 281.1$ \\
\hline Gap, low (\$ millions) & $\$(86.4)$ \\
\hline
\end{tabular}


Three Mile Island 1 is in the "small single unit" category, with a high operating cost of $\$ 425,000 / \mathrm{MW} /$ year and a low operating cost of $\$ 350,000 / \mathrm{MW} /$ year.

Three Mile Island did not "clear" the 2019-2020 PJM Base Residual Capacity Auction and also did not clear the 2018-2019 capacity auction. That means the plant will not receive capacity payments for those periods. While PJM capacity payments are only one source of the plant's operating revenue, they are an important source. ${ }^{17}$

While there are no known current plans to close TMI, the plant remains financially challenged.

\section{NYISO}

The creation of the New York Independent System Operator (NYISO) was authorized by FERC in 1998 and launched on Dec. 1, 1999. The NYISO footprint covers the entire state of New York. NYISO is responsible for operating wholesale power markets that trade electricity, capacity, transmission congestion contracts, and related products, in addition to administering auctions for the sale of capacity. NYISO operates New York's high-voltage transmission network and performs long-term planning.

Transmission constraints in NYISO are in the southeastern portion of the state, limiting power flows into New York City and Long Island. As a result of their dense populations, New York City and Long Island are the largest consumers of electricity in the state. Consequently, energy flows from the west and the north toward these two large markets, with transmission facilities often loaded to their operational limits. This results in transmission constraints and higher wholesale electricity market prices in the New York City and Long Island.

The geographic scope of the NYISO market is shown in Figure 16.

17 http://www.efmr.org/files/2012/PJM\%202016\%20capacity\%20market\%20auction\%20press\%20release\%20Fina 1\%20Final.pdf 


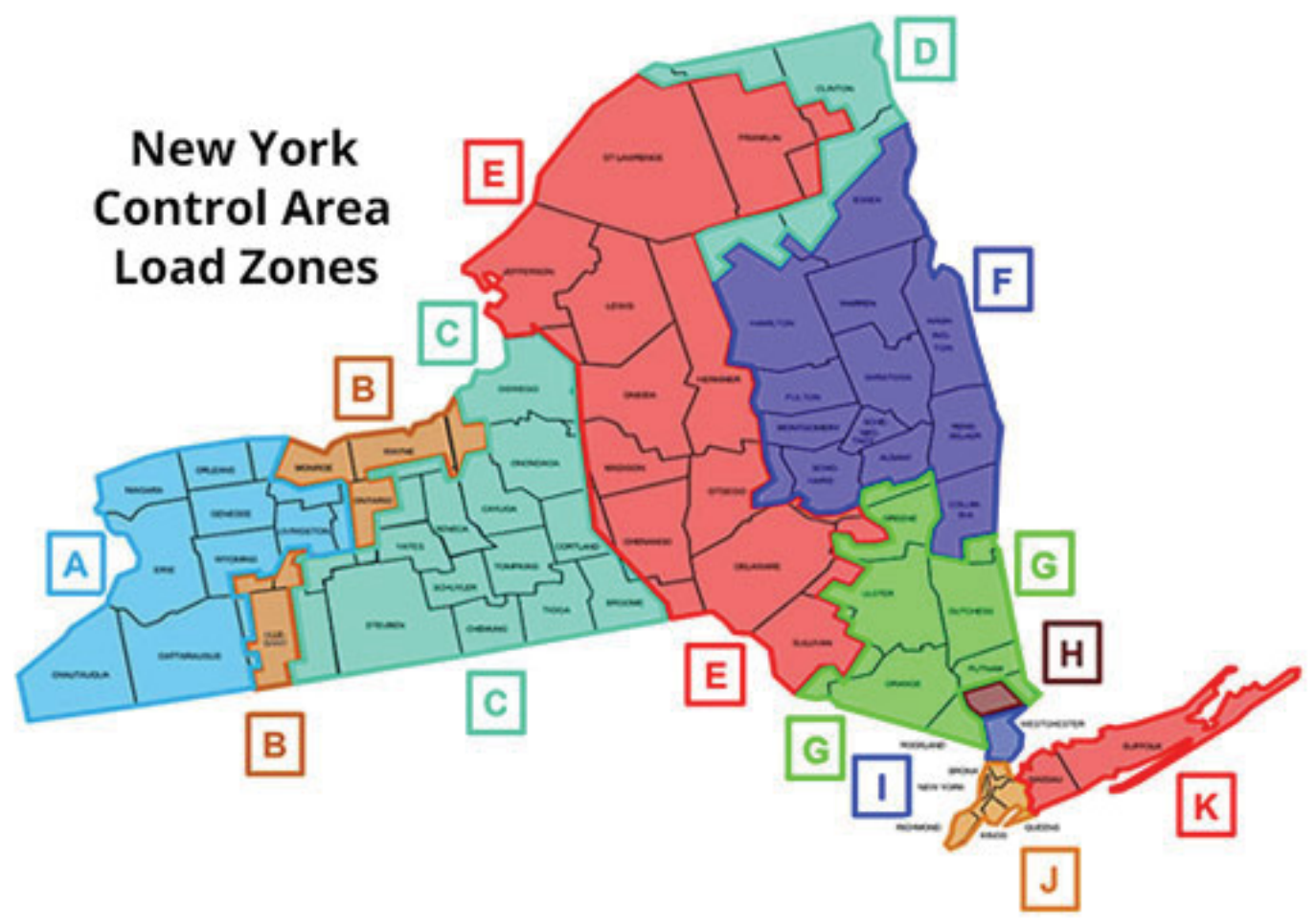

Figure 16. NYISO Zone Map.

a. Ginna

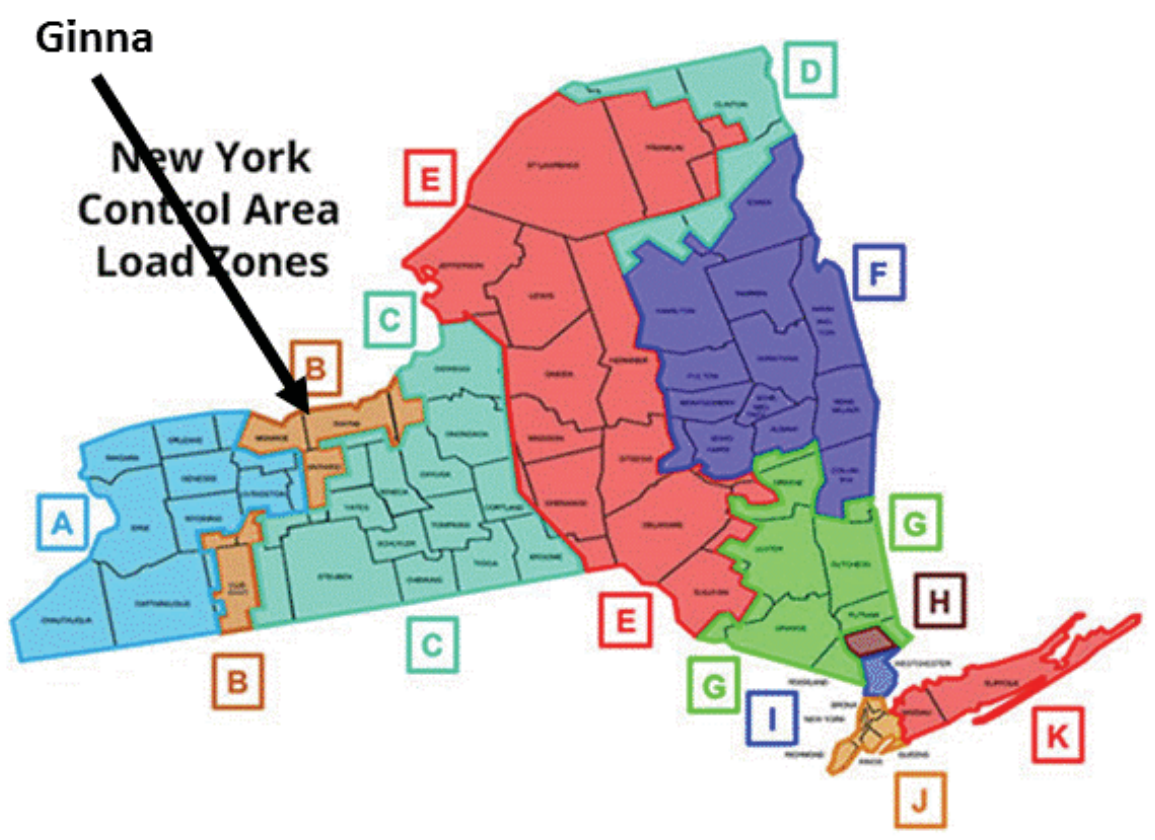

Figure 17. Ginna Map. 
Table 9. Ginna Data.

\begin{tabular}{|l|c|}
\hline Unit & Ginna \\
\hline Owner & Exelon \\
\hline Summer Capacity (2015) & $582 \mathrm{MW}$ \\
\hline Location & New York \\
\hline Market region/zone & Zone B \\
\hline Output (MWh) & $4,826,464$ \\
\hline Electricity revenue (\$ millions) & $\$ 87.7$ \\
\hline Capacity revenue (\$ millions) & $\$ 21.0$ \\
\hline ZEC revenue ${ }^{\mathbf{1 8}}$ (\$ millions) & $\$ 84.4$ \\
\hline Operating cost, base ((\$ millions) & $\$ 174.6$ \\
\hline Gap, base (\$ millions) & $\$ 18.4$ \\
\hline Operating cost, high (\$ millions) & $\$ 247.4$ \\
\hline Gap, high (\$ millions) & $\$(54.3)$ \\
\hline Operating cost, low (\$ millions) & $\$ 203.7$ \\
\hline Gap, low (\$ millions) & $\$(10.7)$ \\
\hline
\end{tabular}

Ginna is in the "small single unit" category, with a high operating cost of $\$ 425,000 / \mathrm{MW} /$ year and a low operating cost of $\$ 350,000 / \mathrm{MW} /$ year.

With ZEC revenue and the base operating cost of $\$ 300,000 / \mathrm{MW} / \mathrm{year}$, the Ginna Gap is positive. However, when the "small single unit" operating cost range is applied, the Gap is significant even with ZEC revenue.

Ginna would have retired early in 2014 except for a NYPSC arrangement to provide additional revenue until local/regional grid reliability issues were resolved.

The New York Public Service Commission (NYPSC) directed Ginna and Rochester Gas \& Electric Corporation (RG\&E; a regulated electricity supplier) to negotiate an arrangement to keep the Ginna nuclear power plant in operation to prevent reliability issues.

As discussed above, Ginna has justified entry into RSSA negotiations because retention of its Facility is necessary for the preservation electric system reliability. Moreover, by affidavit dated October 23, 2014, Ginna now certifies that the revenues it expects from the sale of capacity and energy into NYISO markets will not be sufficient to cover the costs of continued operation, which includes new capital investments that must be made. Absent an RSSA, the Facility would be retired as soon as would be practicable. This affirmation

18 This assessment includes ZEC revenue for 2015-2016 years to illustrate the financial impact. 
buttresses the conclusion that the commencement of negotiations over an RSSA for the Ginna Facility is warranted. ${ }^{19}$

The negotiations resulted in a Reliability Support Service Agreement (RSSA) between Ginna and RG\&E that provided Ginna with a certain and sufficient level of revenue, with any costs paid by RG\&E customers.

The Ginna Reliability Support Services Agreement (RSSA) was developed and implemented to avoid the nuclear plant's closure until a transmission system upgrade could be implemented.

An order adopting the terms of a joint proposal was issued on February 24, 2016, with some minor changes made and incorporated in April 2016. ${ }^{20}$

In this case:

- A NYISO transmission study showed reliability issues if Ginna closed;

- The RSSA has a complex payment approach that increases the level and certainty of revenue to Ginna;

- Intervention of other New York state generators in NYPSC and FERC proceedings related to Ginna RSSA;

- A significant amount of time and effort was required to get this contract approved by state and federal regulators;

- The RSSA is a temporary fix only and when the RSSA expires in March 2017, Ginna will have same financial issues that existed prior to the RSSA.

Ginna is included in the New York ZEC plan, with additional revenue from the sale of ZECs expected to improve the plant's financial performance.

19 State Of New York, Public Service Commission; Case 14-E-0270 - Petition for Initiation of Proceeding to Examine Proposal for Continued Operation of R.E. Ginna Nuclear Power Plant; Order Directing Negotiation of a Reliability Support Service Agreement and Making Related Findings; Issued and Effective: November 14, 2014; page 22.

20 NYPSC Docket 14-E-O2704; FERC Docket Sheet at http://elibrary.ferc.gov/idmws/docket_sheet.asp?DOCKET=ER15-1047. The FERC order in this Docket issued on 1 March 2016 approved the Settlement Agreement with conditions. 


\section{b. FitzPatrick}

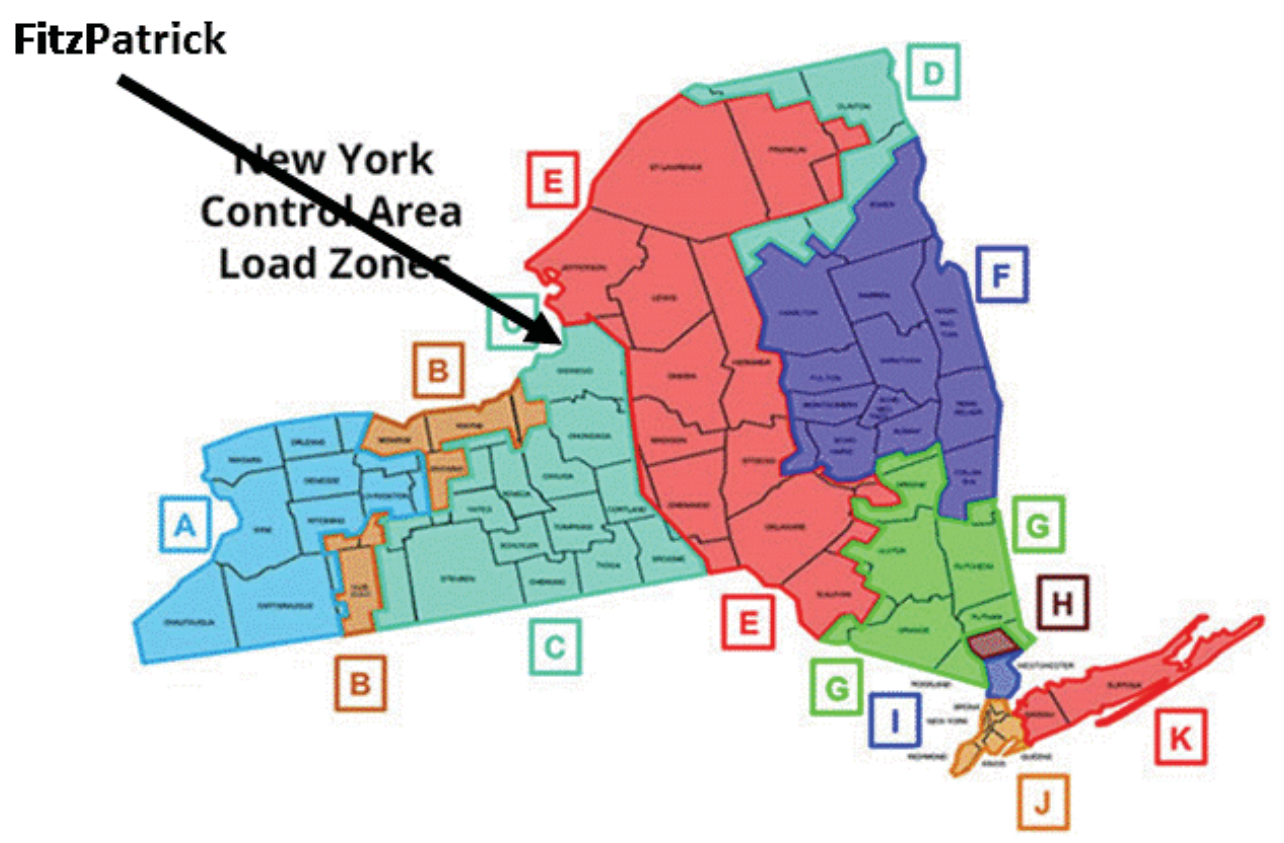

Figure 18. FitzPatrick Map.

Table 10. FitzPatrick Data.

\begin{tabular}{|l|c|}
\hline Unit & FitzPatrick \\
\hline Owner & Entergy (to be Exelon) \\
\hline Summer Capacity (2015) & $852 \mathrm{MW}$ \\
\hline Location & North Central New York \\
\hline Market region/zone & Zone C \\
\hline Output (MWh) & $7,050,307$ \\
\hline Electricity revenue (\$ millions) & $\$ 131.1$ \\
\hline Capacity revenue (\$ millions) & $\$ 30.7$ \\
\hline ZEC revenue $\mathbf{2 1}$ (\$ millions) & $\$ 123.2$ \\
\hline Operating cost, base ((\$ millions) & $\$ 255.6$ \\
\hline Gap, base (\$ millions) & $\$ 29.5$ \\
\hline Operating cost, high (\$ millions) & $\$ 362.1$ \\
\hline Gap, high (\$ millions) & $\$(77.0)$ \\
\hline Operating cost, low (\$ millions) & $\$ 298.2$ \\
\hline Gap, low (\$ millions) & $\$(13.1)$ \\
\hline
\end{tabular}

21 This assessment includes ZEC revenue for 2015-2016 years to illustrate the financial impact. 
FitzPatrick is in the "small single unit" category, with a high operating cost of $\$ 425,000 / \mathrm{MW} /$ year and a low operating cost of $\$ 350,000 / \mathrm{MW} /$ year.

With ZEC revenue and the base operating cost of $\$ 300,000 / \mathrm{MW} /$ year, the FitzPatrick Gap is positive. However, when the "small single unit" operating cost range is applied, the Gap is significant even with ZEC revenue.

The FitzPatrick nuclear power plant, at $852 \mathrm{MW}$, is just below the arbitrary dividing line for small and large units (i.e., $900 \mathrm{MW}$ ) in this study. Putting FitzPatrick in the "small single unit" category may overstate the actual operating costs at the unit. Also, after Exelon acquires this unit, it may be able to share some costs with the nearby Nine Mile Point plant.

Prior to the recent New York ZEC plan, Entergy had announced plans to retire the FitzPatrick nuclear power plant early. Now, Exelon plans to purchase the FitzPatrick nuclear power plant from Entergy and continue operation.

\section{c. Indian Point}

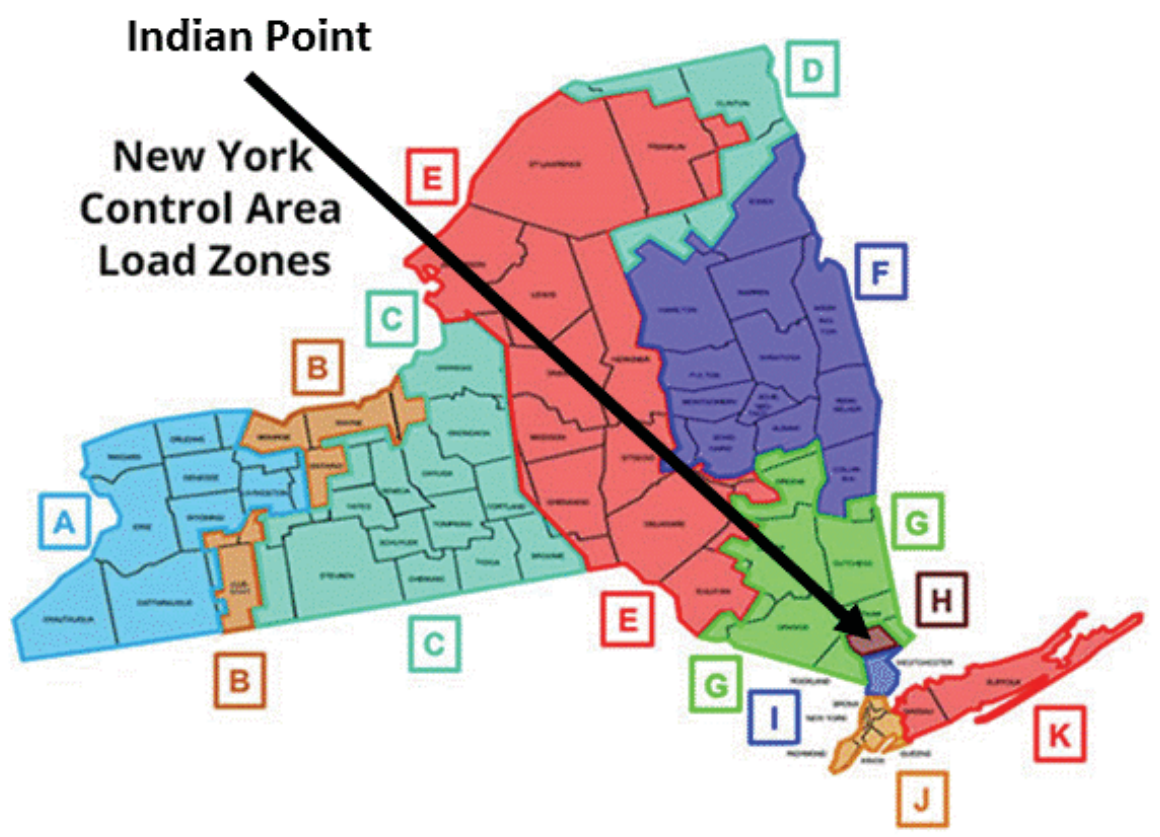

Figure 19. Indian Point Map. 
Table 11. Indian Point Data.

\begin{tabular}{|l|c|c|}
\hline Unit & Indian Point-2 & Indian Point-3 \\
\hline Owner & Entergy & Entergy \\
\hline Summer Capacity (2015) & $1,020 \mathrm{MW}$ & $1,041 \mathrm{MW}$ \\
\hline Location & Southeastern New York & Southeastern New York \\
\hline Market region/zone & Zone H & Zone H \\
\hline Output (MWh) & $6,011,210$ & $8,729,922$ \\
\hline Electricity revenue (\$ millions) & $\$ 160.1$ & $\$ 232.2$ \\
\hline Capacity revenue (\$ millions) & $\$ 85.2$ & $\$ 86.9$ \\
\hline ZEC revenue $\mathbf{2 2}^{22}$ (\$ millions) & $\$-$ & $\$-$ \\
\hline Operating cost, base ((\$ millions) & $\$ 306.0$ & $\$ 312.3$ \\
\hline Gap, base (\$ millions) & $\$(60.7)$ & $\$ 6.9$ \\
\hline Operating cost, high (\$ millions) & $\$ 280.5$ & $\$ 286.3$ \\
\hline Gap, high (\$ millions) & $\$(35.2)$ & $\$ 32.9$ \\
\hline Operating cost, low (\$ millions) & $\$ 229.5$ & $\$ 234.2$ \\
\hline Gap, low (\$ millions) & $\$ 15.8$ & $\$ 85.0$ \\
\hline
\end{tabular}

The Indian Point units are in the "multiple unit" category, with a high operating cost of $\$ 275,000 / \mathrm{MW} /$ year and a low operating cost of $\$ 225,000 / \mathrm{MW} /$ year. This may understate the actual operating costs at the plant, because the two units are thought to have different operator licensing requirements, the result of years of ownership by two different companies prior to acquisitions by Entergy.

The relatively poor financial outcome for Indian Point 2 compared to Indian Point 3 are related to an extended outage (i.e., no revenue) for Indian Point 2 during 2016.

There are no announced plans to retire the Indian Point units early. These units have relatively high revenue due to their location near New York City. The Indian Point units are not included in the New York ZEC program, but there seems to be an option for these units to be included in the future under some conditions.

The Indian Point units are engaged in a long process to renew their NRC operating licenses. The Indian Point license renewal proceedings have not been completed, with the applications being challenged by New York State on various issues, including water use permits for direct cooling using Hudson River water.

22 This assessment includes no ZEC revenue for Indian Point. There is a possibility that this plant might receive ZEC revenue in the future. 


\section{d. Nine Mile Point}

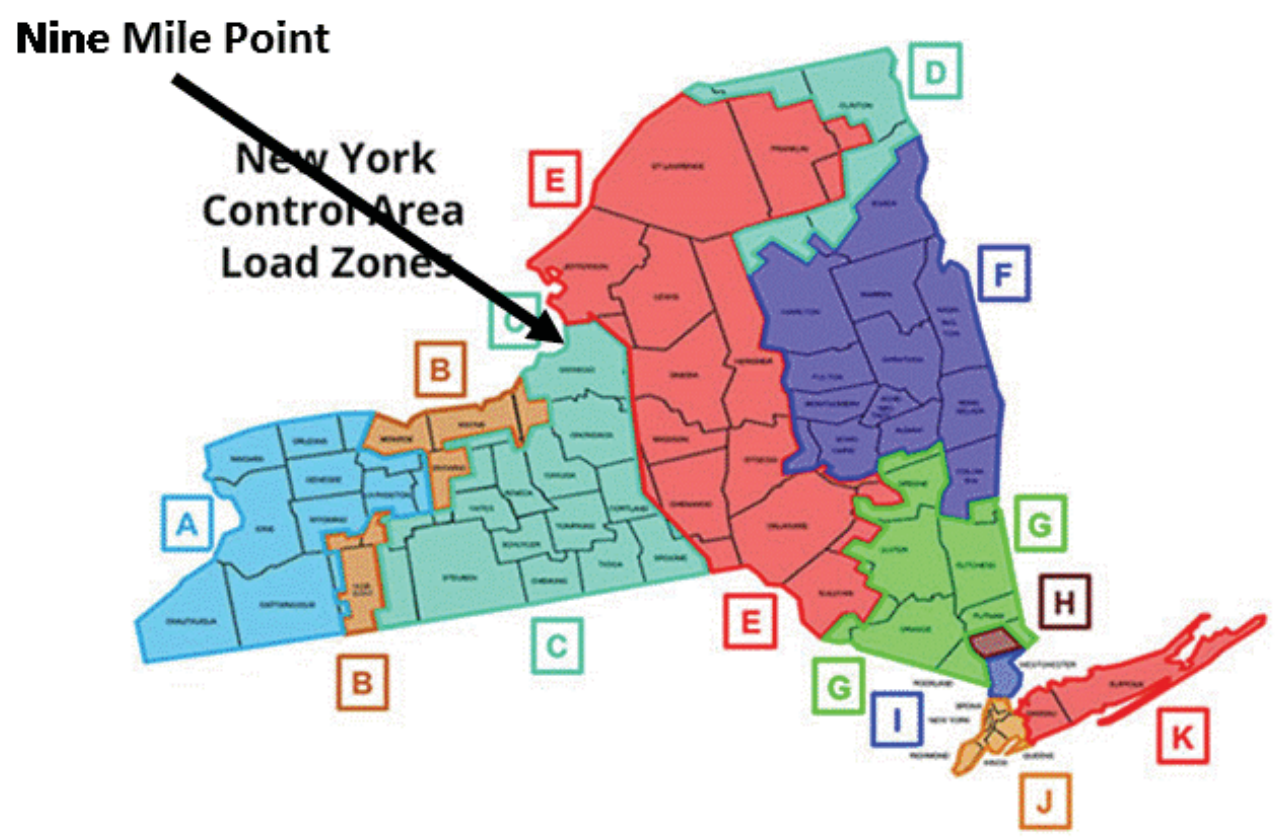

Figure 20. Nine Mile Point Map.

Table 12. Nine Mile Point Data.

\begin{tabular}{|l|c|c|}
\hline Unit & Nine Mile Point-1 & Nine Mile Point-2 \\
\hline Owner & Exelon & Exelon \\
\hline Summer Capacity (2015) & $636 \mathrm{MW}$ & $1,301 \mathrm{MW}$ \\
\hline Location & North Central New York & North Central New York \\
\hline Market region/zone & Zone C & Zone C \\
\hline Output (MWh) & $5,418,774$ & $10,447,226$ \\
\hline Electricity revenue (\$ millions) & $\$ 100.8$ & $\$ 194.2$ \\
\hline Capacity revenue (\$ millions) & $\$ 22.9$ & $\$ 46.8$ \\
\hline ZEC revenue $\mathbf{2 3}^{\mathbf{3}}$ (\$ millions) & $\$ 94.7$ & $\$ 182.6$ \\
\hline Operating cost, base ((\$ millions) & $\$ 190.8$ & $\$ 390.3$ \\
\hline Gap, base (\$ millions) & $\$ 27.6$ & $\$ 33.4$ \\
\hline Operating cost, high (\$ millions) & $\$ 270.3$ & $\$ 455.4$ \\
\hline Gap, high (\$ millions) & $\$(51.9)$ & $\$(31.7)$ \\
\hline Operating cost, low (\$ millions) & $\$ 222.6$ & $\$ 390.3$ \\
\hline Gap, low (\$ millions) & $\$(4.2)$ & $\$ 33.4$ \\
\hline
\end{tabular}

23 This assessment includes ZEC revenue for 2015-2016 years to illustrate the financial impact. 
Nine Mile Point is in two operating cost categories. The two units are different sizes, different vintages and require different operator licensing. While there are some synergies because the units are located on the same physical site, we have placed Nine Mile Point 1 in the "small single unit" category, with a high operating cost of $\$ 425,000 / \mathrm{MW} /$ year and a low operating cost of $\$ 350,000 / \mathrm{MW} / \mathrm{year}$; and have placed Nine Mile Point 2 in the "large single unit" category with a high operating cost of $\$ 350,000 / \mathrm{MW} / \mathrm{year}$ and a low operating cost of $\$ 300,000 / \mathrm{MW} /$ year. This may overstate the operating costs at Nine Mile Point 2.

With ZEC revenue and the base operating cost of $\$ 300,000 / \mathrm{MW} / \mathrm{year}$, the Nine Mile Point 1 Gap is positive. However, when the "small single unit" operating cost range is applied, the Gap is significant even with ZEC revenue.

\section{MISO}

MISO operates the transmission system and a centrally dispatched market in portions of 15 states in the Midwest and the South, extending from Michigan and Indiana to Montana and from the Canadian border to the southern extremes of Louisiana and Mississippi. The system is operated from three control centers: Carmel, Indiana; Eagan, Minnesota; and Little Rock, Arkansas. MISO also serves as the reliability coordinator for additional systems outside of its market area, primarily to the north and northwest of the market footprint.

MISO was not a power pool before organizing as an ISO in December 2001. It began market operations in April 2005. In January 2009, MISO started operating an ancillary services market and combined its 24 separate balancing areas into a single balancing area. In 2013, the RTO began operations in the MISO South region, including the utility footprints of Entergy, CLECO, and South Mississippi Electric Power Association, among others, in parts of Arkansas, Mississippi, Louisiana, and Texas.

The geographic scope of the MISO market is shown in Figure 21. 


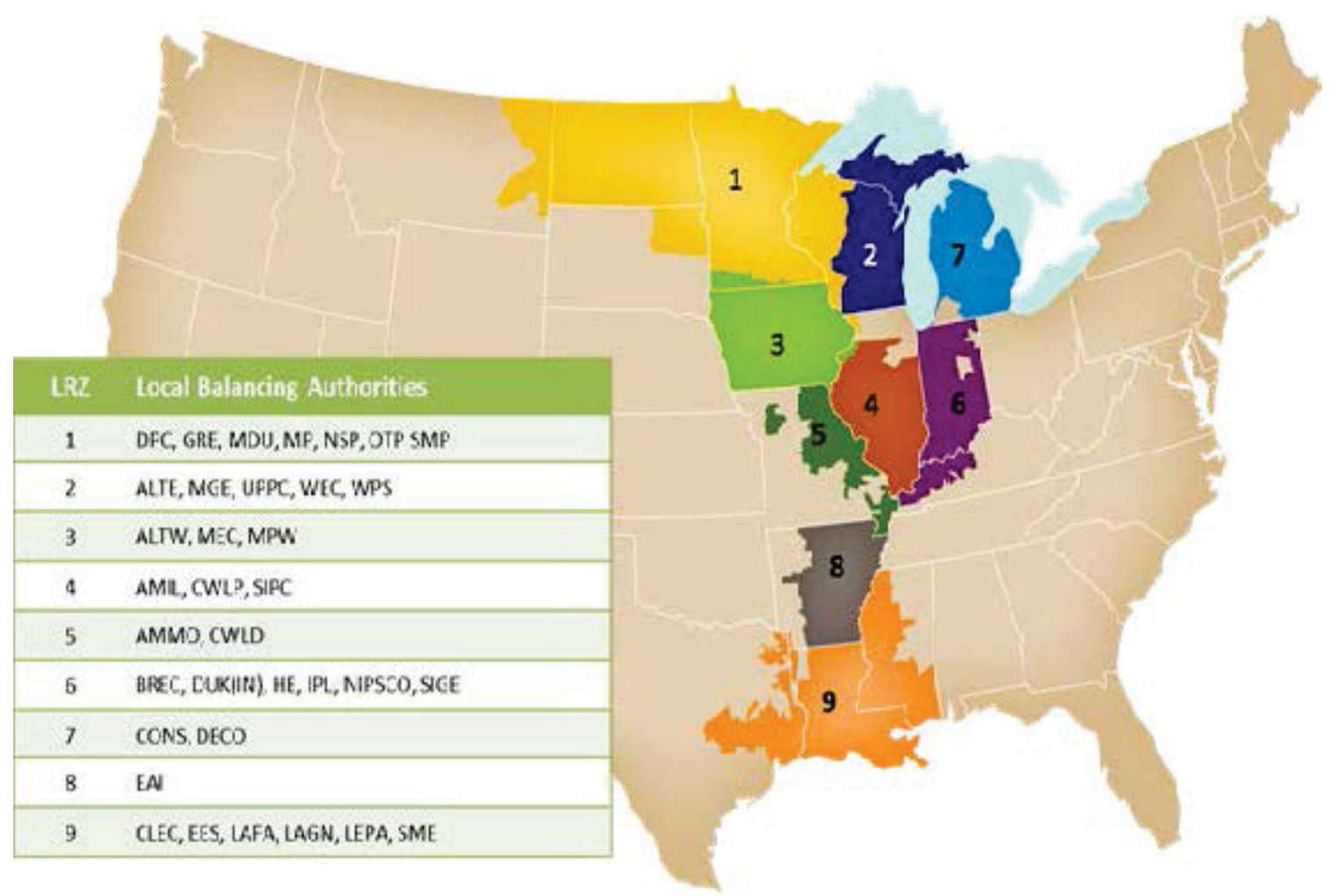

Figure 21. MISO Zone Map.

\section{a. Clinton}

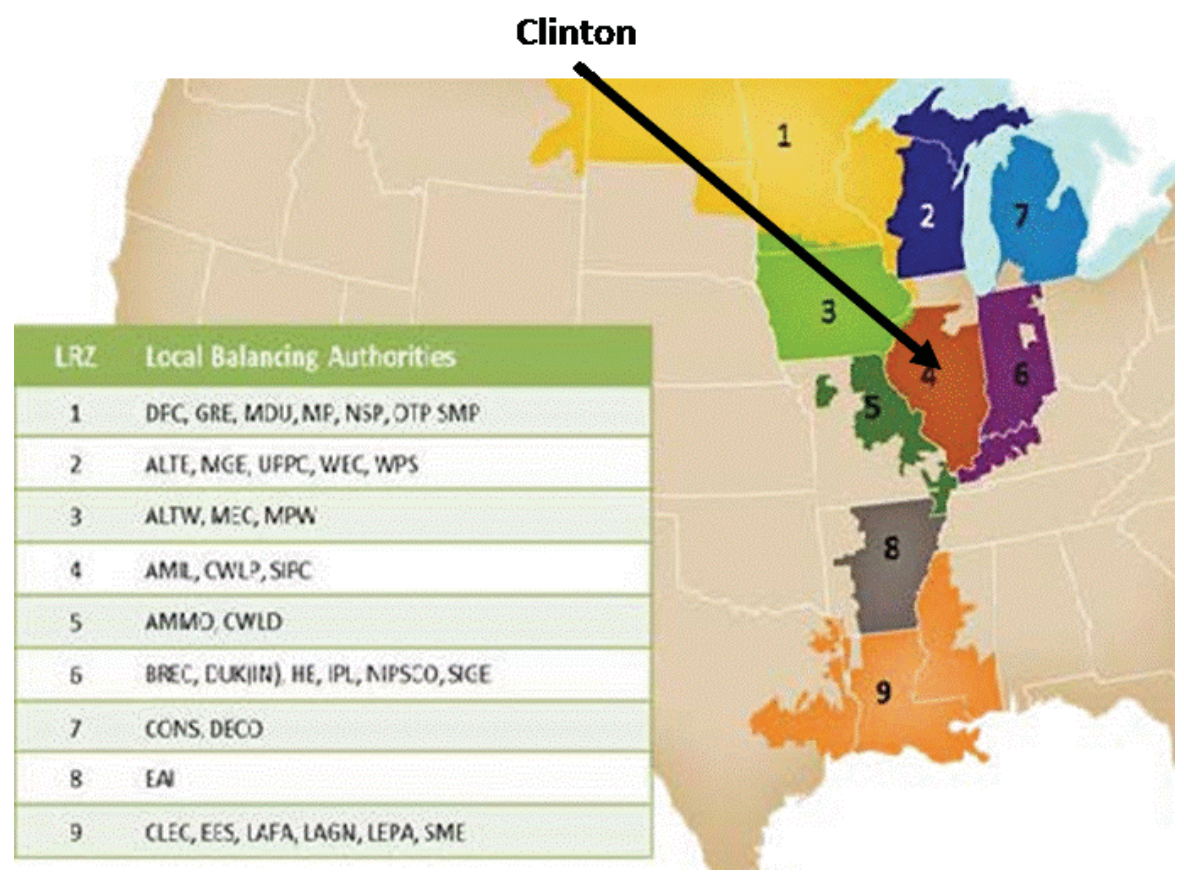

Figure 22. Clinton Map. 
Table 13. Clinton Data.

\begin{tabular}{|l|c|}
\hline Unit & Clinton \\
\hline Owner & Exelon \\
\hline Summer Capacity (2015) & $1,065 \mathrm{MW}$ \\
\hline Location & Central Illinois \\
\hline Market region/zone & Ameren, Illinois \\
\hline Output (MWh) & $9,023,316$ \\
\hline Electricity revenue (\$ millions) & $\$ 212.0$ \\
\hline Capacity revenue (\$ millions) & $\$ 32.0$ \\
\hline Operating cost, base ((\$ millions) & $\$ 319.5$ \\
\hline Gap, base (\$ millions) & $\$(75.5)$ \\
\hline Operating cost, high (\$ millions) & $\$ 372.8$ \\
\hline Gap, high (\$ millions) & $\$(128.8)$ \\
\hline Operating cost, low (\$ millions) & $\$ 319.5$ \\
\hline Gap, low (\$ millions) & $\$(75.5)$ \\
\hline
\end{tabular}

Clinton is in the "large single unit" category with a high operating cost of $\$ 350,000 / \mathrm{MW} /$ year and a low operating cost of $\$ 300,000 / \mathrm{MW} / \mathrm{year}$.

Exelon has announced that the Clinton plant will be retired early unless Illinois approves measures to increase revenue.

Exelon plans to close the Clinton plant on June 1, 2017. Clinton is considered as one of Exelon's best performing nuclear power plants and the early retirement decision is due to low electricity and capacity market prices in the MISO Zone 4.

The MISO electricity market in Illinois (i.e., Zone 4) has low prices and is surrounded by regulated utilities that are not as sensitive to electricity market prices as a merchant nuclear plant like Clinton. 


\section{b. Palisades}

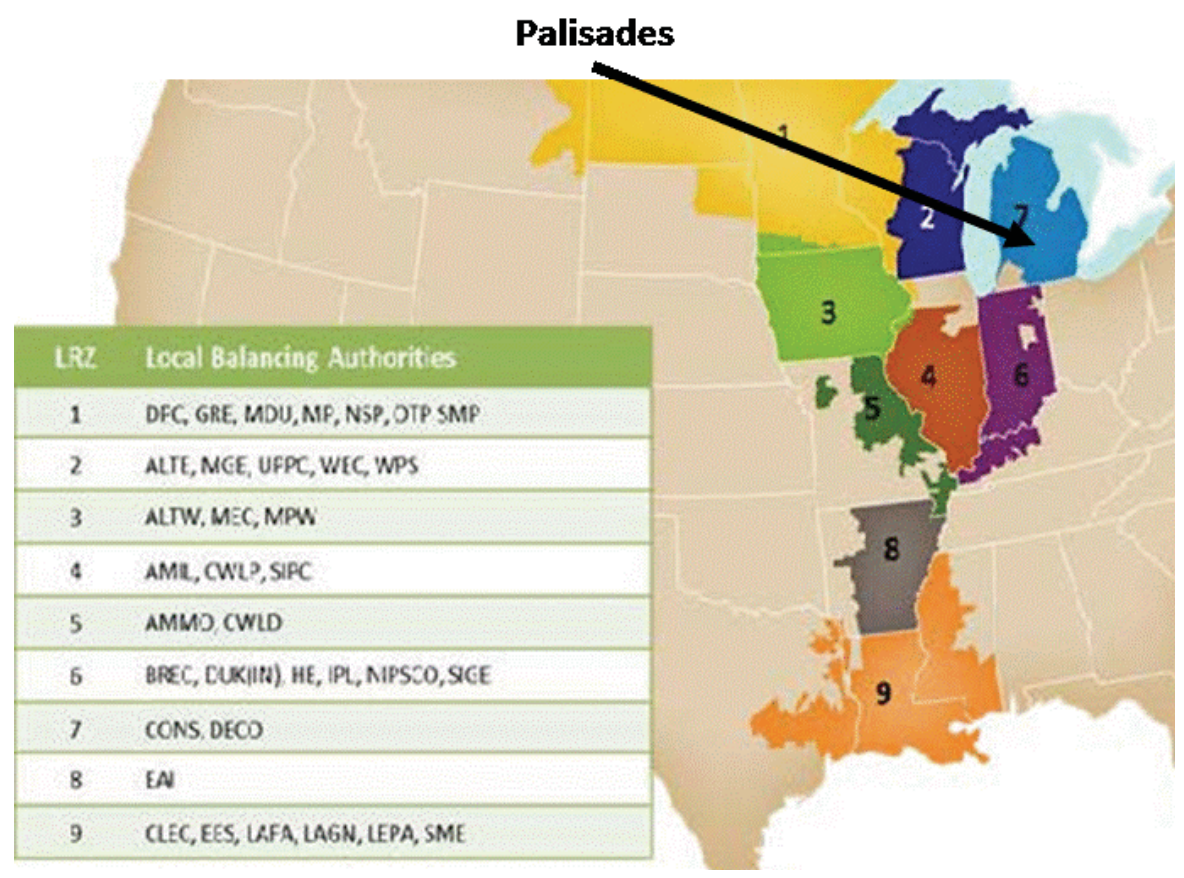

Figure 23. Palisades Map.

Table 14. Palisades Data.

\begin{tabular}{|l|c|}
\hline Unit & Palisades \\
\hline Owner & Entergy \\
\hline Summer Capacity (2015) & $789 \mathrm{MW}$ \\
\hline Location & Michigan \\
\hline Market region/zone & Cons Power, Michigan \\
\hline Output (MWh) & $6,333,643$ \\
\hline Electricity revenue (\$ millions) & $\$ 155.4$ \\
\hline Capacity revenue (\$ millions) & $\$ 2.9$ \\
\hline Operating cost, base ((\$ millions) & $\$ 236.7$ \\
\hline Gap, base (\$ millions) & $\$(78.4)$ \\
\hline Operating cost, high (\$ millions) & $\$ 335.3$ \\
\hline Gap, high (\$ millions) & $\$(177.0)$ \\
\hline Operating cost, low (\$ millions) & $\$ 276.2$ \\
\hline Gap, low (\$ millions) & $\$(117.9)$ \\
\hline
\end{tabular}

Palisades is in the "small single unit" category, with a high operating cost of $\$ 425,000 / \mathrm{MW} /$ year and a low operating cost of $\$ 350,000 / \mathrm{MW} / \mathrm{year}$.

Most of the merchant nuclear power plants rely on revenue from electricity and capacity markets only. Some of these merchant units (e.g., Kewaunee and Vermont Yankee) were sold by the 
original owner along with a power purchase agreement (PPA). These PPAs were typically for the period up to the expiration of the original NRC license. The Kewaunee and Vermont Yankee PPAs expired at a time when electricity market prices were low and expected to remain low.

The Palisades nuclear power plants was sold by Consumers Energy (CMS) to Entergy in 2007 along with a PPA that remains in effect until April 2022. In 2022, Palisades will no longer have a PPA (unless an extension or replacement is negotiated) and will depend on the MISO electricity market for revenue.

The analysis in this report looks at Palisades without a PPA. The large Gap in this analysis shows why there is discussion about a negotiated termination of the Palisades nuclear PPA along with an early retirement.

From the perspective of CMS, the Palisades PPA has prices well above market prices and early termination of the PPA has the potential to lower costs and lower rates to CMS ratepayers. ${ }^{24} \mathrm{~A}$ negotiated agreement between CMS and Entergy to terminate the PPA and retire Palisades early might be structured to provide benefits to both companies.

Of course, such a move would result in the removal of almost $800 \mathrm{MW}$ of carbon free generation from Michigan and would almost certainly result in a net increase in $\mathrm{CO}_{2}$ emissions.

\section{c. Prairie Island}

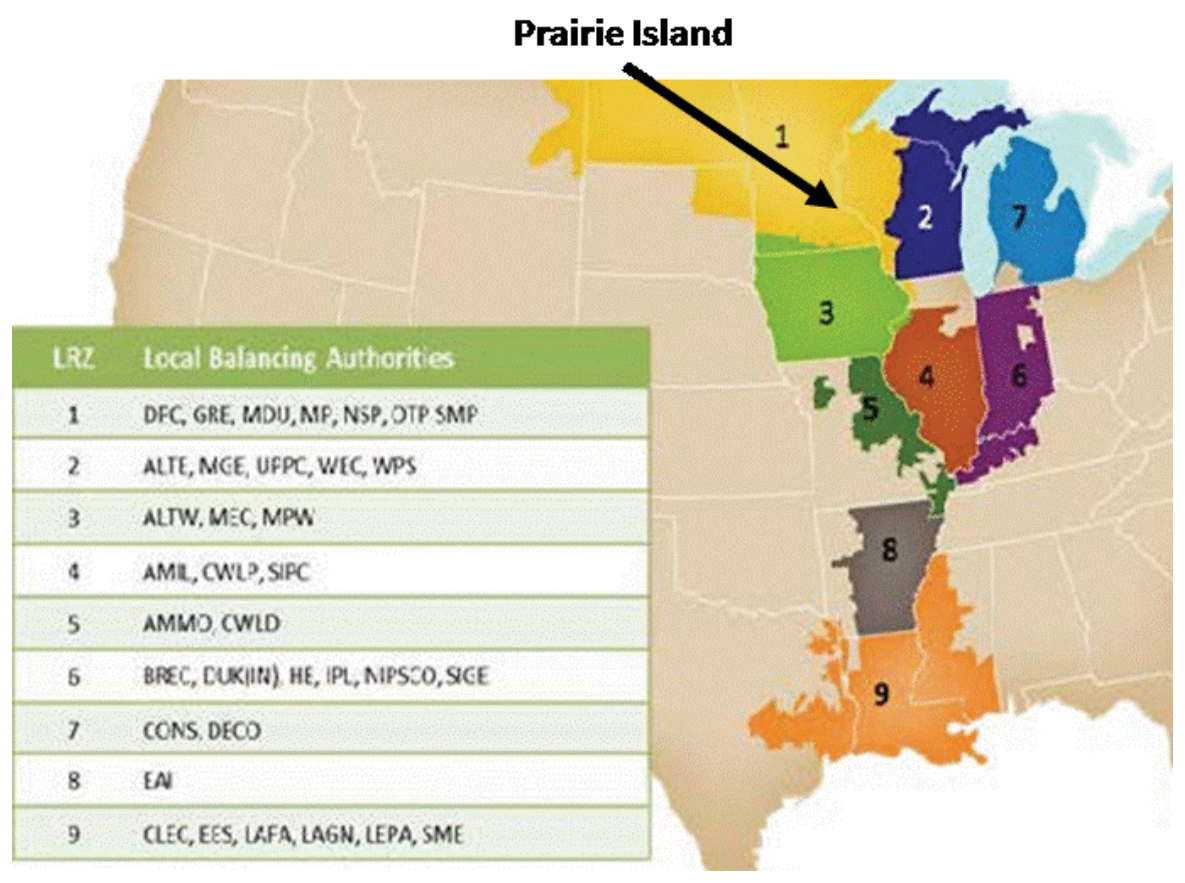

Figure 24. Prairie Island Map.

${ }^{24}$ https://neo.ubs.com/shared/d14IqRMXu5V8/ 
Table 15. Prairie Island Data.

\begin{tabular}{|l|c|c|}
\hline Unit & Prairie Island-1 & Prairie Island-2 \\
\hline Owner & Xcel Energy (NSP) & Xcel Energy (NSP) \\
\hline Summer Capacity (2015) & $521 \mathrm{MW}$ & $519 \mathrm{MW}$ \\
\hline Location & Eastern Minnesota & Eastern Minnesota \\
\hline Market region/zone & NSP, Minnesota & NSP, Minnesota \\
\hline Output (MWh) & $4,717,489$ & $3,113,864$ \\
\hline Electricity revenue (\$ millions) & $\$ 91.3$ & $\$ 60.4$ \\
\hline Capacity revenue (\$ millions) & $\$ 0.6$ & $\$ 0.6$ \\
\hline Operating cost, base ((\$ millions) & $\$ 156.3$ & $\$ 155.7$ \\
\hline Gap, base (\$ millions) & $\$(64.4)$ & $\$(94.7)$ \\
\hline Operating cost, high (\$ millions) & $\$ 143.3$ & $\$ 142.7$ \\
\hline Gap, high (\$ millions) & $\$(51.4)$ & $\$(81.7)$ \\
\hline Operating cost, low (\$ millions) & $\$ 117.2$ & $\$ 116.8$ \\
\hline Gap, low (\$ millions) & $\$(25.3)$ & $\$(55.8)$ \\
\hline
\end{tabular}

The Prairie Island units are in the "multiple unit" category, with a high operating cost of $\$ 275,000 / \mathrm{MW} /$ year and a low operating cost of $\$ 225,000 / \mathrm{MW} /$ year. This assumption may not be appropriate, given the small size of the units.

From a 14 Feb 2016 news $^{25}$ story:

Xcel Energy is awaiting word from the Minnesota Public Utilities Commission to proceed with an 18-month study on the future of Prairie Island nuclear plant and the economics of potentially shutting down the two-reactor facility before its operating license expires in 2034.

Though Xcel Energy believes the plant is a cost-effective part of its goal to reduce carbon dioxide emissions, the utility company is open to analyzing options for early decommissioning in response to higher-than-expected capital expenditures forecasted in the next two decades, according to a Jan. 29 filing with the PUC.

"The Prairie Island plant provides good economic value to our customers, which we just detailed in our latest filing to the Minnesota Public Utilities Commission," according to an email statement Friday by Prairie Island Site Vice President Kevin Davison. "We look forward to working with the commission, local communities and other stakeholders to illustrate the value the plant brings to Red Wing, the state of Minnesota and electric customers across the upper Midwest."

The filing, a supplement to Xcel Energy's 2016-2030 Upper Midwest Resource Plan, states the company anticipates a $\$ 175$ million increase in expenditures in the

$25 \mathrm{http} / / /$ bismarcktribune.com/news/state-and-regional/xcel-open-to-closing-nuclear-plant-early/article_2fd7ab865e86-52e5-a800-8eb5822b007c.html 
next five years over what was predicted in 2012, as well as increases of $\$ 600$ million to $\$ 900$ million from 2021 through 2034.

The driving costs are attributed to new requirements following the 2011 Fukushima Dai-ichi nuclear disaster at Fukushima, Japan, and a general increase in regulations by the U.S. Nuclear Regulatory Commission.

However, the increases are largely offset by lower-than-predicted operating and maintenance costs for the plant, Xcel Energy noted. The company expects to spend $\$ 1$ billion less in fixed costs at Prairie Island through 2034.

\section{d. Fort Calhoun}

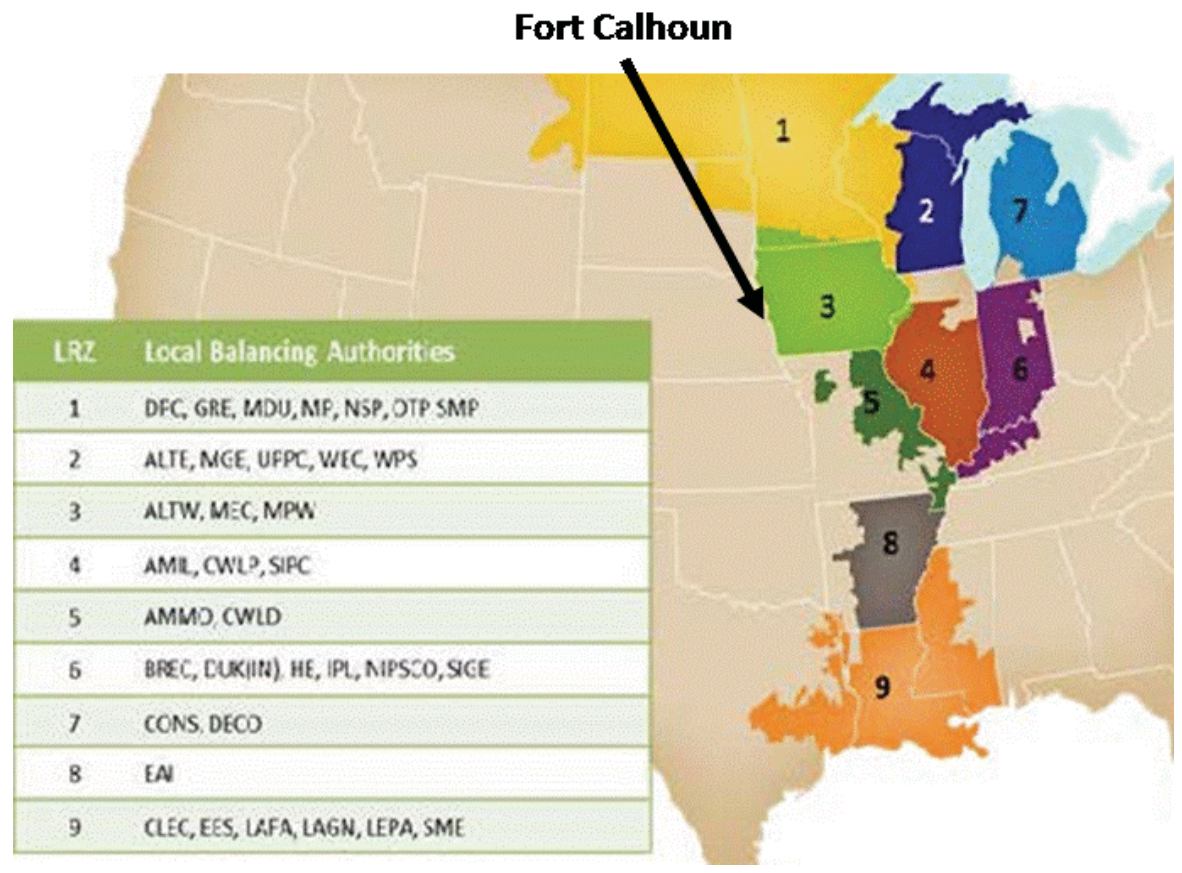

Figure 25. Fort Calhoun Map. 
Table 16. Fort Calhoun Data.

\begin{tabular}{|l|c|}
\hline Unit & Fort Calhoun \\
\hline Owner & OPPD \\
\hline Summer Capacity (2015) & $479 \mathrm{MW}$ \\
\hline Location & Eastern Nebraska \\
\hline Market region/zone & SPP \\
\hline Output (MWh) & $\$, 203,719$ \\
\hline Electricity revenue (\$ millions) & $\$ 86.6$ \\
\hline Capacity revenue (\$ millions) & $\$ 143.7$ \\
\hline Operating cost, base (\$ millions) & $\$(57.1)$ \\
\hline Gap, base (\$ millions) & $\$ 203.6$ \\
\hline Operating cost, high (\$ millions) & $\$(116.9)$ \\
\hline Gap, high (\$ millions) & $\$ 167.7$ \\
\hline Operating cost, low (\$ millions) & $\$(81.0)$ \\
\hline Gap, low (\$ millions) & \\
\hline
\end{tabular}

Fort Calhoun is in the "small single unit" category, with a high operating cost of $\$ 425,000 / \mathrm{MW} /$ year and a low operating cost of $\$ 350,000 / \mathrm{MW} /$ year.

Fort Calhoun is owned by a public power utility, Omaha Public Power District (OPPD) that recovers costs of power (whether purchased or generated by plants owned by OPPD) from its customers. OPPD has decided that the electricity rates for its customers would be lower if the Fort Calhoun nuclear power plant were retired early. The situation at OPPD is different than the other merchant nuclear power plants in this study that may be experiencing financial losses, but is driven by the same factors (i.e., low wholesale electricity prices and high operating costs).

News stories suggested that the cost of power from Fort Calhoun was about $\$ 71 / \mathrm{MWh}$, while the cost of power to OPPD in the market is about $\$ 20 / \mathrm{MWh}^{26}$

The OPPD Board of Directors voted on 16 Jun 2016 to retire the unit, with the unit now scheduled to close on 24 Oct $2016 .{ }^{27}$

OPPD is actually in the SPP market. The SPP market is mostly composed of bilateral transactions that do not allow analysis in the same manner as electricity markets with publicly available hourly Day Ahead and Real Time prices.

OPPD is also at the junction between MISO and SPP (i.e., the MISO OPPD Interface) that has reported hourly prices in the MISO market. We use the MISO OPPD interface prices to illustrate the financial situation at the Fort Calhoun nuclear power plant. Based on public reports and

26 See Omaha World-Herald article at http://www.omaha.com/money/closure-of-oppd-s-fort-calhoun-plant-lookslikely-cost/article 2304be8e-2124-557a-8ce5-5571da107067.html

27 http://www.omaha.com/money/oppd-announces-official-closing-date-for-fort-calhoun-nuclearplant/article_b8cf2e6f-ce65-56fb-9a0b-cb7ad80f8ce4.html 
private discussions with OPPD, the effective cost of power to replace the power from Fort Calhoun is even lower than the MISO OPPD interface prices used in this analysis.

\section{ISO-NE}

As the RTO for New England, ISO-NE is responsible for operating wholesale power markets that trade electricity, capacity, transmission congestion contracts and related products, in addition to administering auctions for the sale of capacity. ISO-NE operates New England's high-voltage transmission network and performs long-term planning for the New England system. ISO-NE serves six New England states: Connecticut, Maine, Massachusetts, New Hampshire, Rhode Island and Vermont. Like PJM and NYISO, ISO-NE was a tight power pool prior to its transformation into an ISO and wholesale electricity market.

ISO-NE is interconnected with the New York Independent System Operator (NYISO), TransEnergie (Québec) and the New Brunswick System Operator. ISO-NE imports around 15 percent of its annual energy needs from Québec, NYISO, and New Brunswick.

In ISO-NE's annual Forward Capacity Auction (FCA), both generator and demand resources offer capacity three years in advance of the period for which capacity will be supplied. The three-year lead time is intended to encourage participation by new resources and allow the market to adapt to resources leaving the market. ISO-NE relies primarily on natural gas-fired and nuclear generation, accounting for $39 \%$ and $34 \%$ of the systems supply in 2014 , respectively.

The geographic scope of the ISO-NE market is shown in Figure 26.

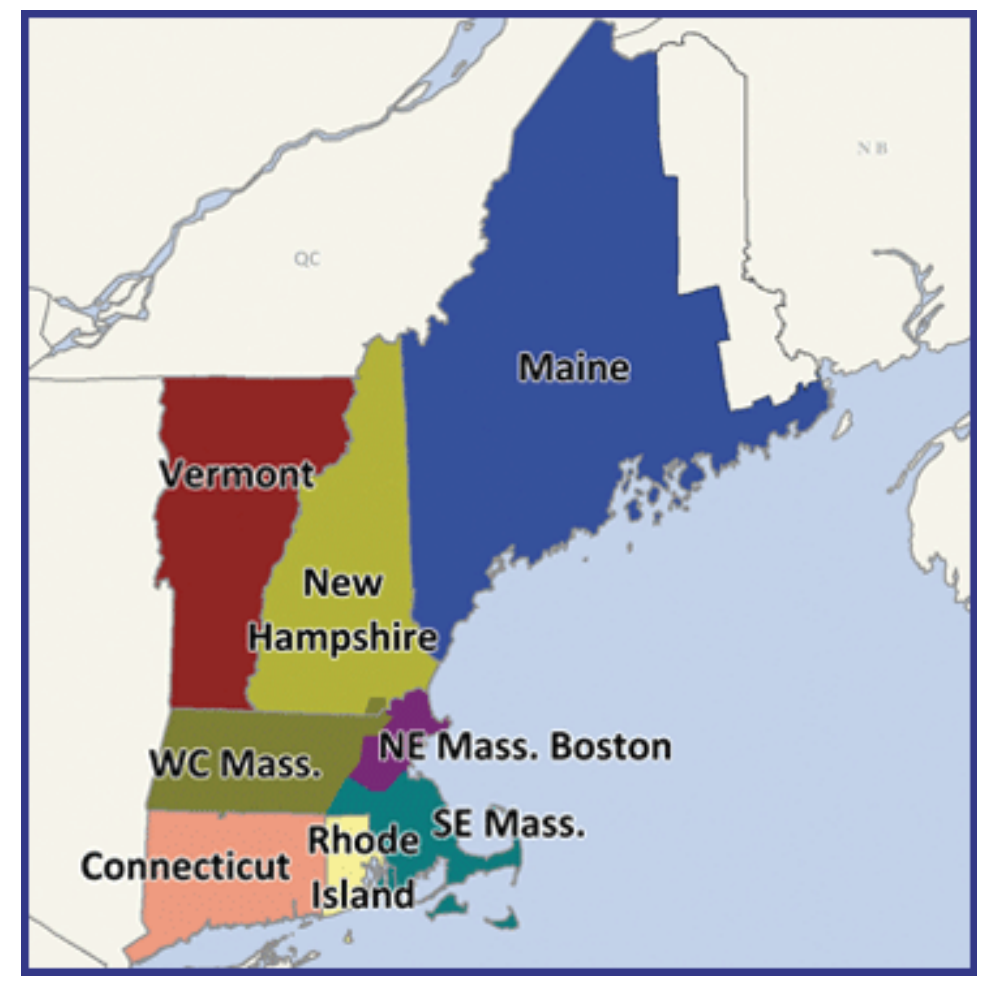

Figure 26. ISO-NE Zone Map. 


\section{a. Pilgrim}

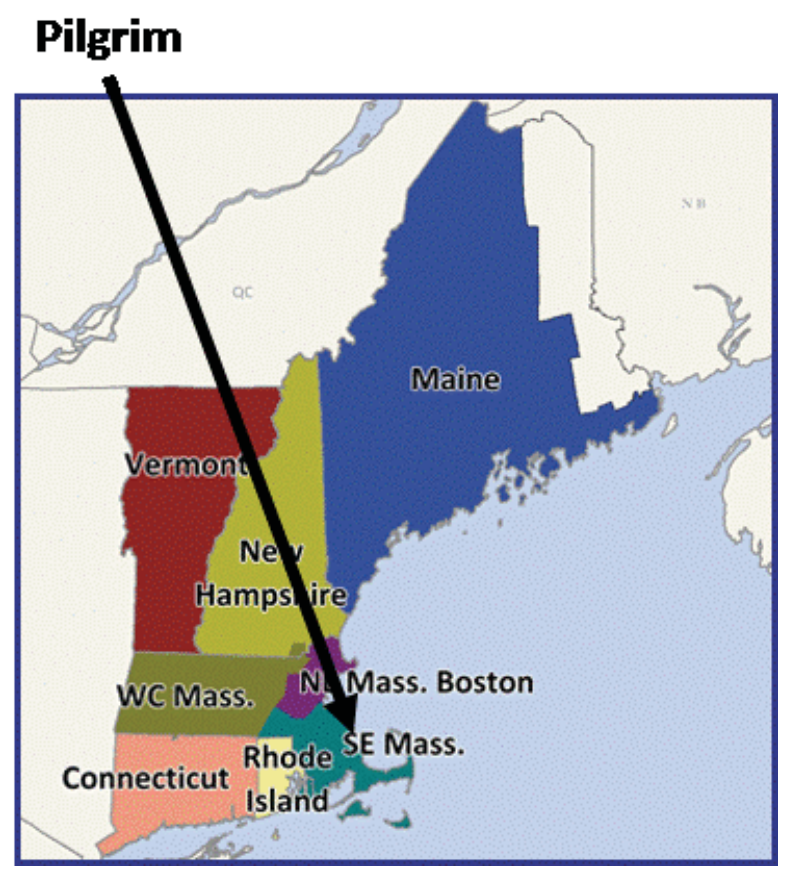

Figure 27. Pilgrim Map.

Table 17. Pilgrim Data.

\begin{tabular}{|l|c|}
\hline Unit & Pilgrim \\
\hline Owner & Entergy \\
\hline Summer Capacity (2015) & $678 \mathrm{MW}$ \\
\hline Location & Southeastern Mass \\
\hline Market region/zone & SEMASS \\
\hline Output (MWh) & $5,785,523$ \\
\hline Electricity revenue (\$ millions) & $\$ 129.7$ \\
\hline Capacity revenue (\$ millions) & $\$ 24.2$ \\
\hline Operating cost, base (\$ millions) & $\$ 203.4$ \\
\hline Gap, base (\$ millions) & $\$(49.5)$ \\
\hline Operating cost, high (\$ millions) & $\$ 288.2$ \\
\hline Gap, high (\$ millions) & $\$(134.2)$ \\
\hline Operating cost, low (\$ millions) & $\$ 237.3$ \\
\hline Gap, low (\$ millions) & $\$(83.4)$ \\
\hline
\end{tabular}

Pilgrim is in the "small single unit" category, with a high operating cost of $\$ 425,000 / \mathrm{MW} /$ year and a low operating cost of $\$ 350,000 / \mathrm{MW} /$ year. 


\section{MAGNITUDE OF NUCLEAR POWER PLANT FINANCIAL PROBLEM}

From a Platts ${ }^{28}$ story 13 Oct 2015:

Entergy will permanently shut its 728-MW Pilgrim nuclear plant in Plymouth, Massachusetts, as early as the spring of 2017, because the unit is losing about $\$ 40$ million annually with little chance that its economics will improve in the foreseeable future, a company executive said Tuesday.

Pilgrim began operating in 1972. Its license was renewed in 2012, allowing it to operate until 2032.

Pilgrim would become the second Entergy nuclear plant in New England to be permanently closed as a result of market conditions, following the retirement at the end of 2014 of the 635-MW Vermont Yankee station.

The exact timing of the closure depends on further discussions with the region's grid operator, ISO New England, and will be decided in the first half of 2016, Entergy said in a statement Tuesday. However, it said the plant will shut no later than June 1, 2019.

Low current and forecast power prices have "significantly impacted Pilgrim's revenues," Entergy said. Prices have declined about $\$ 10 / M W h$ recently, representing a decline in revenue for the single-unit plant of \$40 million/year, the company said.

During the briefing, Mohl said an evaluation of Pilgrim's operating costs and revenues begun earlier this year made it "clear" that "Pilgrim is simply no longer financially viable." He said the evaluation concluded the plant would sustain "losses of revenue of over \$40 million annually" for the foreseeable future.

Mohl ascribed this financial outlook to ISO New England's "poor market structure, regional energy prices and increased operating costs." Citing low "natural gas prices driven by an abundance of shale gas," he said the "delivered price [of electricity] has dropped substantially" since the summer of 2014 "to below \$10/MWh." This commonly is referred to as the energy price, versus the forward, capacity price.

Platts peak forward power prices at the Massachusetts electricity pricing hub have declined this year. Mass hub 2016 forward prices have fallen by more than 13\% from January 2 to October 9, a drop of $\$ 8.25 / \mathrm{MWh}$ to $\$ 53.30 / \mathrm{MWh}$.

Similar declines have taken place in forward Massachusetts hub power prices for delivery in 2017, 2018 and 2019, Platts data shows.

Mass hub peak 2019 prices had fallen to $\$ 48.90 /$ MWh October 9 from $\$ 55.80 / \mathrm{MWh}$ January 2, a decline of 12.4\%. Day-ahead prices in ISO-NE have also fallen compared with a year ago. Average monthly Platts day-ahead prices for Massachusetts in September were down 4.8\% from September 2014.

$28 \mathrm{http}: / /$ www.platts.com/latest-news/electric-power/washington/entergy-to-shut-pilgrim-nuclear-power-plant-as21284265 
In addition, Mohl chided the state of Massachusetts for proposing an energy policy that he said would provide economic incentives for the state's utilities to buy electricity generated by hydroelectric facilities in Canada.

Mohl said another factor in the company's decision to shut Pilgrim was the estimated cost of $\$ 45$ million to $\$ 60$ million that would be required to bring the plant into compliance with U.S. Nuclear Regulatory Commission requirements to remediate issues that prompted NRC earlier this year to move Pilgrim to the agency's highest level of oversight -- short of forcing the plant to shut -- as a result of recent operational issues.

The Entergy executive said it will decide by the first half of 2016 whether to carry out refueling and maintenance at Pilgrim that is scheduled for the spring of 2017. If a decision is made not to refuel Pilgrim, Mohl said the unit would be permanently shut, decommissioned and placed in Safstor, which can last for up to 60 years. He did not specify when the unit would be shut if it is not refueled in 2017.

Should Pilgrim close before June 1, 2019, the date it provided to ISO New England late Monday, according to Mohl, he said Entergy would make arrangements to buy electricity to meet its commitments to the ISO.

Mohl said Entergy will announce by the end of October whether it will shut FitzPatrick, noting: "We've made it clear that this facility is in a similar situation, facing similar economic" and financial situations as Pilgrim.

On April 14, 2016, Entergy announced that Pilgrim will refuel as scheduled in 2017, and operate until May 31, 2019. ${ }^{29}$

\section{CAISO}

The California Independent System Operator (CAISO) operates a competitive wholesale electricity market and manages the reliability of its transmission grid. CAISO provides open access to the transmission and performs long-term planning. In managing the grid, CAISO centrally dispatches generation and coordinates the movement of wholesale electricity in California and a portion of Nevada. CAISOs markets include energy (day-ahead and real-time), ancillary services, and congestion revenue rights. CAISO also operates an Energy Imbalance Market (EIM) in areas outside the CAISO wholesale electricity market, which currently includes PacifiCorp's two balancing authority areas.

CAISO was founded in 1998 and became a fully functioning ISO in 2008. The Energy Imbalance Market launched in 2014 with PacifiCorp as the first member or EIM Entity. The EIM serves parts of Oregon, Washington, California, Utah, Wyoming and Idaho.

\footnotetext{
${ }^{29} \mathrm{https}$ ://www.bostonglobe.com/2016/04/14/pilgrim-nuclear-power-plant-closemay/FRXGHcfMrk3nSngdYueMML/story.html
} 
The geographic scope of the CAISO market is shown in Figure 28.

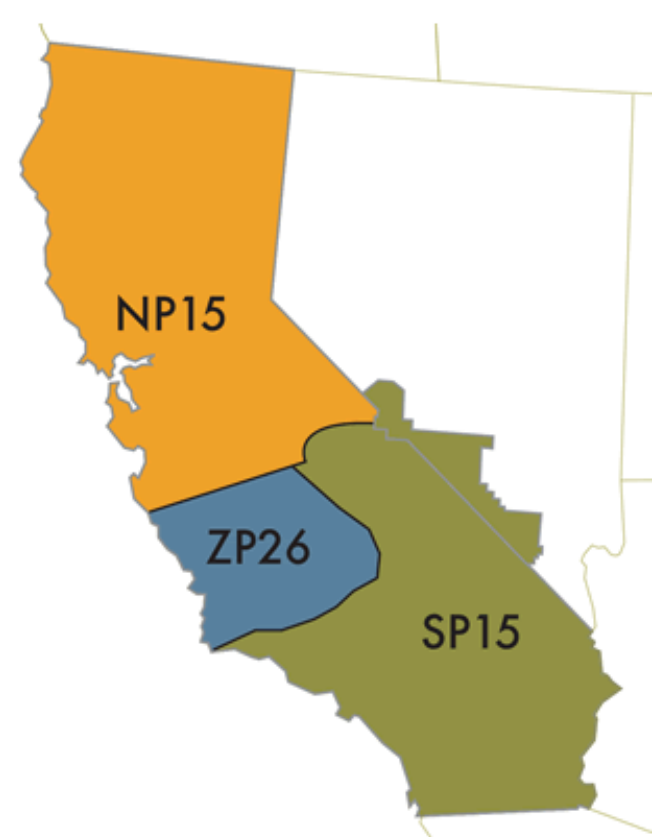

Figure 28. CAISO Zone Map.

\section{a. Diablo Canyon}

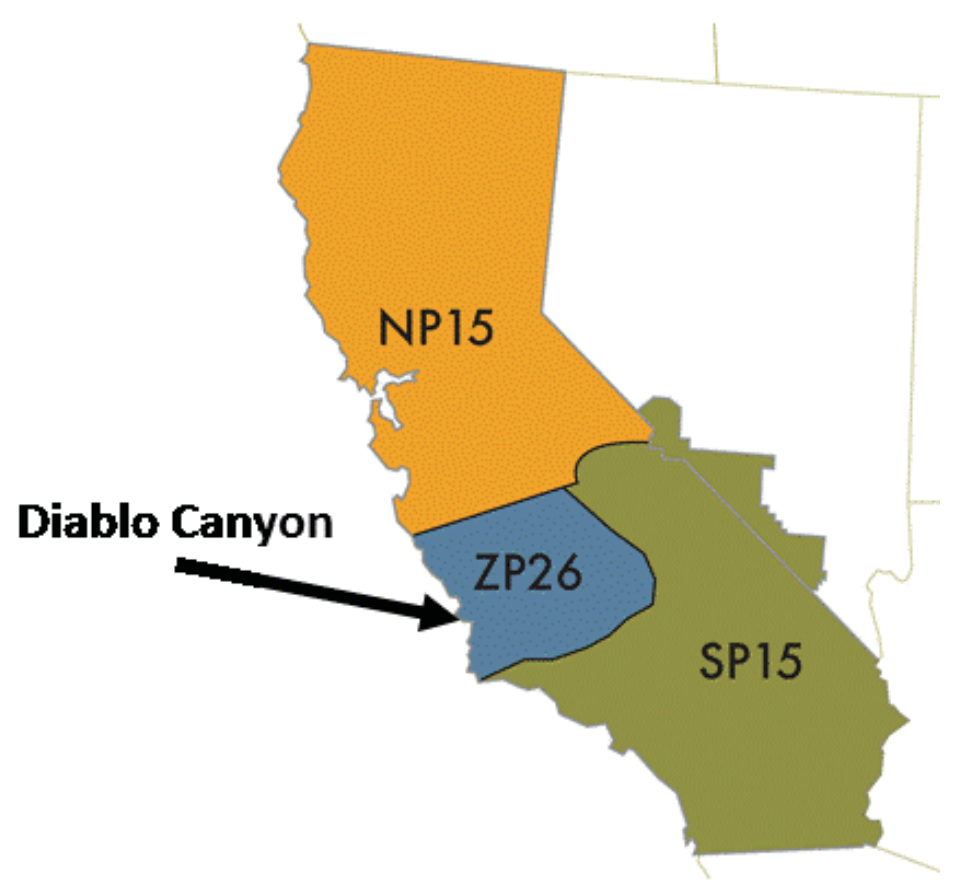

Figure 29. Diablo Canyon Map. 
Table 18. Diablo Canyon Data.

\begin{tabular}{|l|c|c|}
\hline Unit & Diablo Canyon-1 & Diablo Canyon-1 \\
\hline Owner & Pacific Gas \& Electric & Pacific Gas \& Electric \\
\hline Summer Capacity (2015) & $1,122 \mathrm{MW}$ & $1,118 \mathrm{MW}$ \\
\hline Location & Southwestern California & Southwestern California \\
\hline Market region/zone & PG\&E/ZP26 & PG\&E/ZP26 \\
\hline Output (MWh) & $8,932,597$ & $8,783,027$ \\
\hline Electricity revenue (\$ millions) & $\$ 242.6$ & $\$ 238.8$ \\
\hline Capacity revenue (\$ millions) & $\$-$ & $\$-$ \\
\hline Operating cost, base ((\$ millions) & $\$ 336.6$ & $\$ 335.4$ \\
\hline Gap, base (\$ millions) & $\$(94.0)$ & $\$(96.6)$ \\
\hline Operating cost, high (\$ millions) & $\$ 308.6$ & $\$ 307.5$ \\
\hline Gap, high (\$ millions) & $\$(65.9)$ & $\$(68.7)$ \\
\hline Operating cost, low (\$ millions) & $\$ 252.5$ & $\$ 251.6$ \\
\hline Gap, low (\$ millions) & $\$(9.8)$ & $\$(12.8)$ \\
\hline
\end{tabular}

Diablo Canyon is in the "multiple unit" category, with a high operating cost of $\$ 275,000 / \mathrm{MW} / \mathrm{year}$ and a low operating cost of $\$ 225,000 / \mathrm{MW} /$ year.

Diablo Canyon is a regulated asset owned by Pacific Gas \& Electric (PG\&E). PG\&E operates in the CAISO electricity market, but was allowed to retain the Diablo Canyon nuclear power plant as a regulated asset when California restructured its electricity sector. The costs of Diablo Canyon are recovered in PG\&E's rates. Like the earlier analysis of the regulated Surry units, this study estimates a Gap for the Diablo Canyon units that is based on the CAISO wholesale electricity market prices at the generator pricing nodes. In effect, the Gap estimates mean that PG\&E's rates might be lower if the power it now obtains from Diablo Canyon were instead purchased in the CAISO electricity market at current prices.

PG\&E is on the Pacific Ocean coast and sea water is directly used in the nuclear power plant condensers. California has had a long-standing policy either close power plants with direct cooling from the sea or to require these power plants to replace direct cooling with cooling towers. Backfitting of cooling towers for the operating Diablo Canyon units would likely be very costly.

In 2016, PG\&E reached an agreement with the state government (California state lands commission) and the California Public Utilities Commission to close the plant when the original NRC operating license expires in 2024/2025 (i.e., PG\&E will not pursue a 20 -year license renewal application for the Diablo Canyon units). This agreement may be challenged.

California has a cap-and-trade system as one policy tool to reduce the greenhouse gas emissions responsible for climate change. ${ }^{30} \mathrm{~A}$ cap-and-trade program sets a limit on greenhouse gas

$30 \mathrm{http}: / /$ www.c2es.org/us-states-regions/key-legislation/california-cap-trade 
emissions and minimizes the total costs to emitters while achieving the target. This limit is translated into tradable emission allowances (each allowance typically equivalent to one metric ton of carbon dioxide or carbon dioxide equivalent), which are auctioned or allocated to regulated emitters on a regular basis. At the end of each compliance period, each regulated emitter must surrender enough allowances to cover its actual emissions during the compliance period. The total number of available allowances decreases over time to reduce the total amount of greenhouse gas emissions. By creating a market, and a price, for emission reductions, the capand-trade system offers an environmentally effective and economically efficient response to climate change.

In the electricity industry, the California cap-and-trade approach makes the cost of carbon emissions a variable cost for carbon-emitting electricity generators, increasing marginal costs and bids into the CAISO market. This approach means that a cost of carbon is embedded in wholesale electricity market prices, although the impact on wholesale electricity market prices has been relatively small. ${ }^{31}$

The financial benefits to a nuclear power plant of this system are small and indirect. This is different from the New York ZEC approach, where there are direct payments outside of and separate from the electricity market.

\section{E. Industry Efforts to Reduce Costs (Delivering the Nuclear Promise)}

The U.S. nuclear industry faced a trend of increasing operating costs over the last decade, in conjunction with rapidly decreasing revenues associated with a dramatic and extended decrease in natural gas prices. Some of these increases were associated with increased regulatory requirements for physical security as well as major plant and process modifications required as a result of the 2011 Fukushima accident in Japan.

The Nuclear Energy Institute (NEI) presented a snapshot of the U.S. nuclear fleet costs in 2015, shown in Figure 30.

31 http://eec.ucdavis.edu/files/02-06-2014-The-Future-of-Electricity-Prices-in-California-Final-Draft-1.pdf 


\section{Snapshot of 2015 U.S. Nuclear Plant Costs}

(\$ per MWh)

- Average generating costs have decreased from peak of $\$ 39.75 / \mathrm{MWh}$ in 2012 to $\$ 35.50 / \mathrm{MWh}$ in 2015.

- Average generating costs have decreased $2.4 \%$ from 2014.

- Capital spending down 3\% from 2014, and 26\% from 2012 peak.

- $\$ 6.25$ billion in 2015 capex. 2015 Generating Cost

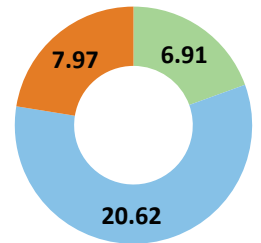

$$
\begin{aligned}
& \text { Fuel } \\
& \text { O\&M } \\
& \text { Capital }
\end{aligned}
$$

2015 Average

Generating Costs

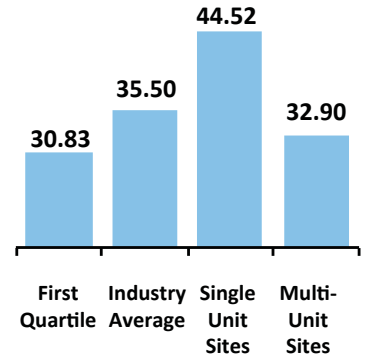

Total generating cost = fuel + capital + operating Source: Electric Utility Cost Group.

\section{NEI

Figure 30. NEI Snapshot of 2015 U.S. Nuclear Power Plant Costs.

As can be seen, with the completion of the regulatory-driven plant modifications, average plant costs have begun decreasing from their peak in 2012.

In light of the current and expected market challenges, however, the industry, in conjunction with NEI, INPO and the Electric Power Research Institute (EPRI), announced in early 2016 a three-year program entitled "Delivering the Nuclear Promise (DNP)." The DNP program is intended to identify efficiency opportunities, adopt best practices and implement technology solutions to reduce overall average industry operating costs by about $30 \%$ from the 2012 peak. This reduction is equivalent to approximately $\$ 10$ per MWh of which approximately $\$ 3$ per MWh has already been achieved as reflected in the NEI 2015 fleet average cost data. For additional information see the NEI web site. ${ }^{32}$

Work is underway throughout the industry on the DNP initiatives to reduce nuclear power plant operating costs. However, even with the aspirational cost reduction goals of this program, these operating cost reductions will not be sufficient to overcome the economic and financial issues at some plants (i.e., due to low electricity market prices) discussed earlier in this report.

32 http://www.nei.org/Issues-Policy/Delivering-the-Nuclear-Promise 


\section{TIMING - NUCLEAR PLANT SHUTDOWN DECISION MAKING AND TIMELINES}

The study reviewed typical timelines a company may experience while making a decision to end operations prematurely and retire a nuclear unit. We will examine the process of preparing to terminate operations, the NRC regulatory implications of ceasing operations, and optionality of reversing an early shutdown decision at various points along the timeline.

This chapter covers all nuclear power plants that have announced plans to retire early, nuclear power plants that have indicated that early retirement may be an option (e.g., Nine Mile Point 2 and Ginna), and nuclear power plants that may retire at the end of the original NRC license (i.e., not pursue license renewal).

\section{A. RTO and Capacity Market Restrictions}

Each load-serving entity (LSE) is required to own or control sufficient capacity to meet its projected peak demand plus a reserve margin (e.g., 15\%). An LSE can obtain this capacity by building power plants or signing power purchase agreements. Most RTOs operate a capacity market that is intended to procure capacity to ensure that the entire RTO (or each regional part of the RTO) has sufficient capacity and to ensure that locational congestion issues are addressed.

Depending on the RTO, an LSE may be required to pay for capacity to the extent that it has not procured sufficient capacity. Other RTOs have capacity auctions that essentially serve as to match LSE needs with generator capacity offerings.

Some nuclear power plant units may participate in the capacity market organized by the RTO in which they are located. Winning in an RTO/ISO capacity market auction may obligate a unit to operate for a certain period. These capacity obligations may require operation of the nuclear unit and even if the unit can be closed prior to the end of the capacity obligation, this may mean significant financial penalties.

\section{PJM}

In the PJM market, an auction ${ }^{33}$ is held annually in May three years prior to the delivery/planning year. Each delivery/planning year covers a period from 1 June to 31 May a year later. For example, the auction in May 2016 was for the delivery/planning year from 1 June 2019 to 31 May 2020. The primary auction is the Base Residual Auction, with subsequent incremental auctions held to cover changes in the delivery year.

Starting in the 2018/2019 delivery year, PJM added Capacity Performance requirements (i.e., there is a Base Residual Auction plus a Capacity Performance Resource auction). Starting with

3330 Jun 2016 PJM Capacity Market Manual (Rev 33) is at https://www.pjm.com/ /media/documents/manuals/m18.ashx 
the auction for the 2020/2021 delivery year, the Base Residual Auction will be phased out and all capacity will be provided by Capacity Performance Resources.

For a Capacity Resource to qualify as a Capacity Performance Resource product type, the resource must be capable of sustained, predictable operation that allows the resource to be available throughout the entire Delivery Year to provide energy and reserves whenever PJM determines an emergency condition exists. For a Capacity Resource to qualify as a Base Capacity Resource product type the resource is not expected to be capable of sustained, predictable operation that allows the resource to be available throughout the entire Delivery Year; however, the resource must provide enhanced assurance to provide energy and reserves during hot weather operations.

There are significant penalties if a generator that wins in the Capacity Performance Resource auction is not available.

\section{NYISO}

The NYISO ICAP market procures capacity to meet LSE capacity obligations that have not been met through self-supply and/or bilateral contracts.

In the NYISO ICAP market, the longest duration capacity agreements are the annual 6-month peak period "strip" bids. This means that a unit that has bid into (and clears) the 6-month strip auction has obligations to perform only during the relevant 6-month period.

\section{MISO}

The MISO Resource Adequacy Requirement construct allows LSEs to meet their capacity obligations as defined by the sum of LSE load projections and a Reserve Margin calculated by MISO (or a by a state).

LSEs are able to meet these obligations by (a) acquiring capacity from MISO annual Planning Resource Auctions; (b) Self-Scheduling Capacity Resources; or (c) submitting Fixed Resource Adequacy Plans.

In the MISO market, auctions are held each year to meet the capacity needs in the immediate following delivery year.

Accordingly, the MISO capacity market may limit the timing of nuclear unit early retirement in the current year only.

\section{ISO-NE}

The ISO-NE capacity market is called the Forward Capacity Market (FCM). It functions with an annual Forward Capacity Auction (FCA) held in February 3 years in advance of a Capacity Commitment Period. A nuclear unit that clears the FCM will have an obligation to operate in the Commitment period three years in the future. 


\section{B. Timing and NRC Regulatory Considerations around Decisions to Terminate Nuclear Unit Operations}

Recent announcements of planned nuclear unit shutdowns can be characterized into two broad groups: those triggered by plant equipment issues, and those resulting from economic decisions.

In the case of a serious plant equipment issue, such as those experienced at Crystal River and San Onofre $2 \& 3$, typically the plant has been shut down for an extended period already. After a period of analysis of the problem, and evaluation of alternatives, the owner/operator may conclude that the anticipated costs of repair or replacement of the equipment are of such magnitude that they are not justified considering the current and anticipated price of electricity in that market. In such cases, the company may announce that the decision has been made to permanently terminate operations, and then proceed into the decommissioning process discussed below.

For example, the Crystal River unit was originally shut down in September 2009 for a refueling and major modification outage. As a result of containment damage discovered after modifying the containment to facilitate replacement of steam generators, the unit remained offline while alternatives were studied and cost estimates developed. In February 2013, the owner company (Duke Energy) concluded that the cost estimates were excessive, and announced that the repairs would not be performed, and that the unit would be closed.

Similarly, the San Onofre (SONGS) Units 2 and 3, were shut down in early 2012 to determine the extent and cause of excessive steam generator tube wear experienced on replacement steam generators recently installed in the units. As the process for proposed restart became more protracted, the company (Southern California Edison) announced in June 2013 that both units would be prematurely retired, following negotiation of a cost allocation agreement with the state Public Service Commission.

In contrast, decisions to end operations early for economic reasons are usually made while the units are operating. Since detailed information about an individual plant's economics are usually proprietary to the owners, it is usually up to the owners to make public the economic challenges a unit may be facing, or that consideration is being given to ending operations. Often, such decisions are announced to be predicated on the results of upcoming power market auctions, or of proposed economic incentives proposed in various states. At some point, the company may make the internal decision to terminate operations, and make a public announcement, thus triggering the decommissioning process. Shutdowns are typically targeted for the end of an operating cycle, when the unit would have been shut down for refueling.

The closure of the Kewaunee unit in Wisconsin is a good example of the classic economic decision process. This unit was purchased by Dominion in July 2005, with a power purchase agreement with the previous co-owner utilities, set to expire in 2013, at the end of the original licensed life. The company made substantial capital investments in the plant, and significantly improved performance, as evaluated by NRC and INPO. It also applied for a 20-year license renewal, which was approved in February 2011, extending the license until 2033. However, as the upper Midwest power market changed, Dominion was not able to come to agreement with 
the previous owners for an extension of the power purchase agreement, as market prices in the region were depressed as a result of low natural gas and coal prices. In April 2011, Dominion announced that it was seeking to sell Kewaunee, as part of an overall corporate strategy to exit the merchant generation business in the mid-west.

In October 2012, Dominion announced that it had been unable to find a buyer for the facility, and that it planned to shut down and move into decommissioning in the second quarter of 2013. In its announcement, it stated: "This was an extremely difficult decision, especially in light of how well the station is running and the dedication of the employees. This decision was based purely on economics. Dominion was not able to move forward with our plan to grow our nuclear fleet in the Midwest to take advantage of economies of scale. In addition, Kewaunee's power purchase agreements are ending at a time of projected low wholesale electricity prices in the region. The combination of these factors makes it uneconomic for Kewaunee to continue operations."

Following shutdown of the unit in May 2013, the company proceeded into its decommissioning plan, rapidly reducing operating staff, and taking steps to place the unit in a SAFSTOR condition. Over half of the 630 person operating staff was released by the end of 2013, with further layoffs in 2014.

Similar economic conditions have persisted in merchant markets. Over the past year, Exelon has announced that its Clinton and Quad Cities units would be shut down over the next 2 years, (Clinton in June 2017 and Quad Cities in 2018) since needed market support has not yet been approved in Illinois. Reports indicate that the Byron units are also facing severe economic challenges. 
Table 19. NRC Dates for All Units in this Study.

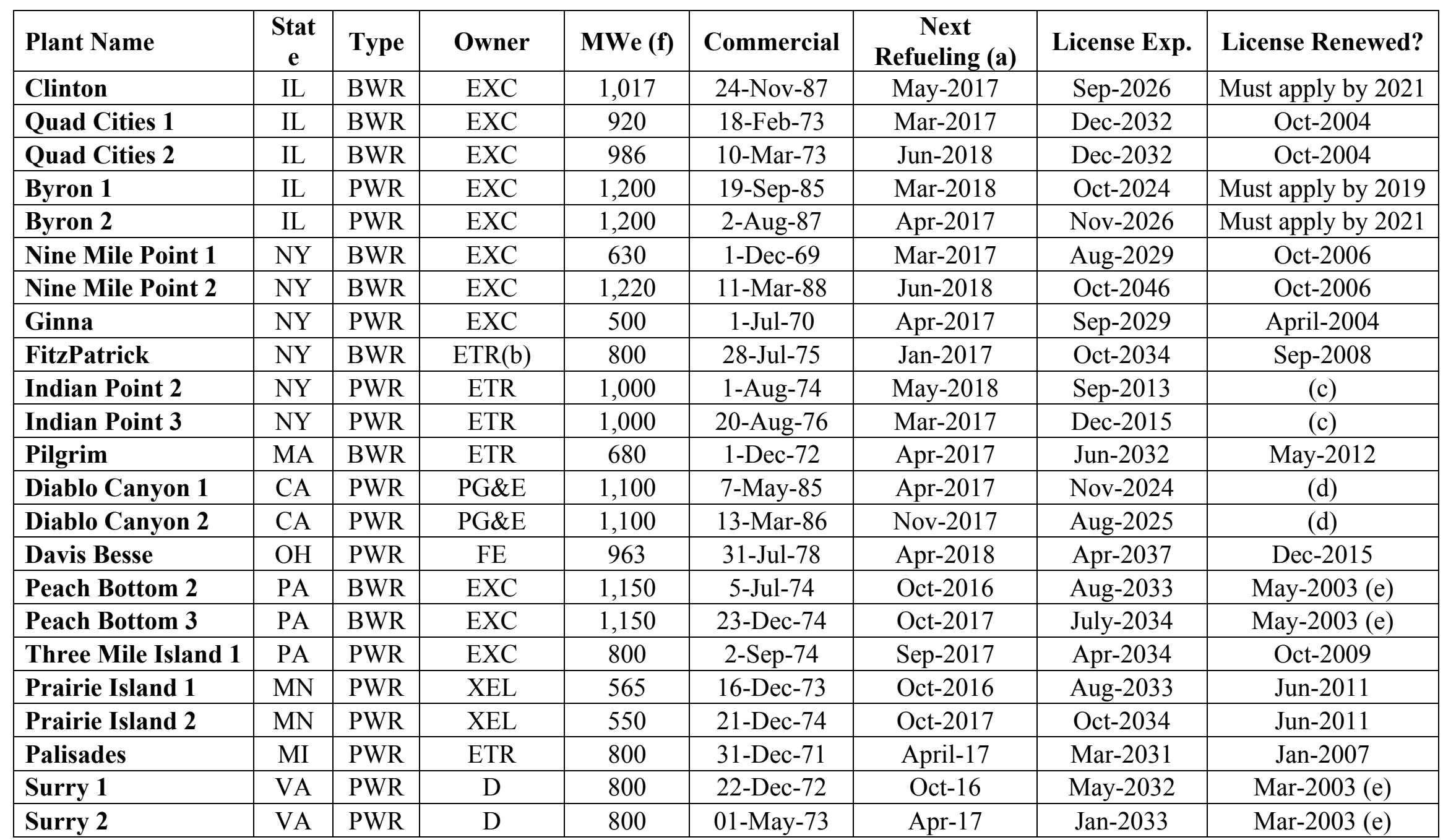


Notes for Table 19:

(a) Refueling dates estimated from public sources; actual dates may be considered commercially sensitive and may differ;

(b) Sales agreement from Entergy to Exelon announced August 2016;

(c) Timely applications for license renewal submitted; NRC proceedings ongoing;

(d) Applied 11/2009, suspended 06/2016. If withdrawn, new application would be required minimum of 5 years prior to license expiration, if renewal subsequently chosen;

(e) Owner has notified NRC that it intends to submit a subsequent license renewal application (i.e., to extend life of plant to a total of 80 years);

(f) The MWe amounts are from NRC website; may not be the same as the Summer Capacity amounts above.

In New York and New England, Entergy Corporation, the owner of the (now closed) Vermont Yankee, Pilgrim, Indian Point and FitzPatrick plants, has indicated a corporate strategy of exiting the merchant nuclear business in the Northeast as a result of low electricity prices. Following closure of the Vermont Yankee plant for economic reasons at the end of 2014, Entergy announced plans to end operations at FitzPatrick in New York in January 2017, and at Pilgrim in Massachusetts in either 2017 or 2019. This was clarified in early 2016 to indicate that Pilgrim would in fact refuel during its scheduled 2017 outage, and operate for one more cycle, until 2019. Following announcement of the New York ZEC plan in July 2016, Entergy and Exelon announced an agreement to for Entergy to sell the FitzPatrick unit to Exelon, with sale closure expected in early 2017.

In New York, Exelon, the owner of the Ginna and Nine Mile Point plants, indicated in June 2016 that unless market concessions were approved by September, refuelings scheduled in 2017 for Ginna and Nine Mile Point 1 may not be performed, and the units would be closed. Adoption of the New York ZEC plan will presumably prevent this outcome.

\section{Decommissioning Timetable}

Regardless of the process taken to decide to end operations, once the decision is made, there are certain milestones required by NRC Regulations, specifically 10CFR 20 Subpart E, 10CFR50.75, 10CFR 50.82, 10CFR 51.53 and 10 CFR 51.95. Regulations require that each nuclear unit licensee maintain a decommissioning fund to have adequate funds available once a unit ceases to operate. The licensee is required to update its decommissioning cost estimates every five years, and to inform the NRC 5 years before the anticipated projected end of operations. This, of course, assumes that decision is made with that much lead time, which has not been the case for any plant shutdown to date.

Once a decision to end operations is made, the licensee is required to report that determination to the NRC within 30 days, per 10CFR 50.82. For each of the plants discussed above, where either 
a shutdown plant was determined to not be economic to repair for restart, or where a future date for early shutdown was determined, the licensees have made the required notification to the NRC. In addition, if the plant is in a merchant market situation, various reports are required to be made to the relevant ISO, and in many cases, the ISO is required to make a determination that grid stability will not be adversely affected by the shutdown. Where a statutory or contractual time period for such an ISO determination is specified, this will often determine when the operating company makes its official announcement in advance of the planned shutdown date.

Once the unit shuts down, the licensee is required to report to the NRC the "permanent cessation of licensed activities" within 30 days. Once all fuel has been removed from the reactor vessel, and placed in the spent fuel pool, the licensee must make a written certification of that event to the NRC. This certification has the effect of surrendering authority to reload fuel back into the reactor, or to operate the unit. Only at this point is the licensee relieved of the obligation to adhere to various license and Technical Specification requirements applicable to an operating unit.

Regulations further require that the licensee prepare and submit to the NRC a Post Shutdown Decommissioning Activities Report (PSDAR), which outlines the licensee's plans and schedule performing the decommissioning of the unit. The significance of this report is that beginning on a date 90 days after its submittal, the licensee can begin "major decommissioning activities," including removal of components. All activities must be determined to not impact the environment in ways not previously evaluated, or they must have prior approval by the NRC. A major significance of the submittal of the PSDAR, which begins a series of NRC activities, including public meetings, is that most of the decommissioning funds are not accessible to the licensee until the 90-day date post submittal. Prior to that date, only $3 \%$ of the funds can be used. This has the practical effect of motivating licensees to submit the PSDAR as soon as practicable, and not use the two-year period in the regulations.

\section{Can a Decision to Shut Down Be Reversed?}

The short answer is yes, but not necessarily without significant cost and most likely a delay in restart following the previously unplanned refueling outage.

Following a decision to end operations, the operating company will immediately begin taking steps to terminate contracts and purchasing arrangements which would have otherwise been planned for the refueling outage and beyond. Of notable importance is the scheduling of deliveries of new fuel assemblies for installation during the refueling. As a general rule, taking into account the need to design the new core and manufacturing lead time, a new fuel delivery order must be placed about a year in advance. A late decision to continue operation, made during the final operating cycle, will probably lead to a delay in receiving new fuel, and consequently delay restart.

In addition to fuel deliveries, many of the activities normally conducted during a refueling outage are planned and scheduled far in advance, including contracting for necessary inspection and maintenance services. Again, a decision to begin this process late in the last operating cycle will likely lead to an extended outage and a delay in restart. 
In addition, there are often capital modifications planned for refueling outages to respond to NRC or INPO requirements. Where planning, engineering and procurement for such modifications is suspended in the year before an outage, additional delay may be experienced in successfully implementing these changes before restart.

There is little long term impact of making the required 30-day notification to the NRC following a determination to cease operations, and then reversing that decision. For example, Entergy had provided the NRC with their notification of anticipated in shutdown of FitzPatrick in 2017 but now that the unit is being sold to Exelon and will not be closed early, that notification is no longer relevant. The two companies will be submitting an application to the NRC to transfer the operating license from Entergy to Exelon, a process that usually takes about 6 months.

Even after the shutdown, if the initial report of "permanent cessation of licensed activities" is made, it is probable (although never demonstrated to date) that this, too, could be reversed after some interaction with the NRC. The next notification, however, that of notifying the NRC that all fuel has been removed from the reactor, and surrendering the authority to operate, would be more problematic. The NRC has no processes in place to reinstate a license that has been surrendered, and such a situation is not provided for in the regulations.

Some have argued that this could require a complete re-review of the licensing basis, and likely major required modifications to conform to current criteria. However, informal communications with the NRC following earlier plant shutdowns suggest that while an extended review might result, it would not necessarily be impossible to restore operating authority, nor would it be certain that new design requirements would be imposed. While not directly applicable, the experience of TVA with its Bellefonte project may be illustrative. Units 1 and 2 at Bellefonte were partially built when TVA decided to not continue with construction, and allowed the NRCissued construction permits to lapse in 2006. Following that decision, TVA began to re-evaluate its construction plans, and, in August 2008, requested that the NRC reinstate the construction permits. At the time, this was widely believed not to be possible, but the NRC did approve the reinstatement in February 2009, with extensive requirements for equipment inspections and status updates. Some similar approach could be conceivable for a licensee desiring to reinstate operating authority, but would necessarily involve substantial regulatory negotiation and extensive plant inspections and testing. Depending on the time since shutdown and the state of plant staffing, extensive requalification of personnel, including licensing of plant operators, would also be needed. Clearly, the more time that elapsed between the shutdown and the decision to attempt restart, the more difficult such an undertaking would be.

It should be noted that some recent shutdown announcements look beyond the current operating cycle for a projected shutdown date; for example, Entergy has announced that Pilgrim will refuel in 2017 and then shut down in 2019. In such a case, the company will strive to optimize core design for the final cycle; this might not be optimum for continued operations if that decision were to be after the design was finalized or the last core loaded.

Closely related to the above discussion is the question of whether it might be possible for a company to close a plant temporarily, essentially placing it into a standby status, awaiting higher energy prices or a better market structure. Under current regulations, this would be very difficult and expensive to implement. A plant's operating license does not recognize a state of "standby" 
or suspended operations, and therefore all of the license requirements would continue to apply, regardless of whether the unit was actually online producing electricity. Since one of the largest operating cost segments for a nuclear unit is payroll (not fuel, which would be variable with output), if the unit is shut down for economic reasons, then headcount must be reduced as soon as possible. This simply cannot be done as long as the operating license requirements remain in force. Even if, over time, the license could be amended to temporarily suspend some of the surveillance, testing, maintenance and corrective action requirements, once staff was released, it could take several years to restore qualifications to permit a restart. For example, restoring the necessary number of NRC licensed operators could take anywhere from 1 to 5 years, depending on the level of experience of the remaining staff and any new hires. Training and qualification requirements for other staff members, while not necessarily specified in regulations, are similar and would take an extended time to implement. As a result, companies have found themselves with a decision to either continue to operate with inadequate revenue, or to shut down the unit, reduce staff quickly, and enter the decommissioning process. 


\section{ACTIONS - POTENTIAL ACTIONS TO STOP EARLY RETIREMENTS}

When commercial nuclear power had its start in the United States more than 50 years ago, most of the electric power sector was structured in what we now call the traditional utility model: public service corporations under cost of service rate regulation by state authorities. In this model, prospective nuclear power plant operators would demonstrate to their state regulators that expected operating cost savings from the very significant fuel cost difference between nuclear and fossil fuels made the investment in new nuclear advantageous to rate payers.

Over the years, states made adjustments to the rate making model, in order to reduce the impact of large additions to the rate base at the time of bringing a new unit into service, such as allowing for rates to be based on construction work in progress, rather than requiring that financing costs be accrued and then added to the rate base (and consequently, rates) at the time of commercial operation.

For decades, even with escalating construction costs and plant modifications required by increasing regulatory requirements, nuclear electricity costs were competitive with coal, and far below the costs of generating electricity by other means, such as oil or natural gas. As a result, almost all utility systems developed around the concept that nuclear was the low cost generation source, assumed to run at full power around the clock to supply base load. Indeed, the industry devoted significant resources to optimizing operations and necessary refueling outages, and has demonstrated the capability to operate at consistent industry average capacity factors in excess of $90 \%$ year after year.

With the changes in market structure, slackening (largely industrial) demand, and dramatic reductions in natural gas prices discussed previously in this report, this cost model has changed. Between 2013 and 2015, five operating nuclear units were prematurely retired, with two of those (Kewaunee and Vermont Yankee) citing purely economic reasons for the decision. Despite this, U.S. policy makers appeared to assume that the vast majority of operating nuclear units would continue to do so indefinitely. For example, the Environmental Protection Agency provided very little recognition or incentives for nuclear in its Clean Power Plan, with an implicit assumption that carbon dioxide free generation from existing nuclear would continue without incentives.

This assumption was severely challenged in 2015 and 2016, with the announcements of additional planned premature shutdowns, and a growing realization that many more units were under economic stress. At the same time, a better understanding of the carbon dioxide emission reductions necessary to meet the commitments made at the COP-21 conference in Paris, has made it clear that these climate goals cannot be met without not only retention of the existing nuclear generation, but expansion of the use of nuclear technology. This has been the theme of several high profile conferences, including the White House Summit on Nuclear Energy in November 2015, the January 2016 Third Way Advanced Nuclear Summit, and the May 2016 DOE Summit on Improving the Economics of America's Nuclear Power Plants. With these meetings, political leaders and policy makers have publicly acknowledged the vital role that nuclear must play in meeting our nation's climate goals. 


\section{ACTIONS - POTENTIAL ACTIONS TO STOP EARLY RETIREMENTS}

It has become clear that existing market structures and pricing do not adequately recognize the clean energy role nuclear plays and that, without significant actions on the state and Federal level, the U.S. runs the risk of losing a significant portion of its current carbon dioxide free electricity generation and falling far short of the necessary reductions in $\mathrm{CO}_{2}$ to meet climate targets.

In mid-2015, in an effort to better inform state policymakers of the critical role of new and existing nuclear energy facilities, the American Nuclear Society (ANS) established a Special Committee on Nuclear in the States to assist the states in formulating responses to the EPA Clean Power Plan, to include new nuclear construction, and to avoid further premature plant shutdowns. The Committee published (February 2016) a Toolkit of a variety of policy and market based options, and broadly communicated these options to state leaders.

The current version of this report (Version 2.0, June 2016) is available at the ANS website. ${ }^{34}$ In conjunction with the ANS Toolkit, a companion report ${ }^{35}$ entitled "The U.S. without Nuclear Energy: A Report on the Public Impact of Plant Closures" was issued by the Committee in April 2016, and is recommended to more fully understand the impacts of further premature loss of operating nuclear plants. The ANS Toolkit describes a broad spectrum of policy actions that could potentially be taken at both the Federal and state levels, and is highly recommended as a starting point for policy discussions within the Government.

As noted in the ANS Toolkit, "Nuclear power plants provide significant economic benefits to local, state, and national governments. Clean air benefits, including carbon-free and emissionfree electricity, accrue to the entire country and to the world. Yet a merchant nuclear power plant owner receives no compensation for these benefits to society. The failure of electricity markets to provide sufficient revenue to operating nuclear power plants to remain in operation is a profound market failure. Only government can step in to address this."

An excellent review of actions taken in various states, since the publication of the ANS Toolkit, was recently issued by the National Conference of State Legislatures. ${ }^{36}$ This provides additional inputs to the various states for consideration. While some of these actions are promising, much more needs to be done, both at the Federal level, led by DOE, and at the state and local levels.

\section{A. DOE Actions}

\section{Clear Federal Policy Statement that Nuclear Power Is Needed}

Perhaps the most important short-term action that should be undertaken by the Department is the promotion and establishment of a Government-wide policy that nuclear plants are necessary to meet the nation's climate goals, and that other agency actions must be consistent with that principle.

\footnotetext{
34 http://nuclearconnect.org/wp-content/uploads/2016/02/ANS-NIS-Toolkit-V2.pdf

35 http://cdn.ans.org/pi/publicpolicy/docs/the-us-without-nuclear-energy-report.pdf

36 It can be accessed at http://www.ncsl.org/research/energy/state-action-in-support-of-nuclear-generation.aspx.
} 


\section{ACTIONS - POTENTIAL ACTIONS TO STOP EARLY RETIREMENTS}

As noted previously in this report, the U.S. energy industries are predominantly privately owned, and therefore respond to economic signals. Present policies and markets do not recognize the social benefits (both from a $\mathrm{CO}_{2}$ reduction standpoint as well as from positive economic impacts) provided by nuclear plants, and therefore do not translate these societal benefits into economic signals to the private owner/operators.

It was noted during the May 2016 DOE Summit, for example, that a proposal to construct and operate a new nuclear facility is subject to extensive and exhaustive reviews of potential environmental and economic impacts but there is essentially no review conducted of a decision to terminate operations at an existing facility, despite the significant negative environmental and economic impacts of such a closure. DOE should investigate means of incentivizing continued operations, and dis-incentivizing shutdowns.

\section{Public Information and Awareness}

Recognizing that energy decisions are made in the context of political and public information and understanding of the issues, DOE should initiate a program to provide public information that clearly defines the challenges of generating sufficient electricity to power a modern and growing economy, while also eliminating the use of carbon based fuels. There continues to be significant misunderstanding of the scale of needed electricity generation, particularly if the transportation sector is to be decarbonized as well.

A public information and awareness effort would include necessary studies, public meetings, media materials, and other outreach activities. DOE should also seek out ways to partner with existing professional and environmental groups in their public information and educational activities. Planning scenarios showing the need to double the existing nuclear generation by midcentury will not be implemented by the private sector without a significant change in the public discussion.

\section{Facilitate Social Cost of Carbon Approaches}

In addition, DOE can, and should, seek ways to promote, encourage and require recognition of nuclear benefits in state and regional market decision processes. These benefits, and negative impacts of early nuclear closures, are still not widely recognized. The adoption of such concepts as the social cost of carbon in these processes should be encouraged and incentivized. DOE should seek out ways to ensure that these processes are adequately informed of the social consequences of the loss of nuclear generation.

A recent decision by the U.S. Court of Appeals for the $7^{\text {th }}$ Circuit affirmed the ability of the Department to use a calculated social cost of carbon $^{37}$ in the establishment of appliance efficiency standards. A similar approach should be used when evaluating the treatment of nuclear generation. DOE should investigate whether it already has sufficient authority for appropriate rulemaking in this area, or whether it should seek enabling legislation.

37 https://www3.epa.gov/climatechange/Downloads/EPAactivities/social-cost-carbon.pdf 
In cases where the individual states or markets are not able to provide adequate recognition of the social benefits of continuing the operation of nuclear units, DOE should investigate mechanisms of transferring ownership to public power entities. Such transfers could include contracting for the continued operation of the facilities by experienced nuclear operating companies.

\section{Nuclear Innovation}

Today's operating nuclear power plants, while capable of safely operating for many more years, will eventually require replacement, and the use of nuclear technology will need to be expanded. Innovative reactor concepts have been proposed that promise cost effective solutions, enhanced safety, and fuel cycle improvements. Progress is needed on innovative new designs to be ready for implementation in time to replace the existing units as needed, as well as meet the need for new construction.

Accordingly, the efforts to assist with the development of innovative nuclear concepts, announced at the November 2015 White House Summit, should be enhanced and expanded.

\section{Support Nuclear Industry Cost Reduction Efforts}

Finally, DOE should help reinforce ongoing efforts by the nuclear industry to reduce costs and complexity. For example, development and deployment of accident tolerant fuels could dramatically reduce or eliminate the likelihood of possible fuel damage events, and therefore result in significant safety enhancements as well as potential cost savings in design, operation and regulation.

Similarly, ongoing efforts to more thoroughly understand the risk implications of existing designs can lead to streamlining of current NRC requirements (under 10CFR50.69). DOE can assist the industry with these efforts with the goal of further reducing operating costs. This can take the form of additional support of existing DOE programs such as the Light Water Reactor Sustainability (LWRS) program, with a particular emphasis on identifying opportunities for cost reduction and safety improvements.

\section{Study Negative Electricity Market Price Issue}

DOE and/or the national laboratories should undertake a detailed study of negative prices in electricity markets. The causes and consequences of these negative prices on the nuclear power industry would be included.

DOE should examine the link between power reduction strategies and operating costs at nuclear power plants. Strategies to modify nuclear power plant equipment and operating modes may be needed to make even greater power reduction approaches feasible.

The U.S. nuclear power industry, in conjunction with EPRI, has embarked a study of potential modifications required to facilitate more extensive use of load cycling. DOE and the national laboratories should seek out ways to assist in these efforts. 


\section{B. Other Federal Government Actions}

The Department of Energy can take a role of advocating actions by other Federal departments and agencies to provide economic support to operating or new nuclear facilities. These actions could include, but are not limited to:

\section{Federal Energy Regulatory Commission (FERC)}

In light of FERC's central role in ensuring the equitable operation of wholesale electricity markets, explicit recognition of the vital contributions of nuclear generating plants to the national interest could be a major factor in permitting adequate returns to owners of operating nuclear plants. FERC actions could take a number of different forms, potentially including the following examples:

\section{a. Carbon Adders}

Assess a carbon adder on all fossil derived electricity as part of its obligation to ensure rates are just and reasonable. Such rates have to protect the public interest. Preventing climate and other environmental costs of generation has been implicitly supported in at least one prior court decision. The amount collected through the adder program would be reimbursed to customers in an equitable manner. ${ }^{38}$

\section{b. RTO/ISO Market Design Changes}

Require RTO/ISO's to institute adjustments in prices used for dispatch to recognize value of non- $\mathrm{CO}_{2}$ emitting energy sources

Require RTO/ISO's to implement specific market rule reforms by a date certain so that price signals support and promote efficient investment decisions, reliability and resource adequacy focusing in particular on the energy and ancillary services markets including fast start resource pricing, commitments to ensure online capacity requirements, regulating and ramping functions, capability to ensure voltage and stability and resolve other system conditions or constraints that lead to out-of-market operator actions.

Adopt other RTO/ISO price formation guidelines to specifically credit social benefits of carbon reduction and limit negative effects of other out of market price supports. Such uniform standards or guidelines could serve to mitigate the need to develop similar new standards in each state or market individually, reducing the time and expense to adopt such measures, and to reduce the need to litigate these issues repeatedly.

38 See Weissman, Webb, U Cal. Berkeley, Law, “Addressing Climate Change without Legislation” https://www.law.berkeley.edu/files/CLEE/FERC_Report_FINAL.pdf 


\section{ACTIONS - POTENTIAL ACTIONS TO STOP EARLY RETIREMENTS}

\section{Other Federal Agencies}

Other Federal agencies, that in the course of their operations, enter into contracts for the purchase of electricity, could be required to adopt Power Purchase Agreements at prices that reflect the social cost of carbon and provide appropriate revenues to nuclear producers. This could include power supply contracts for defense installations, national laboratories and large office complexes.

\section{Environmental Protection Agency (EPA)}

Implementation of the EPA's current Clean Power Plan is on hold, pending legal challenges. If the rule is upheld, or as part of a revision to meet legal issues, EPA should recognize that its goals cannot be met by an unsupported assumption that existing nuclear, which generates over $60 \%$ of today's carbon-free electricity, will continue operate without financial challenges faced by the operators. In addition, several studies have demonstrated scenarios where existing nuclear could be shut down, the generation gap met primarily by $\mathrm{CO}_{2}$ emitting natural gas plants, and a state could be compliance with CPP goals, despite total emissions increasing.

EPA should focus compliance on, and encourage states to adopt, mass based plans which include both existing and new sources.

\section{Congress}

Congress could agree to impose a national carbon tax, which would reflect the social cost of carbon, and raise costs for fossil fuel generators.

Congress could also move to establish tax credits for existing and new nuclear power plants that would act in a manner similar to the production and investment tax credits now in place for renewable generation.

\section{State Actions}

In states where generation continues to be rate regulated, the state regulatory authority typically requires utilities to provide periodic Integrated Resource Plans, detailing plans for capacity additions, fuel mix projections and impacts on retail electricity prices. While the focus of such reviews is usually on the cost and rate impacts, states can, through either policy decisions or legislative direction, require that IRP analyses include evaluations of the emission impacts of generation decisions. Such evaluations, and explicit consideration of air quality impacts of generation, could be a method chosen by a state to meet Federal requirements, such as the Clean Power Plan.

Even in states where generation has been restructured, states have a variety of methods at their disposal to influence the generation mix. Some of these include: 


\section{ACTIONS - POTENTIAL ACTIONS TO STOP EARLY RETIREMENTS}

\section{Energy Portfolio Standards}

Some 29 states, plus the District of Columbia, have various forms of mandatory or voluntary standards in place to mandate the use of non-carbon dioxide emitting sources for electricity production. These typically refer to "renewable" resources, and nuclear is currently included in the standards in only two states. Such standards typically require load serving utilities to acquire some defined percentage of their total supply from renewable resources.

At one time, it was believed that nuclear generation did not require such incentives to be included, and that the standards were needed to stimulate the adoption of more expensive, and yet socially desirable, energy sources. However, today, since the ultimate goal of such standards is to reduce carbon emissions, a broadening of the requirement to include nuclear is justified. This would shift these standards from the typical Renewable Energy Standards to Clean Energy Standards, without pre-selecting individual technologies and explicitly including nuclear power.

\section{Zero Emissions Credits}

Similar to renewable energy credits awarded to wind and solar generators in some states, proposals to broaden such credits to include nuclear plants have been made in several states. Most notably, in August 2016, the New York State Public Service Commission adopted a Clean Energy Standard, which creates a goal of generating 50\% of New York's electricity from noncarbon sources by 2030. It also includes a system of payments to nuclear plants, based on megawatt hours produced, and rates adjusted every two years (for a total of 12) on the basis of market conditions and the social cost of carbon.

It is our understanding that the adopted agreement in New York also contains commitments from the generating companies to keep the nuclear plants operating throughout this period, with substantial penalties if units are shut down. This is significant, since as we discussed earlier in this report, some of the small single unit plants in New York are likely to continue to be unprofitable even with the ZEC payments. However, in the aggregate, the ZEC program should provide adequate return to the operators and retains the carbon free generation of all the operating units.

A similar program for recognizing and compensating for zero emissions sources is currently under discussion in Illinois, where it will require legislative action to be adopted. As previously noted, Exelon has indicated that unless suitable financial support is approved before the end of the year 2016, it will proceed to take steps to shut down the Clinton and Quad Cities plants.

\section{Special Power Contracts}

In various states, proposals have been made or adopted to enter into special power sales agreements with nuclear plants. For example, in early 2016, a Reliability Support Services Agreement was adopted for the Ginna plant in New York, preventing a shutdown until necessary transmission upgrades could be completed. While this agreement is scheduled to expire in 2017, Ginna should now be included the ZEC program for New York, and continued operation is expected. 
Also in 2016, the Public Utilities Commission of Ohio approved a request by FirstEnergy to provide for a Contract for Difference power contract price for output from the Davis-Besse Nuclear Plant. Despite this approval, legal challenges to the order have been mounted and implementation has been delayed.

Mandated Power Purchase Agreements have also been considered. For example, in 2016, a measure was introduced in the Connecticut Legislature which would have authorized the state to direct the state's utilities to purchase some of their supply under long term (up to 10 years) PPA's from the state's nuclear plant. While this was not adopted in the 2016 session, reports indicate that hearings will be held on the proposal later this year, with potential consideration in the 2017 session.

In 2012, the state of Iowa approved an extension of the PPA in place for the Duane Arnold nuclear power plant.

\section{Eminent Domain and Public Power Authorities}

If market measures are not successful or not possible, and plant owners continue to take the position that continued operation of a nuclear unit is not possible, states could exercise eminent domain to take over ownership of the plant in the public interest. This was reportedly considered by New York, where the state has had previous experience with ownership of nuclear units by the New York Power Authority.

\section{Tax Incentives}

States can use tax measures to either increase the cost of carbon based generation (either individually or in regional compacts) or to provide tax credits for nuclear generation. 


\section{KEY FINDINGS, CONCLUSIONS AND RECOMMENDATIONS}

This chapter summarizes the major insights and findings of this study's assessment and provides recommendations on actions and steps could be taken at both the federal and state level to address and alleviate the underlying financial and economic stresses facing operation nuclear power plants and therefore ensure their continued safe, reliable and economic operation.

\section{A. Key Findings}

While not fully appreciated by policymakers and the public at large, this assessment found that there has been a significant decrease over the last decade, and in particular over the last year, in the wholesale price of electricity.

In short, a dramatic decrease in wholesale electricity prices has occurred and is attributable to ultra-low natural gas prices accompanied by increased natural gas market penetration in the power sector as well as changes in electricity demand growth and price formation issues related to out-of-market subsidies for renewables.

Overall, this situation has resulted in nuclear plant operating revenues falling to levels which are often below current plant operating costs, causing nuclear plants to operate in a negative cash flow position. Without actions such as that taken by the State of New York to recognize and monetize the carbon-free electricity generation benefit derived from operating nuclear plants, many more nuclear plants are likely to face premature retirements in the future as nuclear plant owners grapple with the financial stress brought on by these unexpected conditions.

\section{B. Recommendations}

Recent studies have pointed to the need for significantly expanded nuclear generation of electricity in the United States, as well as worldwide, to meet future energy needs, while simultaneously eliminating associated release of greenhouse gases. Increasingly, political leaders have begun to speak publicly of the crucial role nuclear generation plays in current efforts to reduce carbon dioxide emissions, as well as the even more important role nuclear must play in the future. As described in this report, however, current market conditions, as well as current approaches to incentivize non carbon emitting generation, do not adequately recognize the vital role of nuclear power, and do not provide sufficient financial support to the operators of nuclear power plants. Unless actions are taken soon, at both the federal and state levels, it will not be possible for privately owned companies to make the necessary investments in new nuclear technologies, or even to justify the continued operation of many of our existing nuclear facilities. Loss of these valuable clean energy resources, and the failure to develop additional nuclear generation, will make our carbon reduction goals unattainable.

\section{Conclusions}

There is a real risk that additional operating nuclear power plants will retire early for financial reasons in the near term. Losing these operating nuclear power plants decades before they would 
retire for normal reasons would be a setback to U.S. objectives of moving away from carbon in the electricity sector.

A range of actions are discussed that may help prevent some of the early retirement decisions. The primary focus of these actions is states that retain significant responsibility for regulating the electricity sector and for defining and implementing efforts to manage carbon emissions in the electricity sector.

Federal government efforts can help the states by providing financial benefits to operating nuclear power plants (e.g., production tax credits for operating nuclear power plants), by clearing the way for reforms to electricity market reform, by undertaking research to help operating nuclear power plants lower costs and improve performance, and by undertaking efforts to explain the issues facing operating nuclear power plants and what can be done to prevent early retirement of these plants. 


\section{APPENDIX}

This appendix displays information presented in the main report in units of million $\$$ per year, in units of $\$ / M W h$. The appendix includes

- a discussion of the differences between units of million $\$$ per year and $\$ / M W h$;

- Gap estimate summaries in $\$ / M W h$;

- Unit tables in $\$ / M W h ;$ and

- New York and Illinois Gap estimate chart in million \$ per year and \$/MWh.

Nuclear power plant operating costs are fixed - meaning that these costs do not vary directly with output. Because of the fixed nature of nuclear power plant operating costs, these costs are best presented in $\$$ millions per year for each reactor that can be compared directly to the nuclear power plant's revenue for the year.

However, many public indicators of nuclear power plant cost and revenue are denominated in $\$$ MWh. Nuclear power plants generally operate as base load generators and usually have a high (e.g., $90 \%$ ) capacity factor. If operating costs of reactors with a similar capacity factor are compared, the outcome will be similar using either $\$$ million per year or $\$ / M W h$.

However, if a reactor has low output (e.g., due to a prolonged refueling and maintenance outage), the capacity factor for that year will be lower than usual. In this low capacity factor year, the operating costs of that nuclear power plant will be higher when denominated in $\$ / \mathrm{MWh}$, even if the total annual operating costs remain the same.

Operating costs in $\$ / M W h$ provide a measure that combines two factors - operating costs and the annual capacity factor.

Figure A- 1 is another version of the Gap estimate summary for all 24 units presented in Figure 6 in the main body of this report, but in units of $\$ / \mathrm{MWh}$. In Figure 6 , the triangle indicator for operating costs for the two units at Indian Point and Prairie Island are almost the same. In Figure A-1, these triangle indicators are much higher for Indian Point 2 compared to Indian Point 3 and for Prairie Island 3 compared to Prairie Island 2; these differences are due to the relatively low output of Indian Point 2 and Prairie Island 3 compared to the other unit on each site during the 2015-2016 years. 


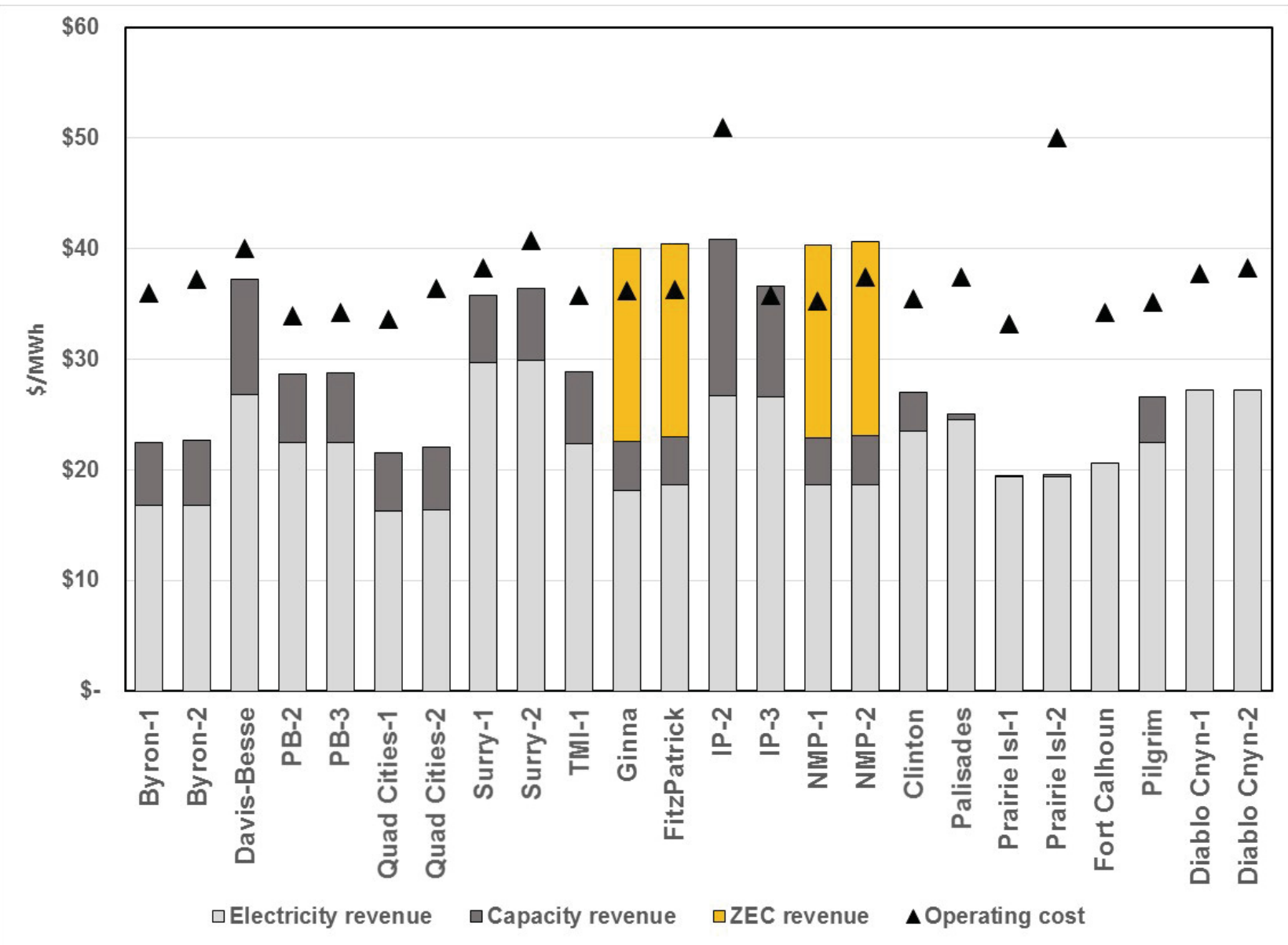

Figure A-1. Gap Estimates ( $\$$ MWh) with Components. ${ }^{39}$

39 Note that this analysis assumes that (a) all units have the same $\$ 300,000 / \mathrm{MW} /$ year operating cost level, and (b) relevant New York units receive ZEC revenue. 
Figure A-2 is another version of the Gap estimate summary for all 24 units presented in Figure 7 in the main body of this report, but in units of $\$ / M W h$.

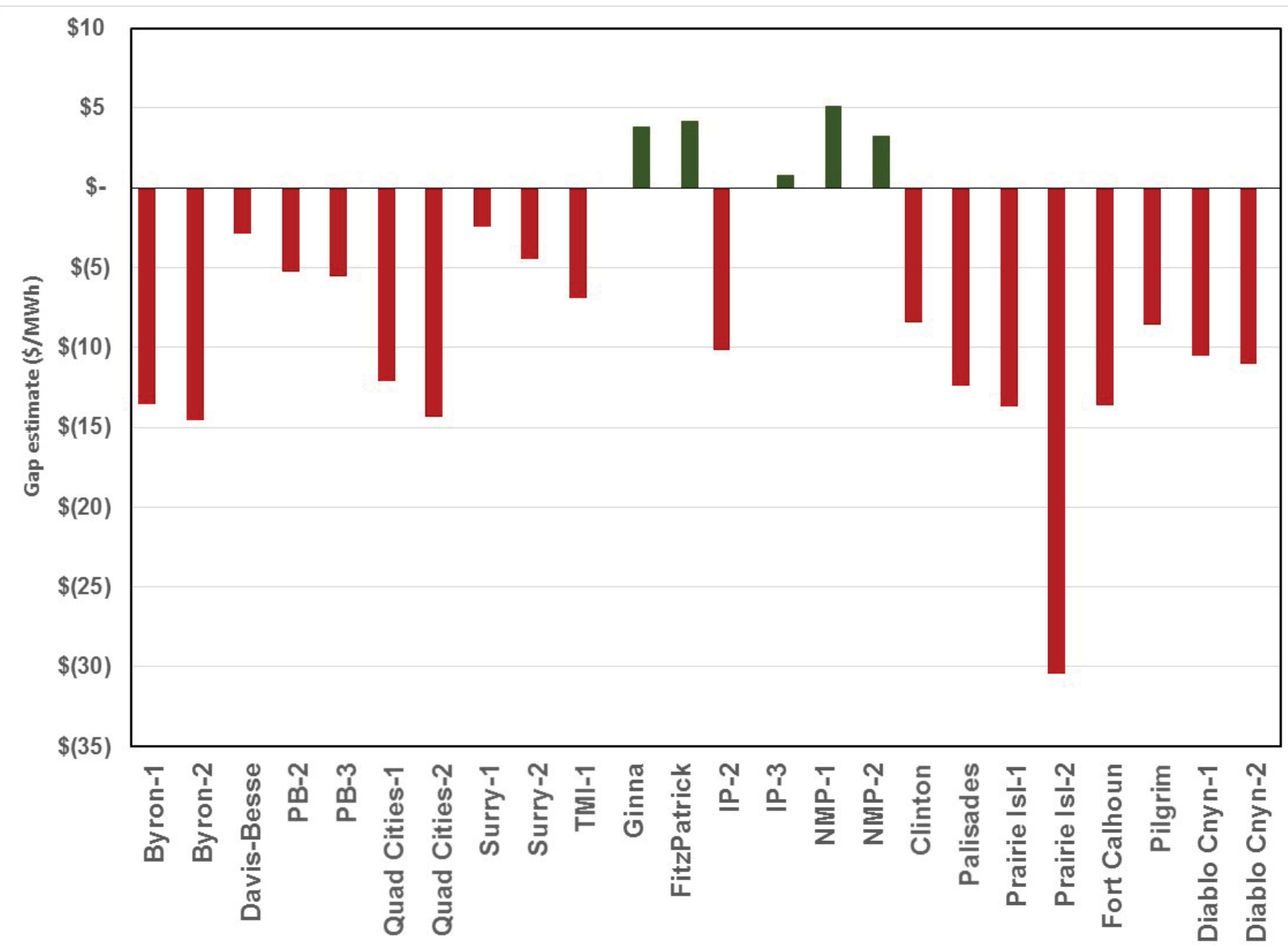

Figure A-2. Gap Estimates (\$/MWh). ${ }^{40}$

40 Note that this analysis assumes that (a) all units have the same $\$ 300,000 / \mathrm{MW} /$ year operating cost level, and (b) relevant New York units receive ZEC revenue. 
The following Tables present the Gap data information for each of the 24 units in $\$ / M W h$.

Table A-1. Gap Data for Byron, Davis-Besse and Peach Bottom.

\begin{tabular}{|c|c|c|c|c|c|}
\hline Unit & Byron-1 & Byron-2 & Davis-Besse & PB-2 & PB-3 \\
\hline Output (MWh) & $9,697,263$ & $9,164,453$ & $6,706,769$ & $11,150,316$ & $9,838,351$ \\
\hline Electricity revenue (\$/MWh) & $\$ 16.78$ & $\$ 16.76$ & $\$ 26.80$ & $\$ 22.42$ & $\$ 22.42$ \\
\hline Capacity revenue (\$/MWh) & $\$ 5.71$ & $\$ 5.89$ & $\$ 10.38$ & $\$ 6.23$ & $\$ 6.29$ \\
\hline Operating cost, base ((\$/MWh) & $\$ 36.01$ & $\$ 37.19$ & $\$ 39.99$ & $\$ 33.87$ & $\$ 34.24$ \\
\hline Gap, base (\$/MWh) & $\$(13.52)$ & $\$(14.53)$ & $\$(2.81)$ & $\$(5.22)$ & $\$(5.53)$ \\
\hline Operating cost, high (\$/MWh) & $\$ 33.01$ & $\$ 34.09$ & $\$ 56.65$ & $\$ 31.05$ & $\$ 31.39$ \\
\hline Gap, high (\$/MWh) & $\$(10.52)$ & $\$(11.43)$ & $\$(19.47)$ & $\$(2.40)$ & $\$(2.67)$ \\
\hline Operating cost, low (\$/MWh) & $\$ 27.01$ & $\$ 27.89$ & $\$ 46.65$ & $\$ 25.41$ & $\$ 25.68$ \\
\hline Gap, low (\$/MWh) & $\$(4.52)$ & $\$(5.24)$ & $\$(9.47)$ & $\$ 3.24$ & $\$ 3.03$ \\
\hline
\end{tabular}

Table A-2. Gap Data for Quad Cities, Surry and Three Mile Island.

\begin{tabular}{|c|c|c|c|c|c|}
\hline Unit & $\begin{array}{c}\text { Quad Cities- } \\
1\end{array}$ & $\begin{array}{c}\text { Quad Cities- } \\
2\end{array}$ & Surry-1 & Surry-2 & TMI-1 \\
\hline Output (MWh) & $\mathbf{8 , 1 0 5 , 7 5 7}$ & $7,515,790$ & $6,584,138$ & $6,171,063$ & $6,737,422$ \\
\hline Electricity revenue (\$/MWh) & $\$ 16.22$ & $\$ 16.31$ & $\$ 29.72$ & $\$ 29.88$ & $\$ 22.32$ \\
\hline Capacity revenue (\$/MWh) & $\$ 5.33$ & $\$ 5.76$ & $\$ 6.05$ & $\$ 6.46$ & $\$ 6.57$ \\
\hline Operating cost, base $((\$ / M W h)$ & $\$ 33.61$ & $\$ 36.36$ & $\$ 38.18$ & $\$ 40.74$ & $\$ 35.76$ \\
\hline Gap, base (\$/MWh) & $\$(12.06)$ & $\$(14.29)$ & $\$(2.41)$ & $\$(4.40)$ & $\$(6.86)$ \\
\hline Operating cost, high (\$/MWh) & $\$ 30.81$ & $\$ 33.33$ & $\$ 35.00$ & $\$ 37.34$ & $\$ 50.65$ \\
\hline Gap, high (\$/MWh) & $\$(9.26)$ & $\$(11.26)$ & $\$ 0.77$ & $\$(1.00)$ & $\$(21.76)$ \\
\hline Operating cost, low (\$/MWh) & $\$ 25.20$ & $\$ 27.27$ & $\$ 28.64$ & $\$ 30.55$ & $\$ 41.71$ \\
\hline Gap, low (\$/MWh) & $\$(3.66)$ & $\$(5.20)$ & $\$ 7.13$ & $\$ 5.79$ & $\$(12.82)$ \\
\hline
\end{tabular}

Table A-3. Gap Data for Ginna, FitzPatrick, Indian Point and Nine Mile Point.

\begin{tabular}{|c|c|c|c|c|c|c|}
\hline Unit & Ginna & FitzPatrick & IP-2 & IP-3 & NMP-1 & NMP-2 \\
\hline Output (MWh) & $4,826,464$ & $7,050,307$ & $6,011,210$ & $8,729,922$ & $5,418,774$ & $10,447,226$ \\
\hline Electricity revenue (\$/MWh) & $\$ 18.17$ & $\$ 18.60$ & $\$ 26.64$ & $\$ 26.60$ & $\$ 18.60$ & $\$ 18.59$ \\
\hline Capacity revenue (\$/MWh) & $\$ 4.34$ & $\$ 4.35$ & $\$ 14.17$ & $\$ 9.96$ & $\$ 4.23$ & $\$ 4.48$ \\
\hline ZEC Revenue (\$/MWh) & $\$ 17.48$ & $\$ 17.48$ & & & $\$ 17.48$ & $\$ 17.48$ \\
\hline Operating cost, base ((\$/MWh) & $\$ 36.18$ & $\$ 36.25$ & $\$ 50.90$ & $\$ 35.77$ & $\$ 35.21$ & $\$ 37.36$ \\
\hline Gap, base (\$/MWh) & $\$ 3.81$ & $\$ 4.18$ & $\$(10.10)$ & $\$ 0.79$ & $\$ 5.09$ & $\$ 3.20$ \\
\hline Operating cost, high (\$/MWh) & $\$ 51.25$ & $\$ 51.36$ & $\$ 46.66$ & $\$ 32.79$ & $\$ 49.88$ & $\$ 43.59$ \\
\hline Gap, high (\$/MWh) & $\$(11.26)$ & $\$(10.93)$ & $\$(5.85)$ & $\$ 3.77$ & $\$(9.58)$ & $\$(3.03)$ \\
\hline Operating cost, low (\$/MWh) & $\$ 42.20$ & $\$ 42.30$ & $\$ 38.18$ & $\$ 26.83$ & $\$ 41.08$ & $\$ 37.36$ \\
\hline Gap, low (\$/MWh) & $\$(2.21)$ & $\$(1.87)$ & $\$ 2.63$ & $\$ 9.73$ & $\$(0.78)$ & $\$ 3.20$ \\
\hline
\end{tabular}


Table A-4. Gap Data for Clinton, Palisades and Prairie Island.

\begin{tabular}{|c|c|c|c|c|}
\hline Unit & Clinton & Palisades & Prairie Isl-1 & Prairie Isl-2 \\
\hline Output (MWh) & $9,023,316$ & $6,333,643$ & $4,717,489$ & $3,113,864$ \\
\hline Electricity revenue (\$/MWh) & $\$ 23.49$ & $\$ 24.53$ & $\$ 19.35$ & $\$ 19.38$ \\
\hline Capacity revenue (\$/MWh) & $\$ 3.55$ & $\$ 0.46$ & $\$ 0.14$ & $\$ 0.20$ \\
\hline Operating cost, base ((\$/MWh) & $\$ 35.41$ & $\$ 37.37$ & $\$ 33.13$ & $\$ 50.00$ \\
\hline Gap, base (\$/MWh) & $\$(8.37)$ & $\$(12.38)$ & $\$(13.65)$ & $\$(30.42)$ \\
\hline Operating cost, high (\$/MWh) & $\$ 41.31$ & $\$ 52.94$ & $\$ 30.37$ & $\$ 45.84$ \\
\hline Gap, high (\$/MWh) & $\$(14.27)$ & $\$(27.95)$ & $\$(10.89)$ & $\$(26.25)$ \\
\hline Operating cost, low (\$/MWh) & $\$ 35.41$ & $\$ 43.60$ & $\$ 24.85$ & $\$ 37.50$ \\
\hline Gap, low (\$/MWh) & $\$(8.37)$ & $\$(18.61)$ & $\$(5.36)$ & $\$(17.92)$ \\
\hline
\end{tabular}

Table A-5. Gap Data for Fort Calhoun, Pilgrim and Diablo Canyon.

\begin{tabular}{|c|c|c|c|c|}
\hline Unit & Fort Calhoun & Pilgrim & Diablo Cnyn-1 & Diablo Cnyn-2 \\
\hline Output (MWh) & $4,203,719$ & $5,785,523$ & $8,932,597$ & $8,783,027$ \\
\hline Electricity revenue (\$/MWh) & $\$ 20.61$ & $\$ 22.42$ & $\$ 27.16$ & $\$ 27.19$ \\
\hline Capacity revenue (\$/MWh) & $\$-$ & $\$ 4.18$ & $\$-$ & $\$$ \\
\hline Operating cost, base ((\$/MWh) & $\$ 34.18$ & $\$ 35.16$ & $\$ 37.68$ & $\$ 38.19$ \\
\hline Gap, base (\$/MWh) & $\$(13.57)$ & $\$(8.55)$ & $\$(10.52)$ & $\$(11.00)$ \\
\hline Operating cost, high $(\$ / M W h)$ & $\$ 48.43$ & $\$ 49.81$ & $\$ 34.54$ & $\$ 35.01$ \\
\hline Gap, high (\$/MWh) & $\$(27.82)$ & $\$(23.20)$ & $\$(7.38)$ & $\$(7.82)$ \\
\hline Operating cost, low (\$/MWh) & $\$ 39.88$ & $\$ 41.02$ & $\$ 28.26$ & $\$ 28.64$ \\
\hline Gap, low (\$/MWh) & $\$(19.27)$ & $\$(14.41)$ & $\$(1.10)$ & $\$(1.46)$ \\
\hline
\end{tabular}


Below, we also present the Gap estimates for the units in New York and Illinois in both \$ millions per year and $\$ / M W h$.

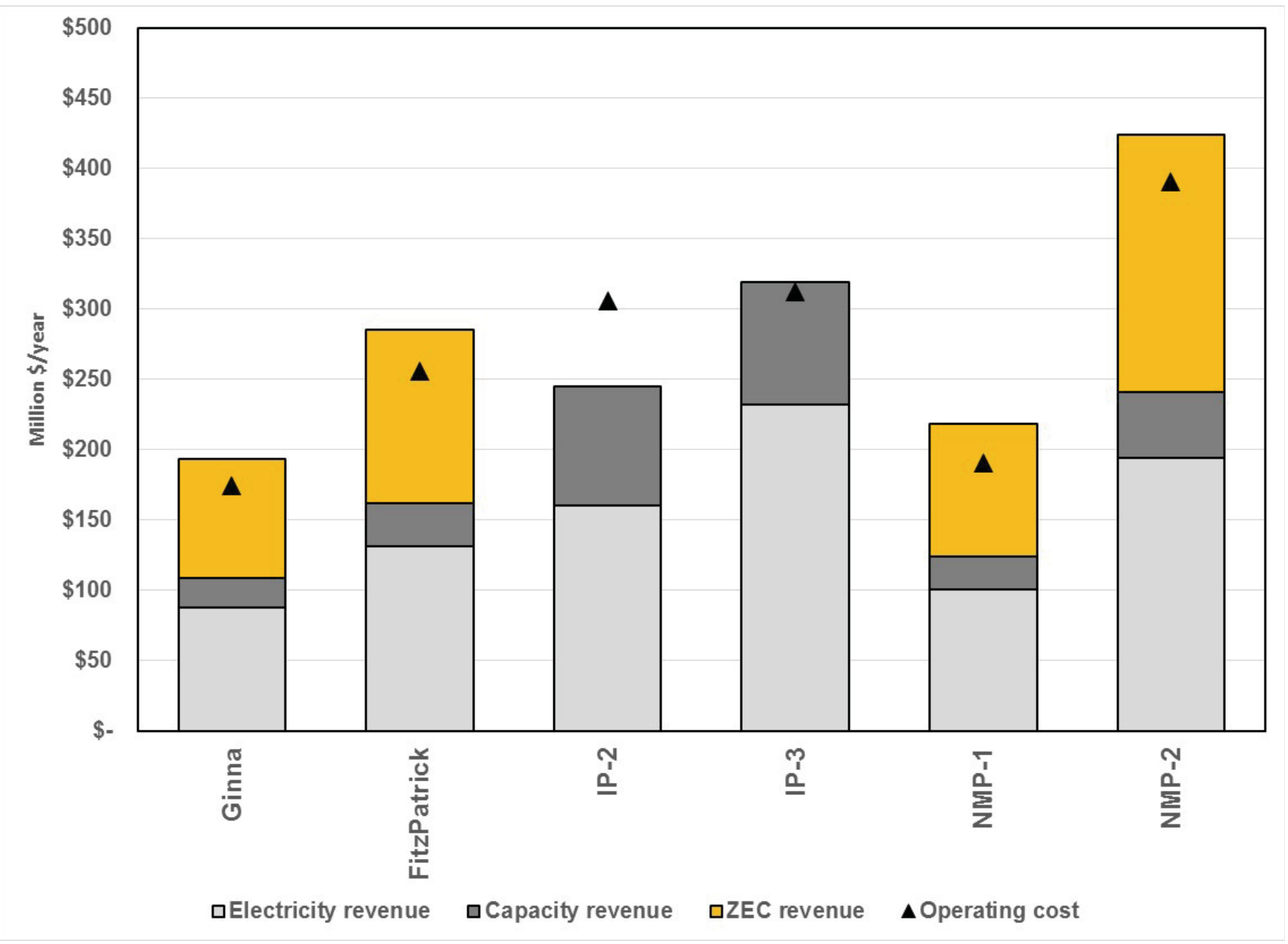

Figure A-3. Gap Estimates (Million $\$ /$ Year) for New York Units. ${ }^{41}$

41 Note that this analysis assumes that (a) all units have the same $\$ 300,000 / \mathrm{MW} /$ year operating cost level, and (b) relevant New York units receive ZEC revenue. 


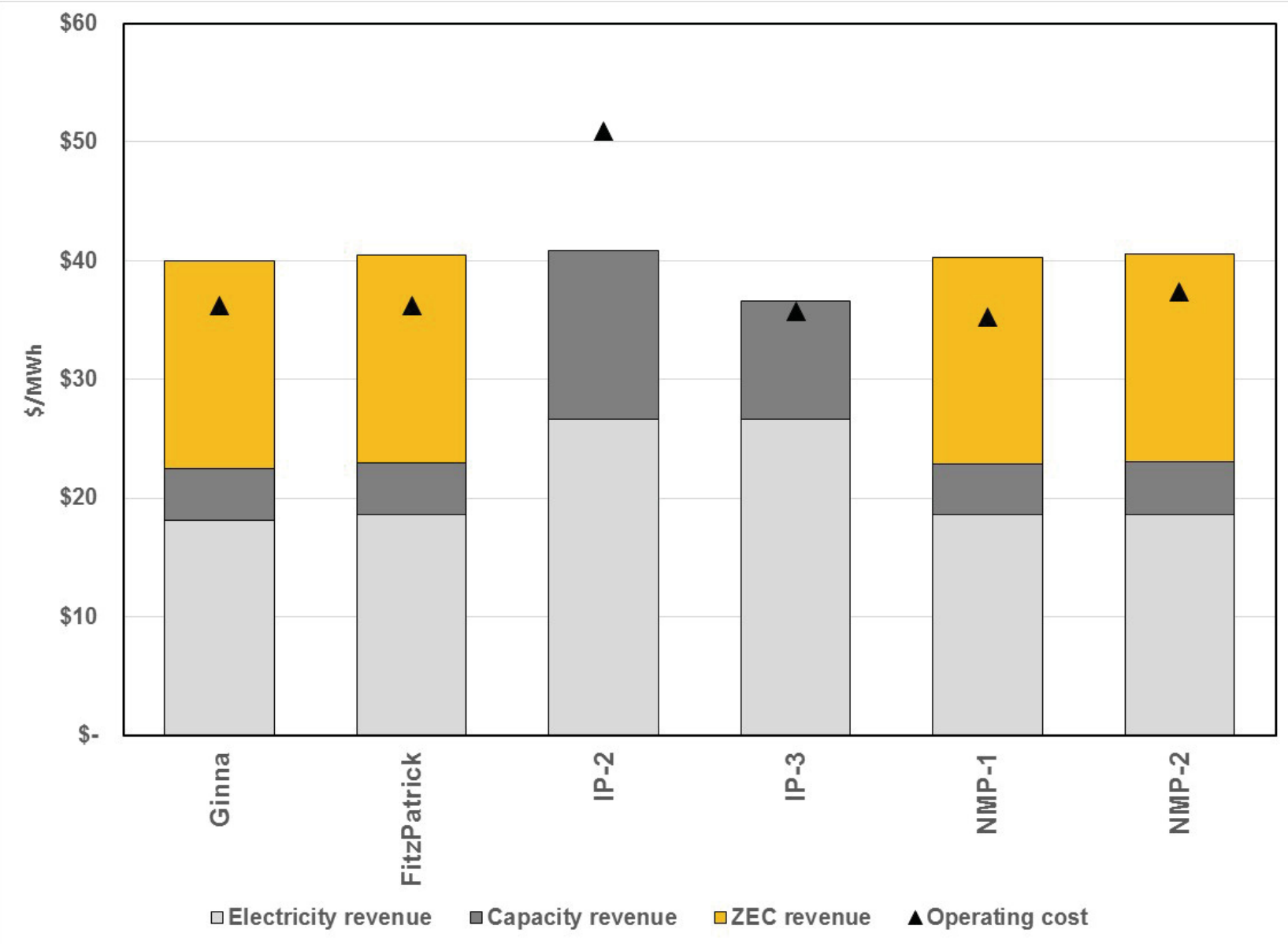

Figure A-4. Gap Estimates ( $\$$ MWh) for New York Units. ${ }^{42}$

42 Note that this analysis assumes that (a) all units have the same $\$ 300,000 / \mathrm{MW} /$ year operating cost level, and (b) relevant New York units receive ZEC revenue. 
APPENDIX

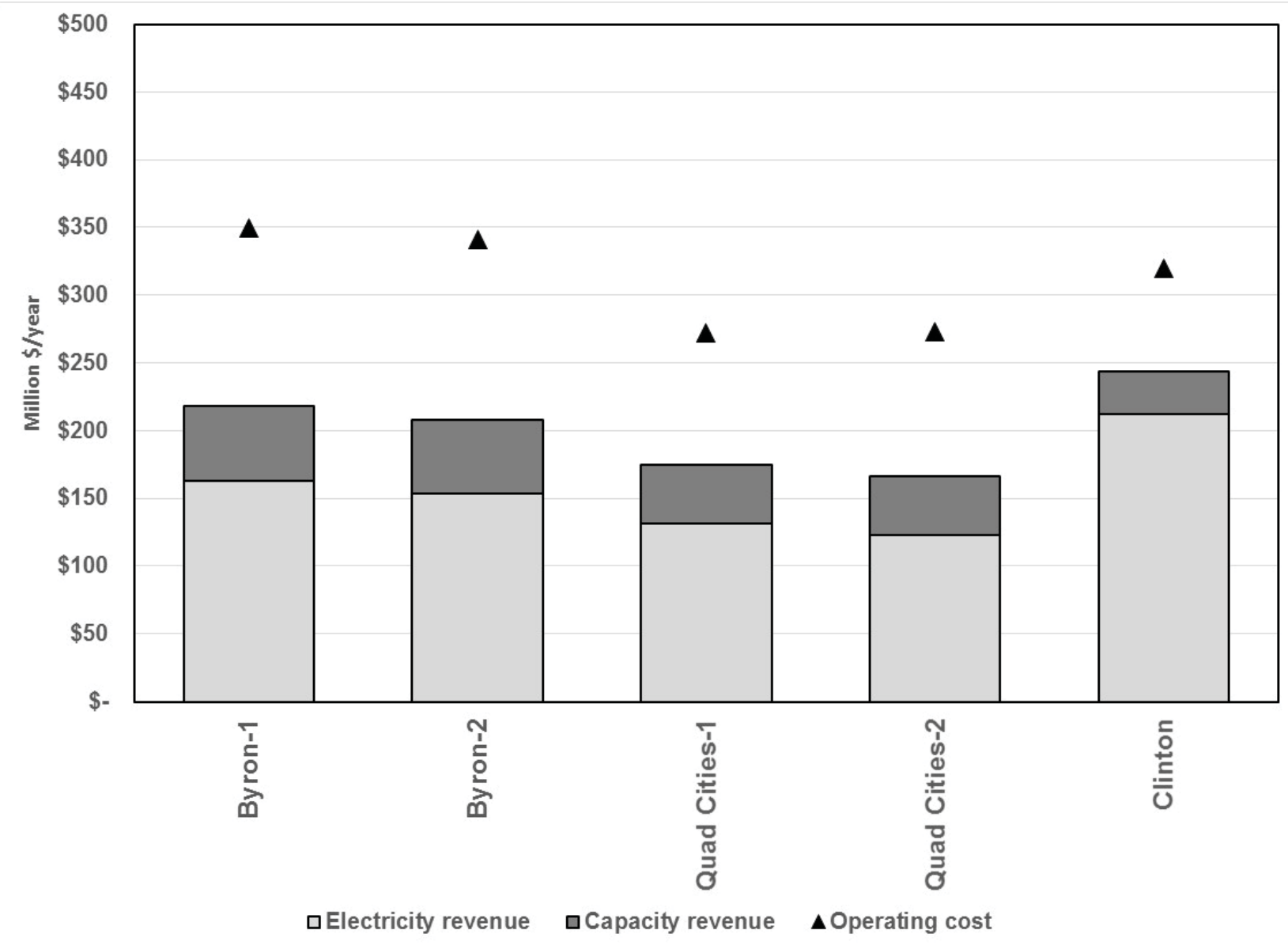

Figure A-5. Gap Estimates (Million \$/Year) for Selected Illinois Units. ${ }^{43}$

43 Note that this analysis assumes that all units have the same $\$ 300,000 / \mathrm{MW} /$ year operating cost level. 
APPENDIX

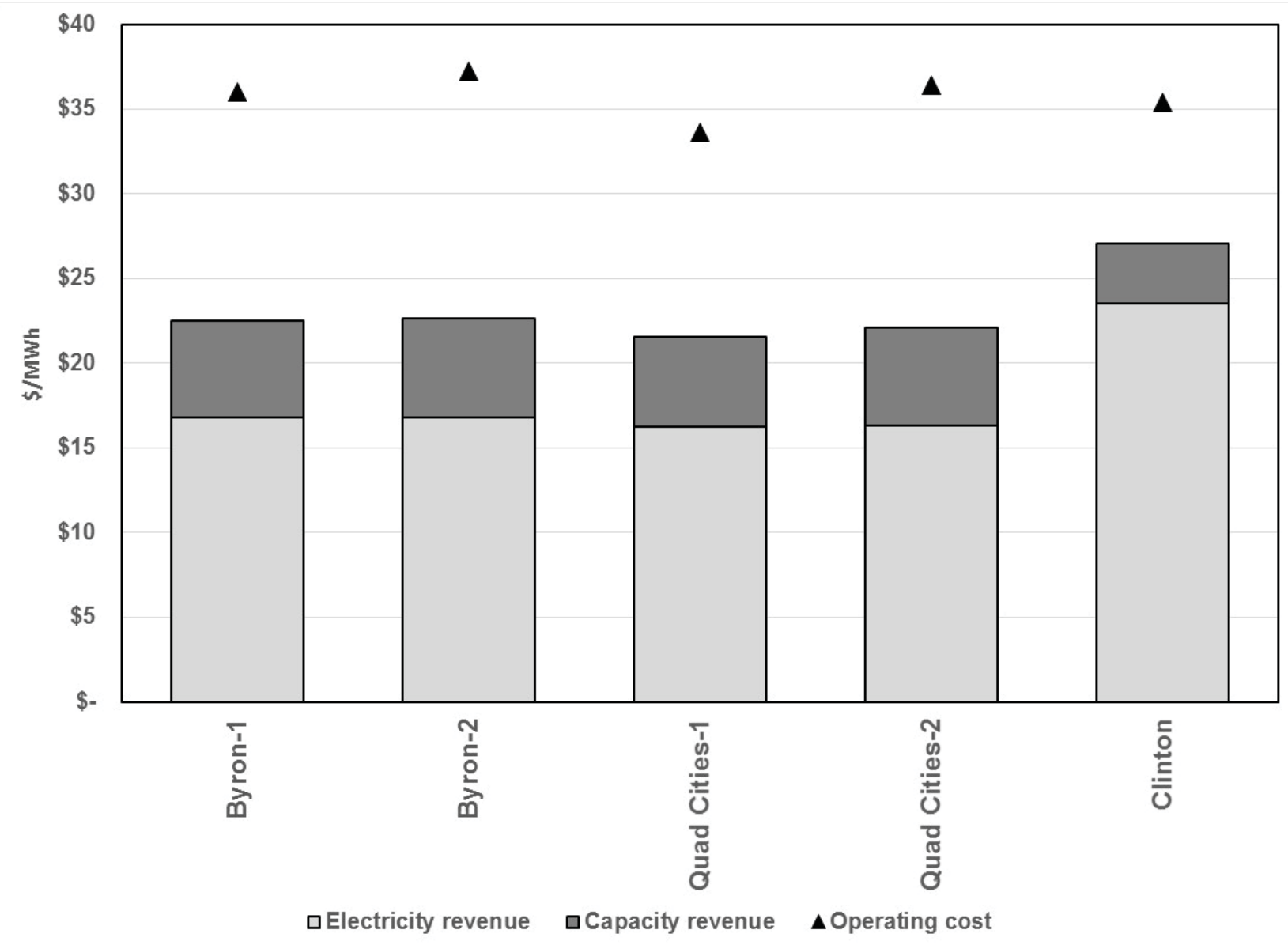

Figure A-6. Gap Estimates (\$/MWh) for Selected Illinois Units. ${ }^{44}$

44 Note that this analysis assumes that (a) all units have the same $\$ 300,000 / \mathrm{MW} /$ year operating cost level. 

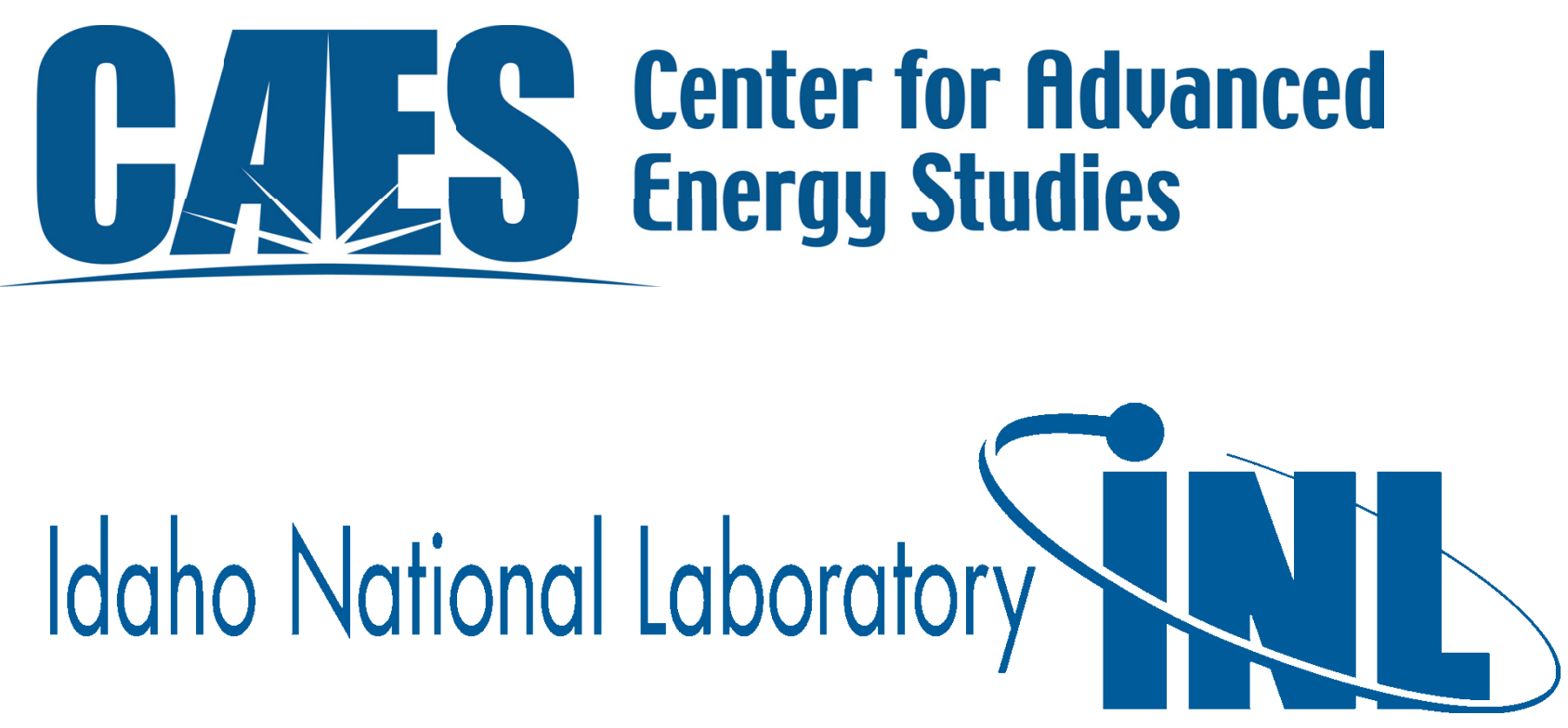